Key Words:

Grout

Flowable Fill

High-Level Waste Tank Closure

Retention:

Permanent

\title{
STATE OF THE ART REPORT ON HIGH-LEVEL WASTE TANK CLOSURE (U)
}

\author{
Authors: Christine A. Langton \\ Westinghouse Savannah River Company \\ Savannah River Technology Center \\ Aiken, SC 29808 \\ And \\ Roger D. Spence and John Barton \\ UT-Battelle \\ Oak Ridge National Laboratory \\ Oak Ridge, TN 37831-6202
}

REPORT DATE: JULY 31, 2001

Westinghouse Savannah River Company

Savannah River Site

Aiken, SC 29808

Prepared for the U.S. Department of Energy Under

Contract Number DE-AC09-96SR18500 
This document was prepared in conjunction with work accomplished under Contract No. DE-AC09-96SR18500 with the U. S. Department of Energy.

\section{DISCLAIMER}

This report was prepared as an account of work sponsored by an agency of the United States Government. Neither the United States Government nor any agency thereof, nor any of their employees, makes any warranty, express or implied, or assumes any legal liability or responsibility for the accuracy, completeness, or usefulness of any information, apparatus, product or process disclosed, or represents that its use would not infringe privately owned rights. Reference herein to any specific commercial product, process or service by trade name, trademark, manufacturer, or otherwise does not necessarily constitute or imply its endorsement, recommendation, or favoring by the United States Government or any agency thereof. The views and opinions of authors expressed herein do not necessarily state or reflect those of the United States Government or any agency thereof.

This report has been reproduced directly from the best available copy.

Available for sale to the public, in paper, from: U.S. Department of Commerce, National Technical Information Service, 5285 Port Royal Road, Springfield, VA 22161, phone: (800) 553-6847, fax: (703) 605-6900

email: orders@ntis.fedworld.gov

online ordering: http://www.ntis.gov/help/index.asp

Available electronically at http://www.osti.gov/bridge

Available for a processing fee to U.S. Department of Energy and its contractors, in paper, from: U.S. Department of Energy, Office of Scientific and Technical Information, P.O. Box 62, Oak Ridge, TN 37831-0062,

phone: (865)576-8401,

fax: (865)576-5728

email: $\underline{\text { reports@ adonis.osti.gov }}$ 
Key Words:

Grout

Flowable Fill

High-Level Waste Tank Closure

Retention:

Permanent

\title{
STATE OF THE ART REPORT ON HIGH-LEVEL WASTE TANK CLOSURE (U)
}

\author{
Authors: Christine A. Langton \\ Westinghouse Savannah River Company \\ Savannah River Technology Center \\ Aiken, SC 29808 \\ And \\ Roger D. Spence and John Barton \\ UT-Battelle \\ Oak Ridge National Laboratory \\ Oak Ridge, TN 37831-6202
}

REPORT DATE: JULY 31, 2001 


\section{REVIEWS AND APPROVALS}




\section{TABLE OF CONTENTS}

LIST OF FIGURES ................................................................................................................. iv

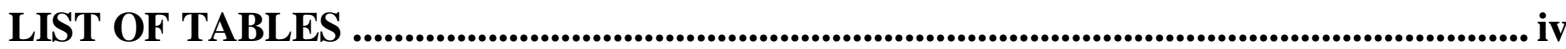

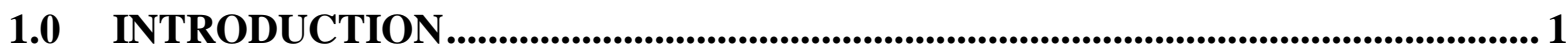

1.1 Background ........................................................................................................................... 1

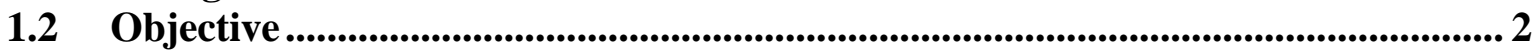

1.3 Approach.................................................................................................................... 2

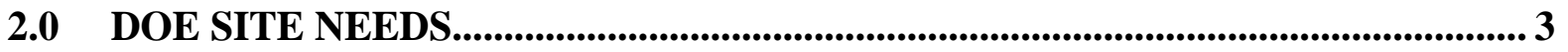

$2.1 \quad$ Hanford Site ..................................................................................................................... 5

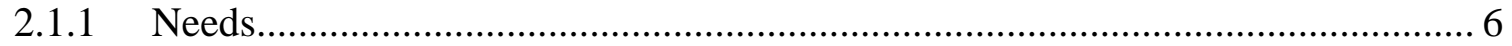

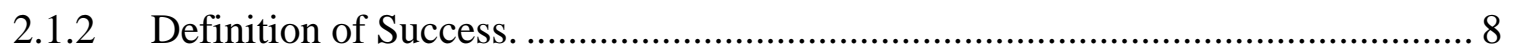

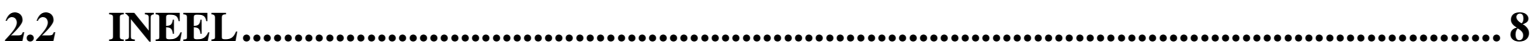

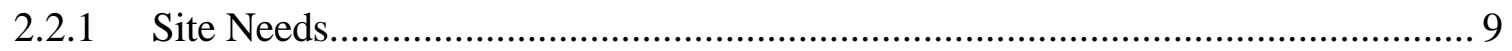

2.3 ORNL..................................................................................................................... 10

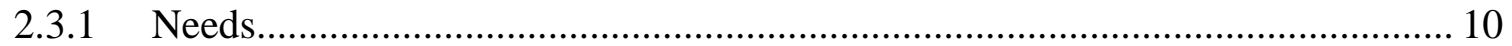

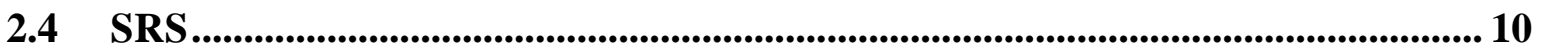

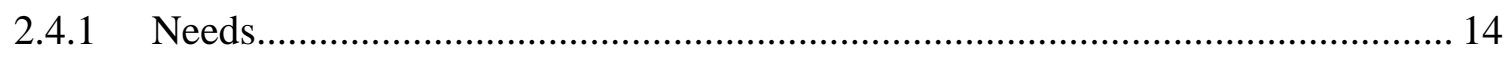

2.4.1.1 HLW Tanks ....................................................................................................................... 14

2.4.1.2 Reactor Disassembly Basins ......................................................... 15

2.4.1.3 Small Tanks (ORBWG OST) ..................................................................... 16

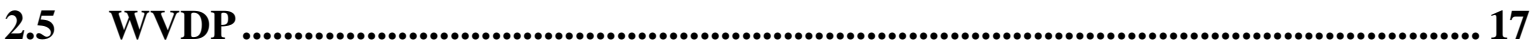

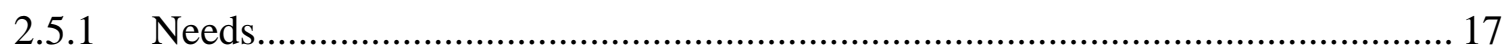

2.6 International Tank Cklosure Practice ........................................................................... 18

2.6.1 United Kingdom (UK) ...................................................................... 18

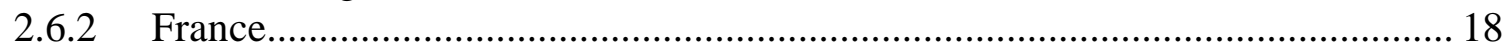

2.7 Summary of Survey Responses ..................................................................................... 19

3.0 FILL MATERIAL REQUIREMENTS.......................................................................... 20

3.1 Waste Treatment Strategies ……................................................................................... 21

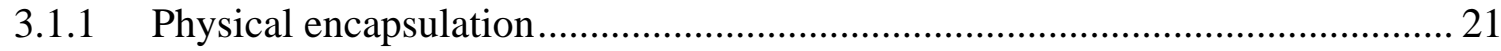

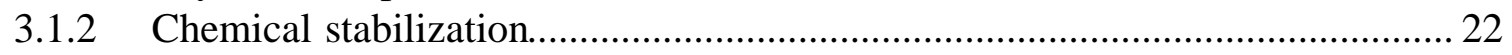

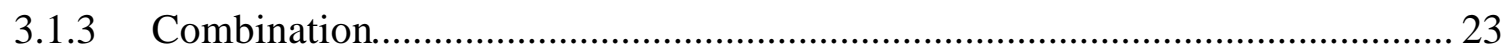

3.2 Strategies for Physical Stabilization of Large Void Structures............................... 23

3.3 Flowable Fill Proportioning, Material, and Production Considerations............. 24

3.3.1 Production/Transportation Methods............................................................... 24

3.3.2 Production of Fill Material Using Contaminated Ingredients............................. 25

3.3.3 Total Volume and Production Rate................................................................. 26

3.3.4 Fill Delivery Method - Pumping..................................................................... 26

3.4 Flowable Fill Placement Requirements ....................................................................... 27

3.4.1 Riser/Port Access Limitation ...................................................................... 27

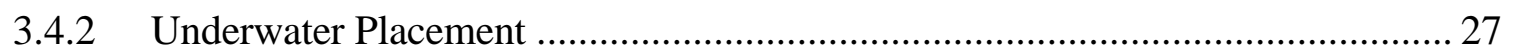

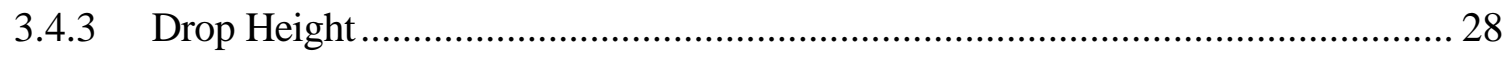

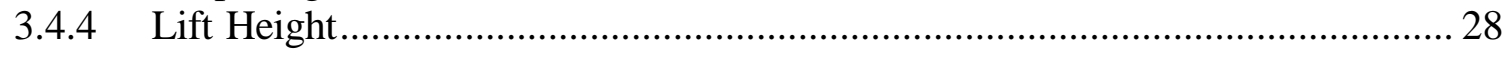

3.5 Flowable Fill Fresh Property Requirements .............................................................. 28

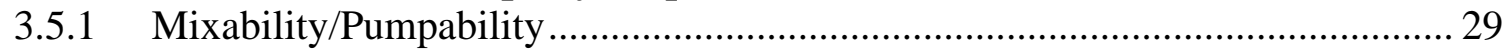

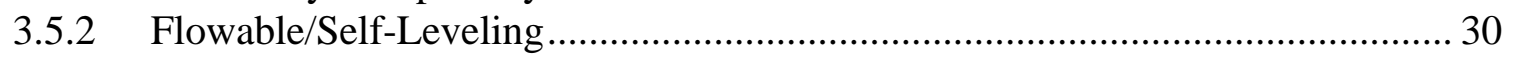

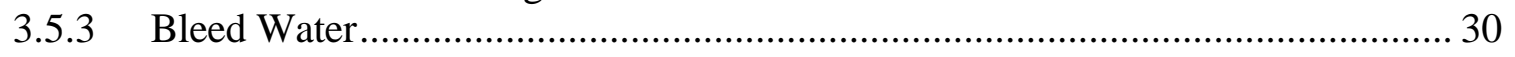




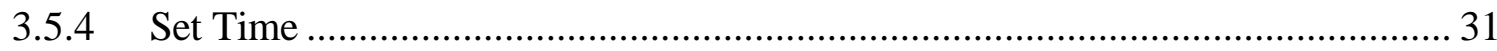

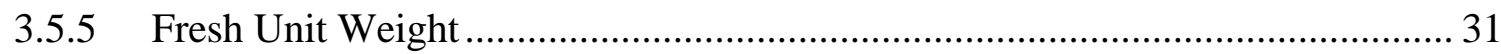

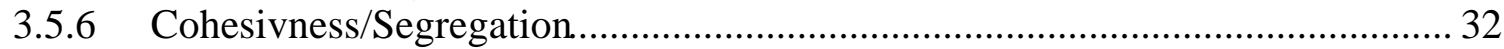

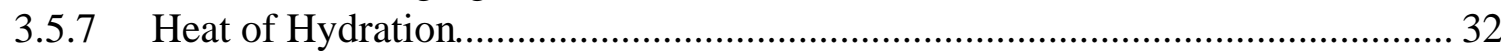

3.5.8 Resistance to Freeze-Thaw and Wetting-Drying Conditions ............................. 32

3.6 Flowable Fill Cured Properties ........................................................................ 33

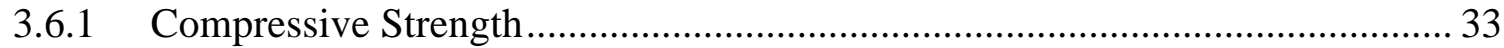

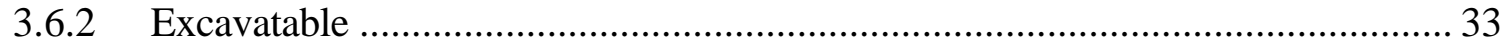

3.6.3 Hydraulic Conductivity (Permeability) ..................................................... 33

3.7 Radionuclide Stabilization - Leaching Properties ............................................... 34

3.8 Durability - Long-Term Properties....................................................................... 37

3.9 Summary of Closure Requirements ............................................................................... 37

4.0 FLOWABLE FILL MIX DESIGNS FOR HLW TANK CLOSURE.................... 38

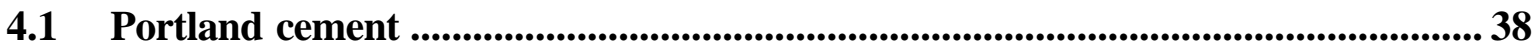

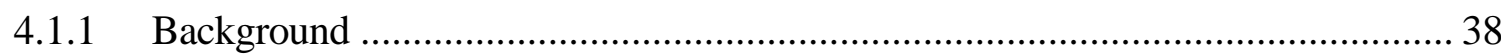

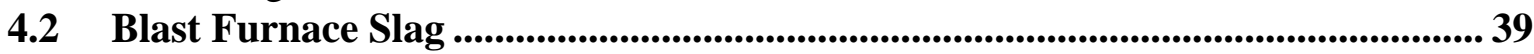

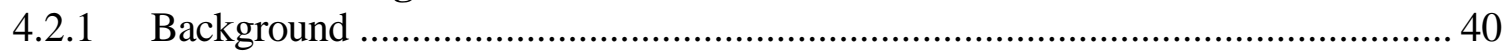

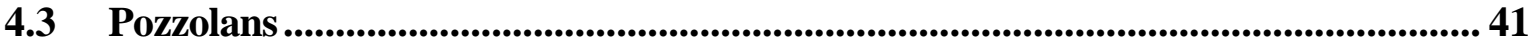

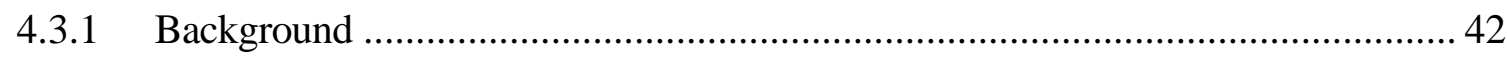

4.4 Reactive Ingredients for stabalizing contaminants............................................ 43

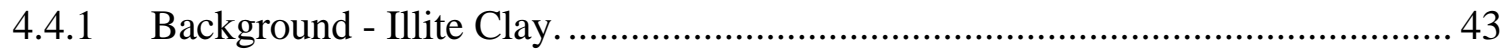

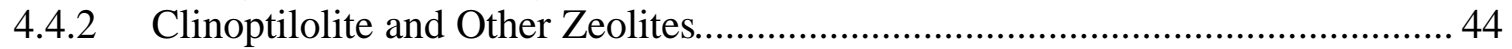

4.4.3 Vermiculite....................................................................................... 45

4.4.4 Phosphate Precipitation and Sorption........................................................ 45

4.5 Slurry property modifiers and Admixtures ....................................................... 47

4.5.1 Background - Foaming Agents and Pre-Formed Foam................................... 47

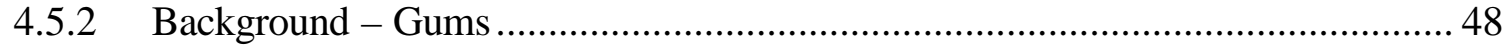

4.5.3 Background - Water Sorptive-Suspension Agents ...................................... 48

4.6 Fine and Coarse Aggregate.............................................................................. 49

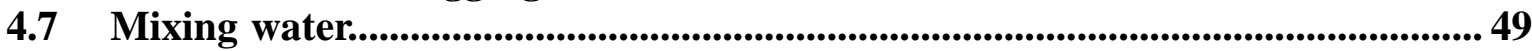

5.0 COMPARISON OF TANK FILL TECHNOLOGY AND SITE NEEDS ............ 50

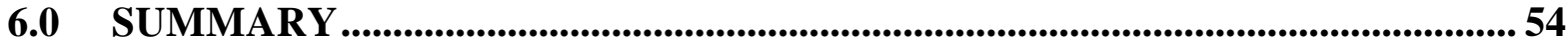

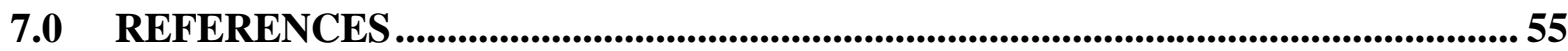

8.0 APPENDIX A. TANK CLOSURE NEEDS SURVEY FORM ............................... 68

9.0 APPENDIX B. INEEL TANK CLOSURE NEEDS SURVey.................................. 72

10.0 APPENDIX C. Hanford TANK CLOSURE NEEDS SURVey .............................. 76

11.0 APPENDIX D. WVDP TANK CLOSURE NEEDS SURVey............................... 82

12.0 APPENDIX E. SRS-HLW TANK CLOSURE NEEDS SURVey ......................... 86

13.0 APPENDIX F. SRS-FDD TANK CLOSURE NEEDS SURV ey........................... 89

14.0 APPENDIX G. SRS-ER TANK CLOSURE NEEDS SURVey............................92

15.0 APPENDIX H. UK TANK CLOSURE NEEDS SURVEy ..................................96

16.0 APPENDIX I. France TANK CLOSURE NEEDS SURVey ........................... 100

17.0 APPENDIX J. ORR GAAT Tank Flowable Fill Technical Specifications ......... 102 


\section{LIST OF FIGURES}

Figure 2-1. Portable continuous auger plant (Throop, Inc.) used to batch fill material for

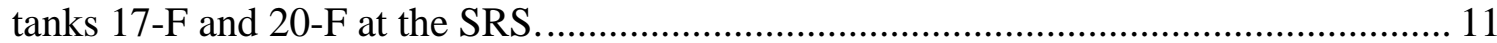

Figure 2-2. Tank 17 zero-bleed fill being discharged into the pump.................................. 12

Figure 2-3. Zero-bleed flowable fill placement in Tank 20-F, SRS, June 1997..................... 12

\section{LIST OF TABLES}

Table 2-1. Summary of in-place tank closure and related activities at the DOE sites............. 3

Table 2-2. Summary of the grout needs for closure of large tanks in the DOE complex........ 4

Table 2-3. Composition of the two grouts identified for closing waste tanks at the Idaho

Nuclear Technology and Engineering Center (INTEC)................................................. 8

Table 2-4. Ingredients and proportions of the flowable fill sued to close the OHF tanks at

Oak Ridge. (Harrison Mix 80 sold by the Harrison Concrete Company) ........................ 10

Table 2-5. SRS high-level waste tank fill formulations used for Tank 17-F and 20-F closure and an All-In-One formulation proposed for Tank 19-F............................................... 13

Table 3-1 Summary of hydrated portland cement and water in oxidizing and reducing environments for various elements [Bradbury and Sarott, 1995].................................... 35

Table 3-2 List of reactive reagents effectively used in combination with portland cement to

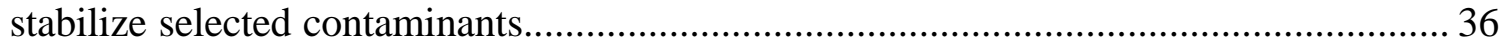

Table 4-1 Description of the various types of portland cement [ASTM, 1989] .................... 39

Table 4-2 Classification of hydraulic slag used in concrete [ASTM C-989] ..........................4 40

Table 4-3 Description of fly ash and natural pozzolans...................................................... 42

Table 5-1. Tank fill physical properties versus available technology and technology needs.52

Table 5-2. Tank fill leaching properties versus available technologies and technology needs. 


\section{LIST OF ACRONYMS AND ABBREVIATIONS}

\begin{tabular}{ll} 
ACI & American Concrete Institute \\
AEA & Atomic Energy Agency Technology \\
ALARA & As Low As Reasonably Achievable \\
ACI & American Concrete Institute \\
ANSI & American Nuclear Society Institute \\
API & American Petroleum Institute \\
ASTM & American Society for Testing and Materials \\
BNFL & British Nuclear Fuels Limited \\
BVEST & Bethel Valley evaporator Storage Tanks \\
CERCLA & Comprehensive Environmental Response, Compensation and Liability \\
& Act \\
cft & cubic foot \\
CLSM & Controlled Low Strength Material \\
cm/kg & centimeters per kilogram \\
cm/sec & centimeters per second \\
CMS & Corrective Measure Studies \\
CST & Crystalline silico titanate (resin) \\
cyd & cubic yard \\
DOE & Department of Energy \\
EE/EC & \\
EIS & Environmental Impact Statement \\
EPA & U. S. Environmental Protection Agency \\
ERD & Environmental Remediation Department \\
FEMS & Fernald Environmental Management Site \\
FFA & Federal Facilities Agreement \\
fl.oz/cyd & fluid ounces per cubic yard \\
ft & feet \\
GAAT & Gunite and Associated Tanks \\
gal/cyd & pounds per cubic yard \\
GGBFS & Ground granulated blast furnace slag \\
h & hours \\
HDW-EIS & Hanford Defense Waste Environme ntal Impact Statement \\
HLW & High-level waste \\
HRWR & high range water reducer \\
HTF & H-Area tank Farm \\
IAEA & International Atomic Energy Association \\
ID & Idaho \\
INEEL & Idaho National Engineering and Environmental Laboratory \\
INTEC & Idaho Nuclear Technology Engineering Center \\
IONSIV & Ion Sieve \\
IRPC & Indian Red Pottery Clay \\
K & Distribution ratio (concentration in/on solid divided concentration in \\
lbs/cyd & liquid) \\
\hline & pounds per cubic yard \\
&
\end{tabular}




$\begin{array}{ll}\text { LLW } & \text { Low-level waste } \\ \text { max } & \text { maximum } \\ \text { MPa } & \text { Mega Pascals } \\ \text { MTVS } & \text { Melton Valley Storage Tanks } \\ \text { NA } & \text { not applicable } \\ \text { NEPA } & \text { National Environmental Policy Act of 1969 } \\ \text { NRC } & \text { Nuclear Regulatory Commission } \\ \text { NY } & \text { New York } \\ \text { OH } & \text { Ohio } \\ \text { OHF } & \text { Old Hydro-Fracture } \\ \text { OR } & \text { Oak Ridge } \\ \text { ORR } & \text { Oak Ridge Reservation } \\ \text { ORWBG } & \\ \text { OST } & \text { Organic Solvent Tanks } \\ \text { PA } & \text { Performance Assessment } \\ \text { PE } & \text { Performance Evaluation } \\ \text { PIMS } & \text { Phosphate-induced metalstabilization } \\ \text { psi } & \text { pounds per square inch } \\ \text { PUREX } & \text { Plutonium Uranium Extraction } \\ \text { RBOF } & \text { Receiving Basin for Off-Site Fuel } \\ \text { RCRA } & \text { Resource Conservation and Recovery Act } \\ \text { RFI } & \text { Remedial Facility Investigation } \\ \text { RI/FS } & \text { Remedial Investigation/Feasibility Study } \\ \text { ROD } & \text { Record of Decision } \\ \text { RPE } & \text { Retrieval Performance Evaluation } \\ \text { SC } & \text { South Carolina } \\ \text { SMITE } & \text { synthetic mineral immobilization technology } \\ \text { SR } & \text { Savannah River } \\ \text { SRS } & \text { Savannah River Site } \\ \text { SRTC } & \text { Savannah River Technology Center } \\ \text { SSTs } & \text { Single-shell Tanks } \\ \text { TBD } & \text { To Be Determined } \\ \text { TFA } & \text { Tanks Focus Area } \\ \text { TFF WM } & \\ \text { TIE } & \text { Technology Information Exchange } \\ \text { TN } & \text { Tennessee } \\ \text { TTP } & \text { Technical Task Plan } \\ \text { TRU } & \text { trans uranic } \\ \text { TSD } & \text { treatment, storage, and disposal } \\ \text { TSP } & \text { Triple super phosphate } \\ \text { UK } & \text { United Kingdom } \\ \text { UOP } & \text { United Oil Products, Inc. } \\ \text { USA } & \text { United States of America } \\ \text { USDOE } & \text { U. S. Department of Energy } \\ \text { WA } & \text { Washington } \\ \text { WSRC } & \text { Westinghouse Savannah River Company } \\ \text { WSRC-RP } & \text { Westinghouse Savannah River Company Report } \\ & \end{array}$




$\begin{array}{ll}\text { WT } & \text { Waste Technology } \\ \text { WVDP } & \text { West Valley Demonstration Project } \\ \text { WVEM } & \text { West Valley Environmental Management } \\ \text { WVNS } & \text { West Valley } \\ \% & \text { per cent } \\ > & \text { greater than } \\ < & \text { less than }\end{array}$




\subsection{INTRODUCTION}

\subsection{BACKGROUND}

The USDOE complex currently has over 330 underground storage tanks that have been used to process and/or store radioactive and chemical mixed waste generated from the production of weapon materials. These tanks contain over 100 million gallons of high-level and lowlevel radioactive waste (HLW and LLW, respectively).

The waste consists of radioactively contaminated sludge, supernate, salt cake, or calcine. Most of the waste is stored at six DOE locations:

- The Hanford Site, Richland, Washington,

- Mixed HLW (hazardous and radioactive) sludge, salt cake and supernate

- The Savannah River Site (SRS), South Carolina,

- Mixed HLW (hazardous and radioactive) sludge, salt cake and supernate

- The Idaho National Engineering and Environmental Laboratory (INEEL), Idaho Falls, Idaho

- Mixed calcined HLW and liquid wastes

- The West Valley Demonstration Project, (WVDP) West Valley, New York, - Mixed HLW tanks were recently emptied.

- The Oak Ridge Reservation (ORR), Oak Ridge, Tennessee, and - Mixed LLW and TRU sludge and liquid waste

- The Fernald Environmental Management Site (FEMS), Fernald, Ohio.

- Mixed LLW (calcined solids).

Hanford has 177 single- and double-shell carbon steel tanks containing over 60 per cent of the total DOE tank waste inventory. Savannah River has 51 large single- and double-shell carbon steel tanks. These tanks have capacities ranging from about 750,000 to 1.3 million gallons. Both of these sites also have numerous smaller underground waste tanks in addition to large reactor disassembly basins and other structures that are candidates for in-situ stabilization and disposal. Two of the SRS single shell tanks (17-F and 20-F) were closed in 1997 and 1998.

The INEEL has eleven 300,000-gallon HLW tanks and four 30,000-gallon tanks that are identified for in-situ closure. These tanks are stainless steel and have secondary containment in the form of concrete vaults. The INEEL also has miscellaneous small tanks, spent fuel storage basins, and reactor disassembly basins that are candidates for in-situ closure and disposal.

The Oak Ridge Reservation has two active tank farms, one referred to as the Melton Valley Storage Tanks (MVST) and the other as the Bethel Valley Evaporator Storage Tanks (BVEST). ORR also has two inactive tank farms, the Old Hydro-Fracture Facility (OHF) and the Gunite and Associated Tanks (GAAT) and several small "orphan" tanks.

The five OHF tanks were recently emptied and closed in-situ in 2000. These carbon steel tanks ranged in size from about 12,000 to 25,000 gallons. Two of the tanks were rubber 
lined. The gunite tanks (six 50-foot diameter and two 25-foot diameter tanks) in the GAAT tank farm were also recently emptied. In-situ closure is currently in progress and is scheduled for completion in 2001.

The BVES and MVS tanks are stainless steel and are currently receiving and storing waste. Therefore, closure plans for these tanks are premature. Some of the orphan tanks contain waste that may be treated in-tank by encapsulation and/or stabilization and disposed of in place. For example, tanks T1 and T2 contain ion exchange resin plus TRU sludge which must be removed. Tank T14, a rectangular concrete vault, contains a waste heel that is difficult to remove.

Calcined waste (dried particulate waste) is stored in stainless steel tanks in bin sets at INEEL and in three one-million gallon underground (at-grade) concrete silos at Fernald. In addition, liquid acid waste is stored in stainless steel tanks at INEEL.

\subsection{OBJECTIVE}

This report was commissioned by the DOE Tanks Focus Area (TFA) per TTP SR16WT51 Subtask H and TTP OR16WT51 Subtask D and is intended to provide a state of the art review of in-place closure of empty HLW tanks. Many of the tanks are in use well beyond their design life. This report includes strategies for treating the incidental waste left in the emptied tanks as non-retrievable heels and methods and materials for physically stabilizing the void space in the tanks to prevent future subsidence.

\subsection{APPROACH}

The approach used for compiling the state of the art for HLW tank closures was to first survey the DOE sites (Hanford, INEEL, ORR, SRS, and WVDP) to determine the status of their tank closure efforts and to develop a list of needs, approaches, and issues. This was accomplished by developing a survey form and sending it to technical and operating personnel at each site. The same survey was also sent to AEA, UK and technical personnel knowledgeable with the French and Russia experience in tank waste. A review of the Russian tank closure efforts and related experience will be issued to the TFA as a separate document per TTP SR16WT51 Subtask H. In addition, relevant hazardous and radioactive waste treatment technology and construction backfill/grouting technology was reviewed and summarized. 


\subsection{DOE SITE NEEDS}

The requirements for HLW tank fill materials were obtained from five DOE sites. A survey was sent to personnel responsible for tank closure at the Hanford Site, the Idaho National Engineering and Environmental Laboratory, the Savannah River Site, the Oak Ridge National Laboratory, and the West Valley Demonstration Project. The blank survey form and cover letter are presented in Appendix A. Additional information was obtained through discussions with engineers and project leaders at the various sites. The survey form was also sent to AEA to obtain the British experience and to technical personnel in France. Relevant Russian technology is the scope of a separate task covered under the Savannah River Technology Center (SRTC) part of this collaborative project and will not be covered in this section or report.

The responses that pertain to the overall tank closure efforts at each site are summarized in Table 2-1. A summary of the surveyed responses that specifically relate to the tank fill material requirements is provided in Table 2-2. In addition, a summary of the needs and issues identified by each site are listed. The actual survey results are listed in Appendix B. ORNL submitted a copy of the "Technical Specification for Flowable Fill Grout Material" in place of completing the survey form and provided input on the overall approach through technical discussions. See Appendix C.

Table 2-1. Summary of in-place tank closure and related activities at the DOE sites.

\begin{tabular}{|l|c|c|c|c|c|c|}
\hline & Fernald & INEEL & Hanford & Oak Ridge & SRS & WV \\
\hline Tank material & $\begin{array}{c}\text { Concret } \\
\text { e Silos }\end{array}$ & $\begin{array}{c}\text { Stainless } \\
\text { Steel }\end{array}$ & $\begin{array}{c}\text { Carbon } \\
\text { Steel }\end{array}$ & $\begin{array}{c}\text { Gunite } \\
\text { (concrete) }\end{array}$ & $\begin{array}{c}\text { Carbon } \\
\text { Steel }\end{array}$ & $\begin{array}{c}\text { Carbon } \\
\text { Steel }\end{array}$ \\
\hline $\begin{array}{l}\text { Tank integrity } \\
\text { Secondary } \\
\text { containment i.e. } \\
\text { annulus void space }\end{array}$ & No & Good & Leaks, dome? & OK & OK (cracks) & Good \\
\hline $\begin{array}{l}\text { Tank obstructions } \\
\text { e.g., cooling coils }\end{array}$ & No & $\begin{array}{c}\text { Yes } \\
\text { tank } \\
\text { bottom) }\end{array}$ & Yes and No & No & Yes and No & Yes \\
\hline $\begin{array}{l}\text { Treatment of } \\
\text { adjacent } \\
\text { contaminated } \\
\text { environmental media } \\
\text { as part of closure }\end{array}$ & No & No & Yes & No & Yes and No & $\begin{array}{c}\text { Yes but } \\
\text { limited }\end{array}$ \\
\hline $\begin{array}{l}\text { Incidental waste in- } \\
\text { tank treatment }\end{array}$ & $?$ & No? & Yes & No (current) & Yes & Yo \\
\hline $\begin{array}{l}\text { Large scale In-tank } \\
\text { aste treatment and } \\
\text { disposal }\end{array}$ & No & No & Possibly & No & No & No \\
\hline $\begin{array}{l}\text { Other related } \\
\text { closure activities }\end{array}$ & No & Yes* & Yes* & Yes & Yes* & No \\
\hline
\end{tabular}

* Reactor disassembly basins, small waste tanks, and other basins and structures associated with decontamination and disassembly activities. \# Small tank stabilization. 
Table 2-2. Summary of the grout needs for closure of large tanks in the DOE complex.

\begin{tabular}{|c|c|c|c|c|c|}
\hline Grout Properties & INEEL & WVDP & Hanford & SRS & ORNL \\
\hline \multicolumn{6}{|l|}{ Fresh properties } \\
\hline Pumpable & Yes & Yes & Yes & Yes & Yes \\
\hline Flowable & Yes & Yes & Yes & Yes & Yes \\
\hline Self-leveling & Yes & Yes & Yes & Yes & Yes \\
\hline Bleed water & Minimum & Minimum & Minimum & Minimum & None \\
\hline Set time & & $?$ & Weeks-months & & $<72 \mathrm{~h}$ \\
\hline Resist solids settling & N/A & Yes & Yes & Yes & No \\
\hline Heat of hydration & & Yes & Maybe & Yes & Yes \\
\hline \multicolumn{6}{|l|}{ Cured properties } \\
\hline Strength & $>500 \mathrm{psi}$ & Low & Low & Low & $>50 \mathrm{psi}$ \\
\hline Excavatable & & Yes & Yes & Maybe & No \\
\hline $\begin{array}{l}\text { Hydraulic } \\
\text { conductivity }\end{array}$ & & $?$ & & Maybe & \\
\hline \multicolumn{6}{|c|}{ Stabilization/solidification properties } \\
\hline Radionuclides & No & $\begin{array}{l}\mathrm{Am}, \mathrm{Cs}, \mathrm{Np} \\
\mathrm{Pu}, \mathrm{Sr}, \mathrm{Tc}, \mathrm{U}\end{array}$ & $\begin{array}{l}\text { Tc, I, C, Se, } \\
\mathrm{Pu}, \mathrm{Am}, \mathrm{U}, \\
\mathrm{Ni}, \mathrm{Nb}, \mathrm{Cm}, \\
\mathrm{Sr}, \mathrm{Cs}, \mathrm{Sn}, \\
\text { TRU }\end{array}$ & $\begin{array}{l}\text { Yes } \\
\text { esp. Tc, } \\
\text { Pu, Se }\end{array}$ & No \\
\hline RCRA metals & No & $\begin{array}{l}\mathrm{Hg}, \mathrm{Cr}, \mathrm{As}, \mathrm{Ba}, \\
\mathrm{Cd}, \mathrm{Se}, \mathrm{Ag}, \mathrm{Pb}\end{array}$ & $\mathrm{Cr}$ & $\begin{array}{l}\text { Yes } \\
\text { esp. } \mathrm{Hg}\end{array}$ & No \\
\hline Others & No & $\begin{array}{l}\mathrm{NaOH}, \text { nitrate, } \\
\text { nitrite (wash } \\
\text { out, not } \\
\text { stabilize)? }\end{array}$ & $\begin{array}{l}\text { Nitrate, } \\
\text { nitrite }\end{array}$ & & No \\
\hline Durability & $\begin{array}{l}500 \text { years } \\
(\mathrm{PA})\end{array}$ & $\begin{array}{l}\text { Until } \\
\text { excavated? 50- } \\
100 \text { years } \\
\end{array}$ & $\begin{array}{l}500-1000 \\
\text { years } \\
30 \text { y (RCRA) }\end{array}$ & $\begin{array}{l}10,000 \\
\text { years }\end{array}$ & $\begin{array}{l}\text { None (no } \\
\text { credit in } \\
\text { PA) }\end{array}$ \\
\hline Implementation & $\begin{array}{l}\text { Displace and } \\
\text { remove heel, } \\
\text { pump/tremie }\end{array}$ & $\begin{array}{l}\text { Batch grout \& } \\
\text { place in tank }\end{array}$ & $\begin{array}{l}\text { Mix heel and } \\
\text { grout; } \\
\text { Pump/tremie }\end{array}$ & $\begin{array}{l}\text { Mix heel } \\
\text { and grout; } \\
\text { pump/ } \\
\text { tremie }\end{array}$ & $\begin{array}{l}\text { Pump and } \\
\text { dump or } \\
\text { tremie }\end{array}$ \\
\hline Grout Identified & Yes & Yes & No & Maybe & Yes \\
\hline Other issues & $\begin{array}{l}\text { Requires grout } \\
\text { to first } \\
\text { displace heel } \\
\text { for removal, } \\
\text { then fill tank; } \\
\text { heel will } \\
\text { interact with } \\
\text { fill }\end{array}$ & $\begin{array}{l}\text { Physical } \\
\text { handling } \\
\text { properties } \\
\text { already } \\
\text { evaluated; heat } \\
\text { of hydration, and } \\
\text { stabilization } \\
\text { TBD } \\
\end{array}$ & $\begin{array}{l}\text { Interested in } \\
\text { apatitic } \\
\text { stabilization }\end{array}$ & $\begin{array}{l}\text { Cost of } \\
\text { grout is a } \\
\text { concern; } \\
\text { likely for } \\
\text { other sites } \\
\text { as well }\end{array}$ & $\begin{array}{l}\text { Needs } \\
\text { already met } \\
\& \text { currently } \\
\text { closing } \\
\text { tanks }\end{array}$ \\
\hline
\end{tabular}




\subsection{HANFORD SITE}

The tank closure needs listed by the Hanford Site personnel were by far the most extensive in the DOE Complex. Waste removal, waste pre-treatment, treatment of the environmental media surrounding the tanks, working in cracked and leaking tanks, designing and testing final cover systems for the closed tanks, and in-tank treatment and disposal of bulk waste were identified as issues. Hanford also identified more contaminants requiring stabilization than the other sites. Hanford is the only DOE site in an arid environment with leaking HLW tanks.

The Hanford needs were so broad that more than one tank fill strategy and tank fill formulation will be required. Strategies and materials are also required for treating the adjacent soil and sediment and for pre-treating tank heels. Currently Hanford is pursuing phosphate precipitation and absorption on phosphate minerals as possible stabilization treatments. At the present time, Hanford is developing strategies for managing and closing the HLW tanks. Tank fill materials will be identified at a later time.

Hanford tanks are currently regulated as treatment, storage, and disposal (TSD) facilities under RCRA. Since contaminants have been detected in the groundwater under some of the Hanford tanks, site characterization is being conducted in support of a remedial facility investigation (RFI) and corrective measure studies (CMS) under RCRA. In a few cases, interim corrective measures are being implemented to minimize the impacts of tank farm operations of human health and the environment. Activities underway include: the cutting and capping of excess water lines, pressure testing of water lines in use, and construction of surface barriers to control run-on of rain water and snow melt.

The Hanford Defense Waste Environmental Impact Statement (HDW-EIS) deferred decisions regarding the final disposition of tanks and tank wastes pending further evaluation of the wastes and alternatives for waste retrieval and tank closure. A supplemental EIS is planned in the next few years as Hanford acquires more information on retrieval system performance and closure technology capabilities. A single-shell tank closure plan was drafted and is undergoing review and comment. The closure plan will be updated every two years to incorporate lessons learned in terms of retrieval and performance.

Under the Tri-Party Agreement, initiation of a tank closure demonstration is planned in 2012 with completion of the closure demonstration in the 2014 time frame. The initial closure demonstration will be on an operable unit or tank farm basis. Closure of all SSTs is to be accomplished by the year 2024 .

RI/FS have been completed for contaminated soil sites (cribs, ponds, ditches, etc.), and cleanup efforts are proceeding under CERCLA. For the tanks however, actual closure decisions have not been made. The current assumption is that tank closure at Hanford will occur under the RCRA requirements for "landfill" closure. This is due in part to the presence of contaminated soils under some of the tanks and the fact that it would be cost prohibitive to remove all of the contaminated soils, tanks, pipelines, and ancillary structures under a "clean" closure scenario. 


\subsubsection{Needs}

The Hanford Site plan and tank closure needs include:

- Characterization of residual wastes.

This requires off-riser sampling. In-situ characterization of chemicals and radionuclides is preferable to collection of actual samples because it will eliminate most of the sampling and laboratory analysis costs. An objective of this effort is to determine the classification of the waste residuals.

- Coordination of the regulatory requirements.

Tank closure at Hanford requires coordination and integration of the regulatory requirements as prescribed under RCRA, CERCLA, DOE Orders, and other appropriate or relevant and applicable requirements. The regulatory drivers include:

NEPA,

RCRA,

CERCLA,

Hanford Federal Facility Agreement and Consent Order (Tri-Party Agreement),

Atomic Energy Act,

Clean Air Act,

Safe Drinking Water Act, State laws (Washington Administrative Codes),

DOE Orders and Management Directives, Code of Federal Regulations,

Energy Reauthorization Act,

Nuclear Waste Policy Act.

- Development and demonstration of a waste treatment strategy that meets regulatory requirements.

- Stabilization of void space in the tank to prevent differential settlement and subsidence and thereby maintain the integrity of the final surface cover systems (landfill cap).

- Identifying fill materials and placement methods that allow for future cost-effective retrieval of the tank waste. Such materials include non-structural grouts, sand, and gravel. Requirements for the fill materials include:

- Self-leveling

- Pumpable

- Low viscosity

- Pours will range in volume from 500,000 to 1,000,000 gallons per tank.

- Set time on the order of weeks to months.

- Minimal bleed water, potential source for contaminant migration.

- Resistant to solids segregation

- Heat of hydration is a possible issue if higher temperatures drive off volatiles. contaminants of concern or driving contaminants deeper into the vadose zone.

- Must be capable of irreversibly sorbing/stabilizing contaminants of concern.

- Leach resistance must be demonstrated for 500 to 1,000 years.

- The selected waste form needs to perform over a period of 500 to 1,000 years.

- In ex-tank applications, must be capable of flowing freely through soils characterized as sands, gravels, and cobbles..

- Fill placement strategy that is compatible with the tank dome load limits.

- Fill placement strategy that allows for cross-site transfer of roughly 2 miles. 
- Immobilization of the radionuclides that drive long-term groundwater pathway risk analyses (i.e., Tc-99, I-129, C-14, Se-79, and uranium isotopes) and the intruder scenarios (Cs-137, Sr-90, Sn-126, Pu isotopes, Am-241, U isotopes, C-14, Ni-59/63, Nb94, Tc-99, I-129, Cm-242, etc.) and other contaminants (chromium, nitrate, nitrite).

- Immobilization of contaminants in the vadose zone surrounding tanks.

These soils and sediments were contaminated as the result of past events/leaks/spills. Insitu treatment requires solidification/encapsulation by mixing and/or injection of stabilizing/solidifying solutions or ultra fine grouts. Hanford sediments are relatively coarse (sands, gravels, and cobbles) and are suitable for this type of treatment. The alternative is excavation. Silt stringers, caliche layers, clastic dikes, and other geologic features affect the fate and transport of contaminants in the vadose zone and may complicate in-situ treatment. The groundwater is about 200-250 feet below the surface at the Hanford tank farm (200 East and West Areas).

- Identification of a suitable surface cover system (landfill cap).

Surface cover systems or barriers control water infiltration, and plant, animal, and human intrusion for 500 to 1,000 years. Under RCRA, a post-closure care period of 30-years is established. Every 5-years an assessment will be conducted to ensure continued effectiveness of provisions to protect human health and the environment. Due to the persistence of some of the contaminants in tank waste, long-term monitoring and stewardship is required. Hanford developed a special protective barrier system in the mid- to late-1980's. The results of roughly 8 years of research and development led to the construction of a full-scale protective barrier prototype (surface cap) on the 216-B-57 crib in 200 East Area. Performance data is being collected on the prototype barrier.

- Identification of post-closure monitoring in the groundwater and vadose zone systems. Post-closure monitoring under semi-arid conditions is needed for the 30-year post closure care period to demonstrate the effectiveness of closure methods in terms of minimizing impacts to human health and the environment. This requires technologies capable of measuring small volumes of moisture under variably saturated conditions. Soil moisture conditions are typically very low.

- Removing waste from the HLW tanks.

The goal under the Tri-Party Agreement is to remove 99\% of the wastes from the tanks. This goal may be limited by the retrieval technologies. Since 67 of Hanford's 149 singleshell tanks (SSTs) are assumed or confirmed to have leaked and since all of the SSTs have exceeded their intended design lives, retrieval systems are being design to use little if any liquids. A Retrieval Performance Evaluation (RPE) methodology has been adopted to support decisions regarding retrieval. The RPE methodology is a risk-based, tank-specific approach that considers past tank leaks, potential leakage during retrieval, and residual waste inventories. This methodology will be used to establish retrieval release criteria and target leak detection rates as a function of tank waste inventories and tank integrity considerations. It also provides an indication of how well the retrieval systems need to perform to provide adequate protection of human health and the environment. 


\subsubsection{Definition of Success.}

Tank closure success is defined by:

- Achieving risk-based retrieval performance objectives calculated by the RPE methodology;

- Immobilizing residual contamination in tanks, pipelines, ancillary structures, and surrounding soils to a level protective of human health and the environment;

- Stabilizing tank void spaces to prevent differential settlement and subsidence;

- Providing a surface barrier capable of controlling water infiltration and plant, animal, and human intrusion; and

- Installing post-closure monitoring to ensure the overall performance of the closure system.

- Enabling cost-effective retrieval of the waste in case decisions are made to remove residual wastes.

- Achieving fill placement in, around, and through in-tank instrumentation and structures. Under worst case conditions, the formulation must be able to flow through roughly 2 miles of cross-site, underground, transfer lines.

\subsection{INEEL}

INEEL has identified a waste retrieval strategy for the first tanks scheduled to be closed. In addition INEEL has identified two tank fill materials that meet their needs. Additional development work is in progress to demonstrate heel removal.

The ingredients and proprotions for the INEEL grout fill formulations are shown in Table 23. One grout is for filling pipes (Pipe Grout); the other is for filling the bulk of tanks and vaults (Tank Grout).

Table 2-3. Composition of the two grouts identified for closing waste tanks at the Idaho Nuclear Technology and Engineering Center (INTEC).

\begin{tabular}{|l|c|c|}
\hline Component & Pipe Grout & Tank Grout \\
\hline $\begin{array}{l}\text { Portland Cement, Type I/ II } \\
\text { (lbs/cyd) }\end{array}$ & 680 & 320 \\
\hline $\begin{array}{l}\text { Fly Ash, Class F } \\
\text { (lbs/cyd) }\end{array}$ & 1,600 & 640 \\
\hline $\begin{array}{l}\text { Sand } \\
\text { (lbs/cyd) }\end{array}$ & N/A & 2,200 \\
\hline $\begin{array}{l}\text { Water } \\
\text { (gallons/cyd) } \\
(\text { lbs/cyd) }\end{array}$ & 96 max & 52 max \\
\hline
\end{tabular}




\subsubsection{Site Needs}

The INEEL site plans and tank closure needs include:

- Close eleven 300,000-gal HLW tanks and four 30,000-gal tanks per Resource Conservation and Recovery Act (RCRA) and DOE 435.1 requirements.

- Complete the Final Environmental Impact Statement (EIS) by June 2001 and complete the Record of Decision (ROD) July 2001 (RCRA closure process). Treatment and closure of the contaminated soil around and under the tanks is covered under the Comprehensive Environmental Response, Compensation, and Liability Act (CERCLA). A Remedial Investigation/Feasibility Study (RI/FS) is complete. (CERCLA closure process uses a RI/FS followed by a ROD. Both RCRA and CERCLA may involve treatability studies.)

- Decontaminate the tanks and attempt to remove all of the waste.

- Define "Empty tank" as the tank containing 3 to 10 inches of waste heel (depending on the tank shape and volume) after bulk waste removal.

- Physically displace the acid waste heel with strategic grout placements to move it closer to the existing pumps. A 5-step pour strategy was designed to push acid toward pump at a fixed location. (This grout plan was tested in a mock-up in 1999, as reported in TFF WM-182 Grout Mock-Up, INEEL/EXT-99-01067; October 1, 1999.)

- Use grout to treat any waste left in tanks after waste removal and decontamination.

- Use grout to physically stabilize, i.e., fill the tanks.

- Design for a 500-year life per the Performance Assessment.

- No mixing of grout with tank heel planned.

- Design a self-leveling fill that flows easily into tank and pipes and has:

- minimum bleed water

- $>500$ psi unconfined compressive strength.

INEEL also plans to deactivate, dismantle and decommission three large nuclear fuel storage basins and transfer canal in the CPP-603 Building. Basin \#1 is 42x80 feet and Basins \#2 and $\# 3$ are 38x59 feet. The pool depth is 21 feet. Grout is planned as the basin fill material. Requirements for the grout include: compatibility with the basin water (contact and/or incorporation in the grout as mixing water), flowable, and suitable for underwater placement (cohesive, non-segregating).

It is important to note the unique nature of the INEEL HLW tank waste, relative to the other DOE sites, i.e., the INEEL waste is acidic. It was not neutralized with $\mathrm{NaOH}$ prior to storage. Chemical reactions between the acid waste and the alkaline grout may create problems for waste retrieval strategy involving grout displacement of the residual waste. Although cement is the minor component of the tank fill, it will still react with the residual acidic waste. Depending on the nature of the solids dissolved in the waste, increasing the $\mathrm{pH}$ could cause precipitation of iron and aluminum hydroxides and may make the mixture more difficult to displace and remove. The acid-base reactions will also be exothermic and may also generate gas and aerosols. 


\subsection{ORNL}

Waste removal and tank cleaning activities at ORNL were so successful that in-tank waste heel treatment has been unnecessary. Therefore, ORNL specified a common flowable fill for closure of the OHF tanks. The fill mix design is given in Table 2-4. This formulation produced some bleed water that required extra processing. Therefore, new low-bleed water formulations are currently being developed and tested for filling the GAAT tanks. The new mix is reported to contain less or no fly ash, less water, and Aquasorb® to control bleed water.

Table 2-4. Ingredients and proportions of the flowable fill sued to close the OHF tanks at Oak Ridge. (Harrison Mix 80 sold by the Harrison Concrete Company)

\begin{tabular}{|l|c|}
\hline Ingredient & Harrison Mix 80 (Harrison Concrete Co.) \\
\hline Fly Ash, Class F (lbs/cyd) & 600 \\
\hline Portland Cement, Type I (lbs/cyd) & 40 \\
\hline Sand (lbs/cyd) & 2330 \\
\hline Water (gal/cyd) & $60 \mathrm{max}$ \\
\hline
\end{tabular}

\subsubsection{Needs}

The ORNL site plans and tank closure needs include:

- Empty tanks per RCRA and then with State's agreement just fill tank

- Use flowable fill as the tank stabilization material with the following properties:

- Compressive strength of at least 50 psig after 28 days

- Flowable such that it is self leveling

- Set time of less than 72 hours

- No bleed water setting

- Minimum heat generation during curing.

\subsection{SRS}

In 1997, two single-shell carbon steel tanks (17-F and 20-F) were emptied and filled with grout at the SRS [Bignell and Ling, 1998 and Ling et al., 1998]. Each tank had a capacity of 1.3 million gallons and each was originally used to store low-heat waste (no cooling coils or other obstructions). See Figures 2-1, 2-2, and 2-3. Two similar tanks 18-F and 19-F are scheduled for closure in the near future. The ingredients and proportions in the SRS tank fill materials are listed in Table 2-5. The closure strategy and the three different fill materials that were used in the closure are described elsewhere [Caldwell, et al. 1998 and Caldwell, 1998]. Several other flowable fills were developed at SRS for special applications [Langton and Rajendran, 1998 and 2000]. These formulations include: 
- Zero-bleed All-In-One grouting system which provides chemical reduction/contaminant stabilization and enables the strength to be adjusted by varying only the proportions of the dry solids.

- Zero-bleed flowable fill containing SRS coal ash.

- Zero-bleed flowable, self-leveling concrete.

- Zero-bleed SRS soil flowable fill.

- Zero-bleed cellular (light-weight) fill.

- Zero-bleed high-water fill for underwater placement.

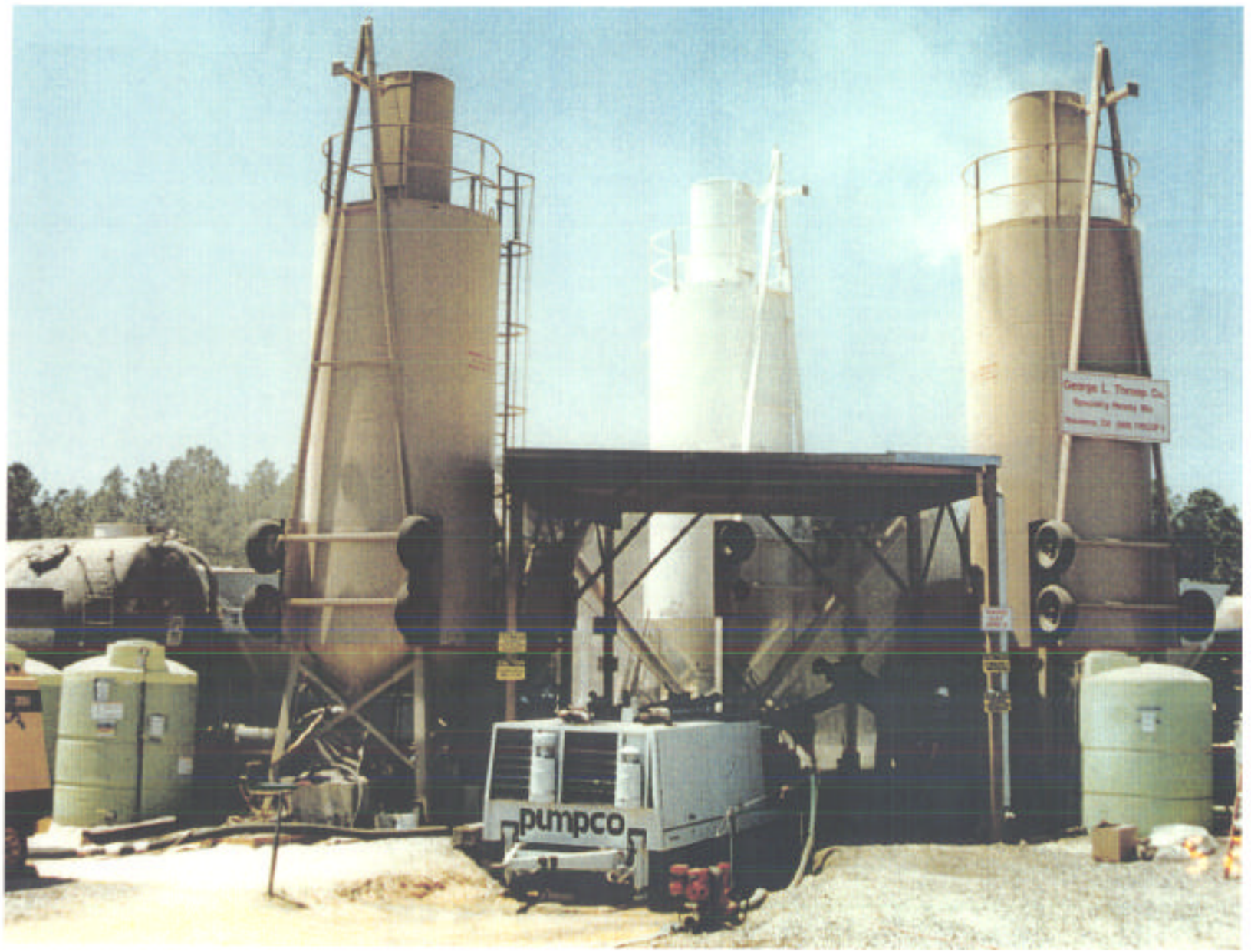

Figure 2-1. Portable continuous auger plant (Throop, Inc.) used to batch fill material for tanks 17-F and 20-F at the SRS. 


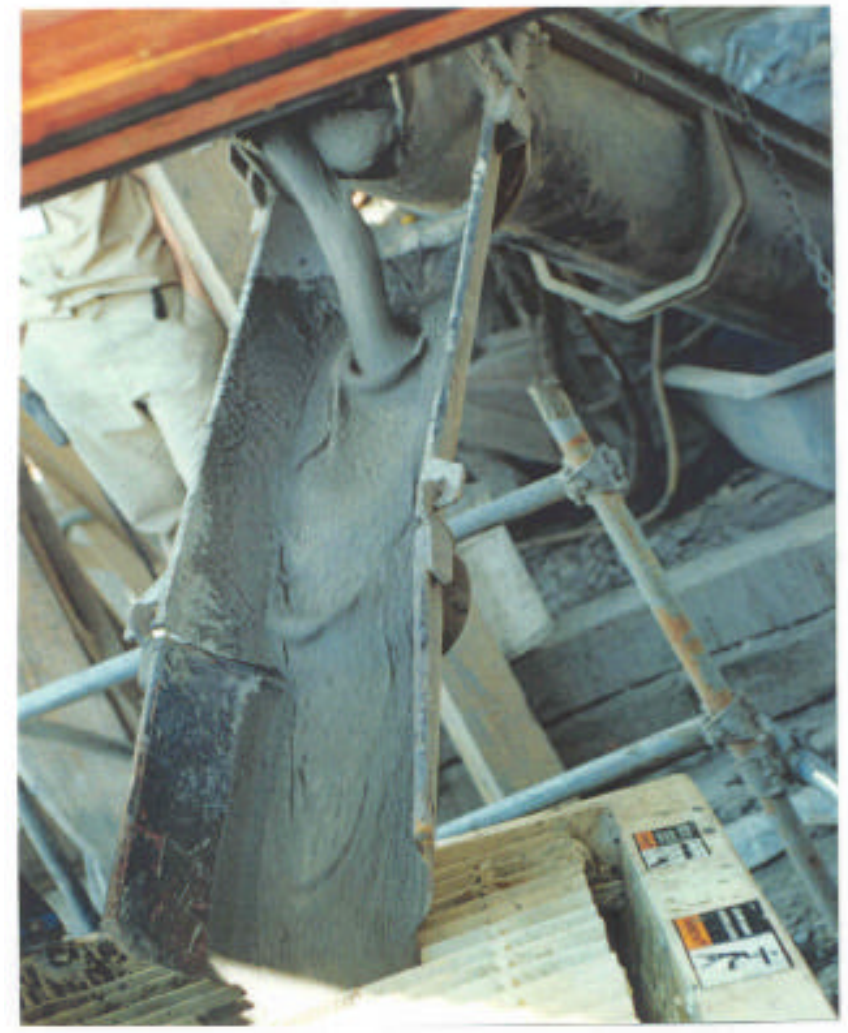

Figure 2-2. Tank 17 zero-bleed fill being discharged into the pump.

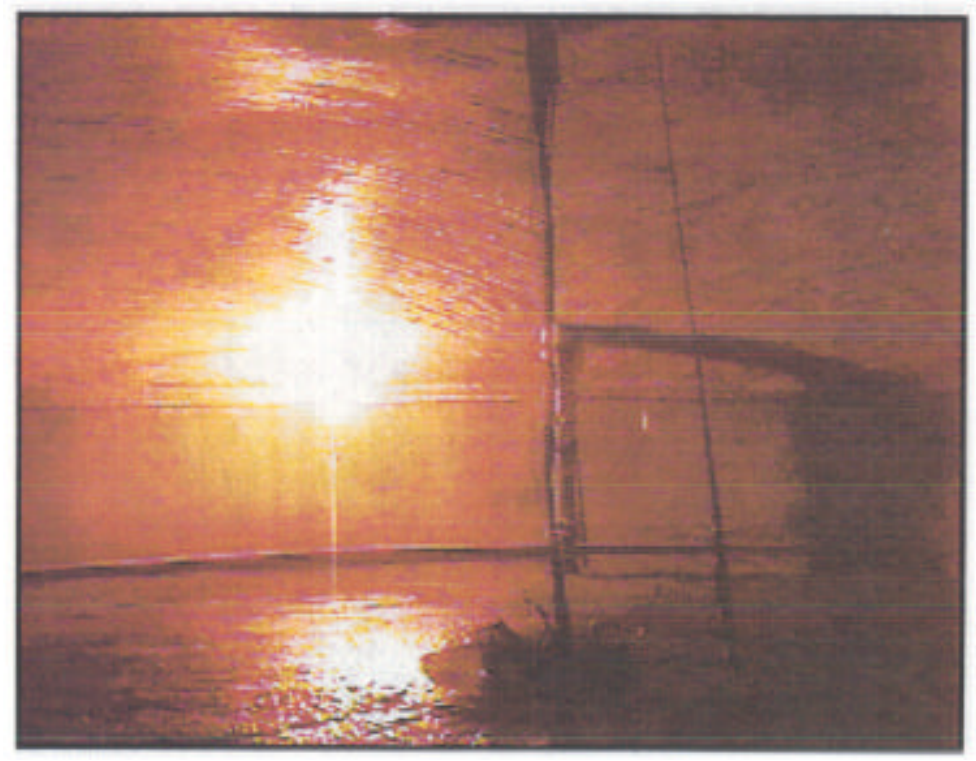

Figure 2-3. Zero-bleed flowable fill placement in Tank 20-F, SRS, June 1997.

The fill was self-leveling, self-consolidating, and flowed evenly from a central discharge point in the dome of the tank 45 feet in all direction. 
WSRC-TR-2001-00359, REVISION 0

JULY 31, 2001

Table 2-5. SRS high-level waste tank fill formulations used for Tank 17-F and 20-F closure and an All-In-One formulation proposed for Tank 19-F.

\begin{tabular}{|c|c|c|c|c|}
\hline & $\begin{array}{l}\text { SRS } \\
\text { Reducing } \\
\text { Grout }\end{array}$ & $\begin{array}{l}\text { SRS Zero- } \\
\text { Bleed } \\
\text { Flowable Fill }\end{array}$ & $\begin{array}{l}\text { SRS Zero- } \\
\text { Bleed 2000 } \\
\text { psi Grout }\end{array}$ & $\begin{array}{l}\text { SRS All-In-One Zero- } \\
\text { Bleed Reducing Fill/Grout } \\
\text { System* }\end{array}$ \\
\hline Application & $\begin{array}{l}\text { Encapsulate } \\
\text { incidental } \\
\text { waste }\end{array}$ & $\begin{array}{l}\text { Bulk HLW } \\
\text { tank fill }\end{array}$ & $\begin{array}{l}\text { Intruder } \\
\text { barrier }\end{array}$ & $\begin{array}{l}\text { Encapsulate waste, Bulk } \\
\text { tank fill, Intruder barrier }\end{array}$ \\
\hline $\begin{array}{l}\text { Portland } \\
\text { cement } \\
\text { Type I } \\
\text { (lbs/cyd) }\end{array}$ & 1353 & 150 & 550 & 75 \\
\hline $\begin{array}{l}\text { Slag, Grade } \\
100 \\
\text { (lbs/cyd) }\end{array}$ & 209 & --- & --- & 210 \\
\hline $\begin{array}{l}\text { Fly Ash, Class } \\
\text { F } \\
\text { (lbs/cyd) }\end{array}$ & --- & 500 & --- & 375 \\
\hline $\begin{array}{l}\text { Silica Fume } \\
\text { (lbs/cyd) }\end{array}$ & 90 & --- & --- & --- \\
\hline $\begin{array}{l}\text { Quartz Sand } \\
\text { ASTM C-33 } \\
\text { (lbs/cyd) }\end{array}$ & 1625 & 2300 & 2285 & 2300 \\
\hline $\begin{array}{l}\text { Water } \\
(\mathrm{gal} / \mathrm{cyd})\end{array}$ & 86.4 & 63 & 65 & 60 \\
\hline $\begin{array}{l}\text { HRWR } \\
\text { (fl.oz/cyd) }\end{array}$ & 250 & --- & --- & --- \\
\hline $\begin{array}{l}\text { Retarder } \\
\text { (fl.oz/cyd) }\end{array}$ & 150 & --- & --- & --- \\
\hline $\begin{array}{l}\text { Sodium } \\
\text { Thiosulfate** } \\
\text { (lbs/cyd) }\end{array}$ & 2.1 & --- & --- & 2.1 (optional) \\
\hline $\begin{array}{l}\text { Advaflow*** } \\
\text { (HRWR) } \\
\text { (fl.oz/cyd) }\end{array}$ & --- & 90 & 140 & 90 \\
\hline $\begin{array}{l}\text { Welan Gum } \\
\text { Kelco-crete*** } \\
\text { (grams/cyd) }\end{array}$ & --- & 275 & 275 & 275 \\
\hline
\end{tabular}

* This mix was developed for future HLW tank closures. The mix proportions can be adjusted to obtain a range of compressive strength suitable for waste encapsulation, bulk fill and intruder protection.

** Added to the mix as a liquid solution.

*** Premixed and metered into the auger as a suspension. 
Technology developed for the SRS HLW tank closures can be applied to other applications, such as, in-place closures of small tanks, large underground pipes, sand filters, and decommissioned nuclear structures. For example, SRS plans to close 3 reactor disassembly basins in the next 3-10 years. The capacity of these basins is 4 to 5 million gallons, and they contain significant quantities of water. The SRS Receiving Basin for Off-Site Fuel (RBOF) is scheduled to be closed in 6-10 years and the 2 remaining reactor disassembly basins are scheduled to be closed in 10-15 years.

In-place closure of small underground tanks that were used to store radioactive or mixed wastes is being planned at SRS. Examples of the small tanks are the Organic Solvent Tanks (OST) located in E-Area that were used to store spent Purex waste. These tanks are designated as ORWBG OSTs and are a solid waste management unit regulated under RCRA 3004(u) Solid Waste Management Unit. (The 1993 FFA lists the OSTs as a component of the ORWBG operable unit, which is a RCRA/CERCLA unit in Appendix C of the FFA for SRS.)

Waste was removed from these tanks, and they are scheduled to be closed starting in 2003. The SRS Remedial Action Objective, as identified in the Proposed Plan and Interim Record of Decision, is to structurally stabilize the tanks. Flowable fill similar to the materials used in closing tanks $17-\mathrm{F}$ and $20-\mathrm{F}$ will be used.

\subsubsection{Needs}

The plans and needs for closing the SRS HLW tanks, reactor disassembly basin and small solvent tanks were identified as the result of the survey distributed for this study and are summarized below:

\subsubsection{HLW Tanks}

Two Type IV HLW tanks, 17-F and 20-F, were closed at the SRS according to the task and material requirements listed below. These tanks are single shell carbon steel tanks that were used for low-heat waste. The same criteria are being applied to future SRS HLW tank closures. These tanks are being closure under CERCLA.

- No RI/FS or ROD yet, though there was a RI/FS for the groundwater in HTF.

- Remove waste from tanks. Tank closure success is defined to meet DOE 435.1 and Performance Standards.

- Piping, slurry pumps, and other equipment left in the tanks will be grouted in-place. Piping over 1-in. diameter will also be filled with grout.

- The annulus space between the Type I, II, and III tank secondary containers will also be closed, i.e., filled with grout or other material to minimize infiltration of water and subsidence.

- Grout physical/handling properties listed in the survey form are design considerations (strength, flowability, self-leveling, pumpability, viscosity, workability time, set time, bleed water, hydraulic conductivity, excavatable, resistant to solids segregation, heat of hydration). 
- The contaminants of concern are RCRA metals (especially mercury and characteristically hazardous waste constituents) and radionuclides. (Tc-99, Pu-239 and Se-79 were the main dose contributors in the Tank 17-F and 20-F closures.)

- Stabilize contaminants of concern.

- Longevity/durability of 10,000 years for chemical properties, as long as possible for physical properties.

- Use locally available ingredients, i.e., sand, cement, etc.

- Pump the grout up to 2000 feet with a positive displacement pump.

- Mix grout and tank heels.

- Minimize materials and construction/placement cost.

- Incorporate SRS fly ash and contaminated soil in flowable fill/grout. Mixes addressing this need were developed for tank fill applications.

\subsubsection{Reactor Disassembly Basins}

- Closure probably under CERCLA non-time critical removal action, not RCRA

- Plan to close under an EE/EC

- No RI/FS, and none planned

- Radioactivity regulated under DOE

- Prefer to grout the water in the basin in-situ or use the basin water as mixing water. The grouting equipment can be rinsed and re-used on the successive closures.

- Success is defined as basins partially drained (to have enough space to accept the grout plus all above ground walls and roofs), the remaining water grouted in place in the basin, and a cap installed.

- Low Strength, minimum 50 psi, 100-200 psi better, but not required.

- Under water flowability

- Self-leveling not critical

- Pumpability up to 300 feet

- Viscosity low enough to pump, high enough to set before dispersing underwater

- Set time not critical

- Low bleed water is better, but not critical, any bleed water can be controlled with a final clay soil backfill

- Does not have to be excavatable or resistant to solids segregation

- Contaminants of concern are tritium, Cs-137, Sr-90, I-129, C-14, and Tc-99, no RCRA metals

- For enhancing leach resistance the lower the permeability the better. Reducing grout not needed. No stabilization of the contaminants of concern, just immobilization. Reversible sorption is probably acceptable.

- ANSI 16.1 testing would be nice, but not critical

- No short term accelerated testing or long term testing.

- Desire whatever it takes to meet the above criteria and provide the least volume increase from water to grout.

- Mix water in basin with dry mixture, and return to basin(s)

- Pump the grout up to 300 feet 
- Mix the grout blend and slurry water, probably with a mechanical mixer, to solidify the water in the basin with minimal volume increase (suggests pumping water out of the basin, mixing it with a dry blend into a grout ex situ, and then pumping the resulting grout back into basin, which still contains water)

\subsubsection{Small Tanks (ORBWG OST)}

Hundreds of thousands of gallons of solvent were used in the chemical separation facilities at SRS in a process that removes plutonium and uranium from spent fuel rods. The spent solvent generated from this plutonium-uranium extraction (PUREX) process consisted of a mixture of tri-n-butyl phosphate and dodecane. It was managed as low level radioactive waste and stored for aging in the OSTs.

- The SRS Remedial Action Objective, as identified in the Proposed Plan and Interim Record of Decision, is to structurally stabilize the ORWBG OSTs..

- The ORWBG OSTs are a solid waste management unit regulated under RCRA 3004(u) Solid Waste Management Unit. The FFA (1993) lists the OSTs as a component of the ORWBG operable unit, which is a RCRA/CERCLA unit in Appendix C of the FFA for SRS.

- WSRC ERD has submitted an Interim Record of Decision, WSRC-RP-2000-4193, Rev. 0 dated February 2001.

- A RI/FS has been done, WSRC-RP-98-4012, Rev. 1.1, dated September 2000

- Empty tanks are defined as tanks that contain no visible residuals.

- The definition of tank closure success is completely filling the tanks with grout having an unconfined compressive strength of $50 \mathrm{psi}$ or greater. Safely completing the project with no negative impacts to human health or the environment. Completing the project on time and within budget.

- The grout physical/handling properties of interest include: unconfined compressive strength of greater than $50 \mathrm{psi}$, flowable, self-leveling, pumpable, 28-day cure, zero bleed, less than 125 degrees $F$.

- No grout chemical properties are of interest, except that the grout be non-reactive with tank residuals, i.e., enhancing leach resistance is not a regulatory objective.

- The contaminants of concern are radionuclides and solvents, not RCRA metals.

- The implementation plan is to pump the grout into the tanks over a distance of approximately $50 \mathrm{ft}$. using some form of positive displacement pump.

- Solidification of the tank heels will be accomplished prior to production grouting of the tank void space. Plan is to deliver the grout in $1-2 \mathrm{ft}$. stages, partially solidifying the residuals in increments until a solid matrix exists at the tank bottom. No attempts will be made to enhance mixing of the grout and residuals; thus, mixing will occur only from the agitation/turbulence of grout delivery.

- Some of the tanks contain internal piping that will be entombed within the grout matrix and will not be filled by design. If there is an open pathway in these internal pipes they will be at least partially filled with grout, but the grout need not be designed for flowing into and filling pipes. No external piping exists for the ORWBG OSTs. 


\subsection{WVDP}

West Valley is the only HLW management site regulated by the NRC. West Valley Stakeholders are generally not fully supportive of in-place closure/disposal of the tank. Although DOE has not yet made a decision on the final site configuration, including tank disposition, West Valley management has suggested an option for evaluation which includes waste removal, tank decontamination/cleaning, and physical stabilization with a lowstrength, retrievable grout. If necessary, the tank grout and the tank itself can, at some time in the future, be dismantled and removed from the current location.

The New York State Department of Environmental Conservation is the cognizant regulatory agency for RCRA closure. The NRC will eventually resume regulatory responsibility for the West Valley site after DOE completes its requirements under the West Valley Demonstration Project Act and returns control of the site to New York.

The detailed final configuration is not known at this time, since DOE has not reached a Record of Decision on final tank disposition. However, the preference at this time would be to remove as much equipment and piping as is feasible. Any piping and/or equipment that might be left in the tanks would need to be grouted to eliminate void space and preferential transport pathways over time.

Grout formulations for the WV tank closure were developed and are patent pending. These mix designs are proprietary and were not available at the time this report was compiled. Additional testing is currently being conducted to determine properties such as heat of hydration and to measure $K_{d}$ s for specific radionuclides. Based on the response to the survey that was distributed as part of this study, the WV mix designs are reported to contain an ion exchange resin, UOP IONSIV TIE-96, as one of the reactive reagents for stabilizing contaminants.

\subsubsection{Needs}

West Valley has already evaluated the grout for the physical handling properties required. The plans and needs for closure of WV HLW tank, are summarized below:

- The only additional property still needing evaluation (measurement or calculation) is the heat of hydration. The heat of hydration is of concern in this application considering the elevated temperatures that will be encountered within the High Level Waste Tanks.

- High temperatures could cause the tanks to rupture. With this in mind, it is definitely necessary to quantify the temperature rise resulting from the heat of hydration of the CLSM as placed.

- Stabilization of the eight characteristic RCRA metals

- The first tier metals, of highest concern, are mercury $(\mathrm{Hg})$ and chromium $(\mathrm{Cr})$.

- The second tier metals are arsenic (As), barium (Ba), cadmium (Cd), selenium (Se), silver $(\mathrm{Ag})$, and lead $(\mathrm{Pb})$.

- Stabilization of the radionuclides of concern: americium (Am), cesium (Cs), neptunium $(\mathrm{Np})$, plutonium $(\mathrm{Pu})$, strontium $(\mathrm{Sr})$, technetium $(\mathrm{Tc})$, and uranium $(\mathrm{U})$. 
- Other contaminants of concern are sodium hydroxide $(\mathrm{NaOH})$, nitrate $\left(\mathrm{NO}_{3}{ }^{-}\right)$, and nitrite $\left(\mathrm{NO}_{2}{ }^{-}\right)$. The concern here is whether to implement a pretreatment system to remove these components prior to grouting.

- The $\mathrm{pH}$ of the fill needs to be alkaline and the redox potential of the fill needs to be reducing to optimize the stabilization of the radionuclides and RCRA metals present.

- The grout should be batched and mechanically mixed prior to placing in the closure facilities.

- There is no special interest in mixing the tank heel and grout. This is somewhat counter to the desire for the grout to immobilize RCRA metals and radionuclides.

\subsection{INTERNATIONAL TANK CKLOSURE PRACTICE}

The responses received from AEA, UK, and from France imply that only Russia and the USA are faced with the problem of HLW tank closure. The Russian experience and technology are being pursued in another task and is not presented here.

\subsubsection{United Kingdom (UK)}

In general, all major radioactive waste producers in UK store liquid waste in above-ground tanks. The UK strategy for such waste is to retrieve the waste from the tanks and condition it (solidify) for disposal as appropriate. ILW is slated for deep geological disposal (to be developed). LLW will be disposed of by shallow land burial (existing route).

The UK strategy for "decommissioning" nuclear power plants, generally applied to all nuclear liabilities, is to undertake decommissioning as soon as it is reasonably practical and return the nuclear sites to "greenfield" status. Consequently, the strategy for tank closure is to remove all the waste and eventually dismantle the tanks for disposal. In general, there is no intention to perform grouting of contents within the tanks or to fill the tanks and leave in place.

\subsubsection{France}

Apparently, France does not have large tanks of radioactive wastes, since the waste itself is considered and managed as a part of the process and is treated without delay by grouting, vitrification or even with bitumen. Therefore, there are some small units inside of the plants generating waste that are collecting the waste until enough is obtained for treatment. The responder never heard of in-situ tank grouting and suggested that only Russia and the USA had such large tanks of radioactive waste needing to be emptied and closed. 


\subsection{SUMMARY OF SURVEY RESPONSES}

The DOE site needs associated with in-situ waste tank closures can be divided into the following issues:

- Tank waste removal and the requirements for declaring the tank "empty."

- In-tank waste treatment strategy. The heel of irretrievable waste left in an emptied/cleaned tank may or may not require further treatment depending on the nature of the waste and on the regulatory and performance assessment requirements.

- Void space filling to physically stabilize the site and prevent future subsidence.

- Intruder barrier strategy. An intruder barrier can be designed into the tank filling activity or it can be installed subsequent to filling and prior to capping the tank area.

- Treatment of associated environmental media.

- Post closure monitoring.

All of the sites have adopted the approach of physically stabilizing underground tanks with flowable fills. It appears that all of the sites have used or modified the American Concrete Institute standard practice and reference material [ACI 229R-94] for this purpose. The drivers for these modifications were site specific. For example, SRS is committed to eliminating bleed water in tank fill formulation. ORR was willing to manage bleed water. Consequently zero-bleed fills were developed for closing tanks 17-F and 20-F at the SRS, and common flowable fill was specified for closing the OHF tanks.

Most of the sites will have to develop in-tank waste treatment strategies for at least some of their tanks. However, two of the five sites surveyed, INEEL and ORNL, plan to remove waste to the extent that in-tank treatment of a heel or incidental waste is not necessary. These sites are designing fills based on placement requirements, compressive strength, and cost. INEEL needs the grout to perform an additional function, i.e., the grout needs to "push" the acid waste heel to the pump for removal.

WVDP also plans to remove all of the waste and decontaminate the tank to the extent that contaminant stabilization may not be necessary per applicable DOE orders. However, since the site is regulated by EPA and NRC, and since the local stakeholders disapprove of permanent tank disposal on-site, WVDP has designed tank fills that provide chemical stabilization and are retrievable (excavatable).

The SRS developed a waste treatment strategy that was used to close two HLW tanks. This strategy included encapsulation and chemical stabilization of incidental waste. SRS also decided to install an intruder barrier inside the tank rather than above the tank. This resulted in a tank fill plan that consisted of three different materials: Reducing Grout for incidental waste treatment, Zero-Bleed Flowable Fill to fill the bulk of the space, and Zero-Bleed 2000 psi Grout to provide an intruder barrier.

In summary, DOE sites have developed tank closure plans that include tank specifications for fill materials. Waste treatment strategies are evolving as waste retrieval activities and regulatory restrictions become limiting. Only Hanford seems to be in the early stage of developing grout formulations for in-situ tank closures. 


\subsection{FILL MATERIAL REQUIREMENTS}

The overall objective of closing DOE HLW tanks is to permanently remove the tanks from service and place them in a condition that minimizes the long-term environmental consequences of in-place decommissioning and disposal.

The primary tasks involved in closing the DOE HLW tanks include:

- Emptying and cleaning the tank

- Treating waste heels and any incidental waste which can not be practically and/or economically removed from the tanks,

- Physically stabilizing the void space in and around (annulus spaces between the primary and secondary containers, adjacent soil, etc.) the tanks to negate future collapse/subsidence, and

- Installing a landfill cap to minimize the infiltration of water. Additional backfill or other work may be required as part of the cap construction.

This report summarizes the current state of the art of treating incidental waste in the DOE HLW tanks and physically stabilizing the void space in the tank. Tank cleaning, soil and other environmental media decontamination and/or treatment, and cap construction practices are beyond the scope of this report.

In-tank waste treatment strategies can be physical (encapsulation), chemical (chemical stabilization), or a combination of both as summarized below:

- Microencapsulation (mixing to achieve dispersion of the waste particles and liquid waste phase in a matrix),

- Macrencapsulation (sandwiching of the waste particles between layers of matrix material or between the metal or concrete tank wall and a matrix material), and

- In-situ chemical treatment to convert the contaminants of concern to less leachable forms

- Encapsulation of waste with reagents that also chemically treat the soluble contaminants of concern (combination).

Physical stability can be achieved by filling the tanks with a material that has properties compatible with the surrounding soil and the intended overburden. Such materials must be solids although they may be placed in the tanks as slurries that will hydrate, gel or settle to form a solid.

Specification of materials used to close high-level waste tanks depends on the requirements for treating the waste which can not be removed from the tanks in addition to requirements associated with producing, placing, curing, leaching and aging the fill materials. Production, placement, and performance properties of the actual fill materials can be further classified as follows: 
- Proportioning, Material, and Production Considerations and Limitations

- Fresh Properties (prior to setting/solidification)

- Cured Properties (post setting)

- Leaching Properties

- Durability and Long Term Performance Properties.

Identification of the requirements is the first step in designing a closure plan and specifying fill materials. Once the requirements are established, materials for treating the waste and for physically stabilizing the void space in the tanks can be developed, tested and deployed. A summary of the generic requirements and material properties relevant to specification of a waste treatment strategy and to design of a fill material is provided below.

It is assumed that tank fill materials will, at least in concept, resemble flowable fills used in the construction industry. The standard construction practices for formulating, testing and using this type of material is described in the American Concrete Institute Manual of Standard Practice, ACI 229R-94, which refers to flowable fill as Controlled Low Strength Material (CLSM) [Adaska, 1994; ACI, 1999]. These materials typically contain portland cement as the primary binder and are delivered as slurries containing the cement binder and a fine aggregate. The ultimate strength of the fill material, the maximum size of the aggregate, and the composition of the binder can all be varied as needed for specific tank closure applications to the extent that the materials can be described as flowable construction grouts/concrete.

\subsection{WASTE TREATMENT STRATEGIES}

The waste treatment strategy selected for any tank closure depends on the amount of waste left in the tank, the contaminants in the waste, the need to reduce the leachability of the contaminants, and the applicable federal, state, and local regulation/requirements. If the waste is removed from the tanks and the tank surfaces are adequately cleaned, there is no need for a waste treatment strategy. If some waste is left in the tanks because of technical or economical limitations associated with complete removal, the treatment requirements must be defined. These requirements are state, site, and even tank specific. Consequently, criteria and precedents can only be discussed in a general manner.

\subsubsection{Physical encapsulation}

Physical encapsulation is intended to reduce contact between the waste and the environment by physical isolation of the contaminants and contaminated media. It is also intended to reduce the likelihood and/or consequences of intruder contact with the waste again by providing a "recognizable" physical barrier. This can be accomplished on a macro-scale where the bulk of the waste is encased, surrounded by, or sandwiched between a special, "recognizable" solid media. It can also be accomplished on a micro-scale where contaminated particles and associated liquid are intimately mixed with materials that form a matrix in which the waste is dispersed. The matrix should also be "recognizable." 
In a HLW tank, macroencapsulation can be accomplished in several ways:

- The bottom and sides of the tank (steel, concrete, or both) may be considered as part of the encapsulating structure. For this case, a layer of grout or other solid material on top of the waste is all that is required to complete the encasement and to meet the treatment objectives.

- Or, the incidental waste can be displaced with heavier weight (higher density) grout and lifted off the bottom of the tank. Additional grout layers can be added to encase/sandwhich the waste within a single media. If the waste contains a large amount of water, dry material may be placed on top of the "floated waste" to dry the liquid and minimize the spread of contamination in the tank. This is referred to as "top dressing" the grout to hydrate the water and to minimize the number of times this process is required to totally encapsulate all of the material. Otherwise the aqueous portion of the waste can be incorporated into successive pours as the result of the mixing action achieved during placement.

In order to displace the waste at the bottom of a large tank, the solids in the waste must be easy to suspend and must stay in suspension long enough for the waste to be displaced. Placement testing with simulated waste is required to determine whether or not this concept can be applied to the material in a particular tank. Multiple point placement using this concept were successfully carried out at the SRS on Tanks 17F and 20F [Caldwell, et. al., 1998]

Microencapsulation is accomplished by intimately mixing the incidental waste with the fill material. Microencapsulation can be accomplished in several ways. This type of treamtent requires mixing the waste and grout/fill together as a slurry and minimizing subsequent settling or segregation. Microencapsulation can be accomplished by:

- In-tank mechanical mixing using robotic mixers.

- In-tank slurry mixing using existing HLW tank mixers or re-circulating mixers.

- Scouring of the particulate waste settled on the bottom of the tanks and folding it into the grout/fill material. This type of mixing was demonstrated in pilot testing at the SRS.

- Single-Point and Multi-Point Jet grouting. These techniques were developed and demonstrated by the DOE TFA as methods of accomplishing in-tank microencapsulation [Loomis, 1996 and Whyatt, 1998; and Kauschinger, et. al., 1998, respectively]. To date, none of these technologies nor technologies utilizing other types of mixing equipment (for example multiple agitators or slurry pumps) have been used to microencapsulate incidental waste in HLW tanks.

\subsubsection{Chemical stabilization}

Chemical stabilization of contaminants in the incidental waste involves treating the soluble contaminants with reactive reagents to reduce their leachability into the environment. Mechanisms for chemical stabilization include; precipitation, ion exchange, and sorption. 
Some soluble species are more readily precipitated in a chemically reducing environment compared to an oxidizing environment. By definition the particulate solids in the incidental waste are not soluble in the wash water used in the attempt to remove them from the tank. Consequently they are already in a relatively insoluble form and not readily leached into the environment. Chemical stabilization by itself does not provide a barrier for intruder mitigation and does not result in minimizing dispersion of solid particles in the event of intrusion.

\subsubsection{Combination}

The combination strategy combines encapsulation with chemical stabilization by selecting and including reagents in the encapsulating media that react with the contaminants to reduce their solubility/leachability. This approach has the potential for increasing the acceptable inventory of contaminants in the incidental waste and /or increasing the allowable volume of incidental waste by improving the long-term leaching performance of the closed tank(s).

A combination strategy of physical encapsulation and chemical stabilization was deployed for closing two SRS HLW tanks. These tanks were the first HLW tanks closed in the United States. Approximately 3000 gallons (one inch heel) and 6000 gallons ( 2 inch heel) of waste (particulate solids and liquid), were left in Tank 20F and 17F, respectively, because of the technical difficulty and expense associated with complete removal. The waste treatment strategy adopted for both tanks was macroencapsulation in which the sludge waste was displaced by and folded into the grout. Dry grout was used to "top dress" the waste slurry displaced to the top of the initial grout placement. A second layer of grout was placed on top of the "dressed" first layer to encapsulated the displaced waste. This procedure was repeated several times in each tank. The chemicals and materials in the dry grout were specified to include ingredients that chemically reacted with the contaminants of concern, e.g., Tc-99 [Caldwell, et. al. 1998 and Caldwell, 1997].

\subsection{STRATEGIES FOR PHYSICAL STABILIZATION OF LARGE VOID STRUCTURES}

High-Level waste tanks are underground (surrounded by earth) structures. In many cases they were also constructed below grade. Issues associated with aged and abandoned underground structures and vessels include:

- Roof and side wall collapse,

- Filling with water from run-off and internal seepage which can lead to overflowing/leaking/leaching (bathtub effect) and,

- Buoyancy.

In order to minimize these problems, the void spaces in the structures must be filled with a compacted, load bearing material with a specific gravity greater than that of water to prevent buoyancy. Uncompacted or poorly compacted material will subside under its own weight over time and create new void space. In addition risers, pipes and other ancillary entries into 
the tank must be sealed off. This can be accomplished by filling such access points with a low porosity, low permeability material. Low viscosity is usually specified for the pipe fill materials since it is important that they flow into small voids and form good seals.

Conventional construction practices rely on filling/back filling voids with soil and/or other solid materials (sand, gravel, and rubble). These materials must be mechanically compacted to achieve the self -supporting requirement [US Army Technical Manual 5-818-4, 1968]. Mechanical compaction is labor intensive is not suited to closing HLW tanks because of exposure of personnel to radiation (ALARA considerations) and because limited of access to confined spaces. Consequently the remainder of this discussion will be focused on pumpable, self-leveling, self-compacting, flowable fill materials.

Flowable fill materials can have a wide range of physical properties in order to meet the sitespecific objectives for each tank closure. For example, the requirements can range from high-strength, non-retrievable monolithic fills to low-strength/excavatable fills that can be retrieved if necessary. In addition, more than one type of fill material may be required to meet the closure needs of a single tank. Three different fill materials/grouts were used to close Tanks $17 \mathrm{~F}$ and $20 \mathrm{~F}$ at the SRS as indicated below:

1) Reducing grout for waste encapsulation and stabilization and for closure of the risers and pipes accessing the tanks,

2) Zero-bleed Controlled Low Strength Material for the bulk of the tank, and

3) Zero-bleed 2000 psi grout for an intruder barrier placed in the dome of the tank [Caldwell, et. al. 1998].

\subsection{FLOWABLE FILL PROPORTIONING, MATERIAL, AND PRODUCTION CONSIDERATIONS}

Grouting methods, types of grouts including non portland cement materials, grouting equipment, and grouting applications are reviewed elsewhere [US Department of the Army and the Air Force, 1970; US Army Corps of Engineers, 1984]. In practice, numerous constraints will be placed on the design of fill materials used to close HLW tanks. Location of the tanks relative to existing grout production facilities, total volume of fill required, restrictions on the delivery of fill materials to tanks and access into tanks, production rate and production method, etc. affect design and specification of the fill materials. Other conditions, such as, waste treatment strategy, underwater placements, drop height of the fill, and lift height must also be taken into consideration.

\subsubsection{Production/Transportation Methods}

The production and transportation methods selected for the flowable fill used to stabilize HLW tanks must be compatible with the total volume of material required, the proximity of the HLW tank to an existing batching facility, and the production rate/closure schedule. Options for production and delivery to the job site include: 
- Batch plant at a remote location plus trucking (mixing takes place in the truck)

- Batch and mixing plant at the HLW tank location (trucking not required)

- Continuous batching and mixing plant at a remote location plus trucking (not practical)

- Continuous batching and mixing plant at the HLW tank location (trucking not required).

Selection of an on-site versus off-site batching and mixing will depend on the distance to the nearest existing facility and on the logistics of the filling operation. Traffic conditions, other production commitments, and scheduling are important considerations. A portable on-site facility provides the most flexibility for remote locations.

In a typical batch plant, solids are proportioned by weight and the liquids are proportioned by volume. Some batch plants have a central mixing unit; others mix the material in a truck as it is being delivered to the job site. If a batch plant is installed at the HLW tank location, stationary mixers will be required. Standard practices for operation of a Ready-mix plant is covered in ACI 311.5R. [American Concrete Institute, 1999].

There are several types of continuous plants. Most of these plants use volumetric proportioning for both the solids and the liquids. Volumetric plants are best suited to relatively simple mix designs because proportioning of minor solid ingredients is difficult to control. If high-volume production of multi-component mix designs is required, preblending some or all of the solids and/or metering the minor components as solutions or suspensions are recommended.

Auger plants typically use a single screw auger to achieve mixing. These plants are portable and are commonly used for concrete/grout/fill production in remote construction locations where the travel-distance and/or logistics from a central batch plant is not practical. Two portable auger plants were operated simultaneously at the SRS to produce grout for closure of tanks 17F and 20F [Caldwell, et. al., 1998]. Standard practices for operation of continuous batching plants are summarized in ACI 304.6R [American Concrete Institute, 1999]. Recirculating plants are also portable and are used to produce grouts for the oil well drilling industry. These plants typically use pre-blended solids that are mixed with water and/or other slurries at the remote job site.

\subsubsection{Production of Fill Material Using Contaminated Ingredients}

The equipment described above is suited to mixing "clean" fill material that is intended for placement into a HLW tank. In other words, the mixers are open to the air and surroundings and are not suited for mixing radioactive liquids or solids. Options for producing fill materials using radioactively contaminated solids or liquids are listed below:

- Use a sealed mixer and material feed system, or

- Conduct the mixing in the tank.

Continuous sealed auger mixers and re-circulating mixers have been used in the DOE complex for radioactive waste treatment at the SRS and Hanford, and Oak Ridge, 
respectively. These mixers are also suited for or can be adapted for producing HLW tank fill materials.

In-tank mixing has been developed and demonstrated for applications in the DOE complex [Kauschinger, et. al., 1998, Spence and Kauschinger, 1997, Spence, et. al., 1999, and Whyatt, 1998]. In-tank mixing is achieved by agitating materials/waste in the tank with material added to the tank. Mixing can be accomplished by mechanical stirring or with air, water, or slurry jetted under high pressure. Multiple point agitation is required for the large HLW tanks. The type, placement and operation of the agitators or jets are important considerations for successful in-tank mixing. Proportioning, delivery, and probably mixing systems are also required to prepare the material that is placed in the tank.

\subsubsection{Total Volume and Production Rate}

The total volume of material required and the production schedule are very important considerations in selecting a production facility. DOE HLW tanks have capacities ranging form several hundred thousand gallons to 1.3 million gallons. From the viewpoint of conventional fill/concrete/grout production and transportation these are large volumes. Such high volumes necessitate high production rates, which in turn require that the fill material be

designed for mass placements. For reference, 1000 gallons is approximately 3.8 cubic meters ( 5 cubic yards), and 1.3 million gallons is approximately 5000 cubic meters $(6500$ cubic yards). The capacity of a concrete delivery truck is about 8 cubic yards.

A typical continuous auger plant can produce about 40 cubic yards of fill per hour. A typical central batching plant can produce 24 to 40 cubic yards per hour provided that trucks are available for receipt and mixing of material. To meet the production schedule at the SRS for filling tanks $17 \mathrm{~F}$ and $20 \mathrm{~F}$, two portable auger mixers were set up and at times operated simultaneously. Truck deliveries were successfully coordinated for filling the Old Hydrofracture Tanks at Oak Ridge, TN.

\subsubsection{Fill Delivery Method - Pumping}

Fill materials will typically be pumped into the HLW tanks via a metal pipeline and tremie. (A tremie is a flexible hose attached to the end of the delivery pipe and is recommended for use only inside the tank.) Tremie lines are disposable and can be disconnected from the metal pipe and disposed of inside the tank at the end of each day or lift placement. This minimizes the opportunities for spreading contamination and is relatively simple. The length and diameter of the pipeline will depend on the production rate, the distance between the pumping station and the HLW tank, elevation difference between these points, the type of pump, and rheological properties of the fill. 


\subsection{FLOWABLE FILL PLACEMENT REQUIREMENTS}

Placement requirements are unique to each HLW tank. For example, working space, potential for contamination incidents and spills, configuration of the access port/risers relative to the delivery pipeline and the pump distance are unique to each site and to each tank.

\subsubsection{Riser/Port Access Limitation}

In general the access into a DOE HLW tank will be through risers that are large enough so that the size of the aggregate used in the flowable fill is not restrictive. Even if the risers contain other support equipment, cables, cameras, etc., it is assumed that the tank will have accesses of at least 0.3 meters ( 12 inches). Therefore, the specifications for the delivery pipeline and tremie and pump will in practice limit the size of the aggregate.

The relative diameters of the cooling coils and ancillary accesses to the HLW tanks, the limited space between the primary and secondary containers, and the small gaps between equipment in and on the bottoms of the tanks may also limit the size of the aggregate specified for the fill material. For clearances of less than 6 inches, only fine aggregate (concrete or masonry sand) should be considered in the mix design to facilitate complete placement and to avoid line plugging due to aggregate bridging. If the size limitations are even more severe, fine aggregate can be replaced with ultra fine aggregate such as fly ash. In such a case, the resulting material will resemble waste forms rather than fills or grouts.

Although severely limited accesses are not encountered for the majority of the large HLW tanks, this is an issue for in-place closure of many small tanks in the DOE complex. These tanks often have very small risers, 2 to 4 inches in diameter. For such tanks, the size (maximum dimension) of the aggregate in the flowable must be limited to fine (concrete or masonry sand) or ultra fine (Class F fly ash) aggregate. As an additional safeguard against plugging the delivery line, screening of the flowable fill to remove "stray" coarse aggregates that may have inadvertently gotten into the material from the delivery truck, stock pile, or hopper bin is highly recommended. (Note: The aggregate size recommendations made above are somewhat arbitrary. They are more conservative than that used in conventional concrete practice in which aggregate is typically limited to one-third the diameter of the pipeline or smallest opening.)

\subsubsection{Underwater Placement}

Underwater placements require special mix designs that are cohesive, self-consolidating and flow underwater without dispersing or trapping water which results in voids. See the section on Cohesion. If an underwater placement is specified, the flowable fill should be tested for compatibility with any liquid in the tank. Special additives for underwater placements are marketed by the concrete admixture suppliers and should be considered if such placements are required. 


\subsubsection{Drop Height}

Drop height is the distance between the flowable fill discharge point and the floor or fill level in the tank. The drop height in a large HLW tank can be up to 40 feet if the fill is discharged from the bottom of the riser located in the dome/top of the tank. Consequently, the potential for segregation of the sand from the interstitial matrix "paste" in a mix upon impact in the tank is an important consideration. See section on Segregation. Drop heights of 1.5 to 3 meters are acceptable for most flowable fill mix designs. Excessive drop heights of more than about 6 meters should be avoided if possible by the use of a tremie. If large drop heights are required, the mix designs must be evaluated for segregation. The placement conditions must be simulated to the extent possible and observations extrapolated to performance in the actual placement.

\subsubsection{Lift Height}

The lift height is related to the thickness/depth of the flowable fill placement that is achieved without interruption and/or time for setting to occur. The lift height and the time between lift are important with respect to the following engineering issues:

1. Hydraulic force exerted on the tank walls by a fluid with the specific gravity of the flowable fill. The lift height should be specified so that there is no danger of overloading the HLW tank. Tank integrity, flowable fill set time, and the unit weight, and production schedule and requirements must be taken into account to specify acceptable lift heights. Set time and fresh unit weight must be measured to assess the hydraulic force of the fill.

2. Heat dissipation. Heat is generated as the result of hydration reactions that occur as the fill is transformed from a slurry into a solid material. High strength encapsulating materials or intruder barriers have correspondingly higher cement contents and therefore generate more heat. The lift height and time between lifts must be controlled to prevent thermal cracking and dehydration of the material. The amount of heat generated and the resulting temperature rise is usually not a limiting design issue for flowable fills because they have relatively low cement contents (therefore low temperature rises) relative to construction concrete and high strength fills. Temperature rise measurements must be made on insulated mass pours to assess this issue.

3. Cold joint formation. A cold joint is the horizontal interface between a set (solid) placement/layer of fill and a fresh placement. This property is important in construction practice because such boundaries are typically porous and weaker than the bulk material. For low to moderate strength flowable fills, these interlayer zones have less impact on the overall performance because strength is not an issue and setting is usually delayed (24 to 72 hours). Also the difference in the set and unset material are less.

\subsection{FLOWABLE FILL FRESH PROPERTY REQUIREMENTS}

In this discussion, it is assumed that the flowable fills are mixtures of fine aggregate (sand), water and paste containing cement, slag, fly ash, silica fume, and/or other hydraulic or 
pozzolanic particles that are less than 1 to about 100 micrometer in size. The flowable fill may also contain a coarse aggregate (gravel) fraction and/or chemicals and materials to improve processing properties (admixtures and suspension agents) and leaching properties (reactive reagents/aggregates). Specification of these materials is discussed in more detail in a later section.

It is also assumed that placement will be accomplished by pumping the flowable fill as a slurry. Fresh properties apply to the flowable fill while it is in a fluid state, prior to hydration/reaction of these particles to form a solid (self-supporting) matrix. The fresh property requirements are related to mixing and placement requirements. In most cases ASTM or other standard tests are available to determine the relevant properties. Applicable test protocols are identified and typical ranges for the fresh properties are discussed.

\subsubsection{Mixability/Pumpability}

Mixing properties of construction concrete, grout, and flowable fill are usually evaluated qualitatively in the laboratory by mixing 0.5 cubic foot batches in a Hobart paddle mixer or by mixing 1 to 3 cubic foot batches in a small concrete/grout mixer. Larger batches 3 to 8 cubic yards are considered pilot-scale testing. Significant observations include the uniformity, segregation, and whether the mixture contains sufficient paste/matrix to hold the aggregates together. Unsuitable mix designs will be readily apparent in that there may be insufficient water to achieve a uniform product or too much water, which will result in settling/segregation. Mixes with too little binder/matrix are described as "lean" and are also unsuitable for pumping since the aggregate can become compacted and bridge due to the pressure exerted by the pump.

Pumping properties of construction concrete, grouts, and fills are also routinely evaluated qualitatively by conducting pumping tests ( 3 to 5 cubic yards). Pump pressures, length, diameter, and inclination of the pipeline, and rate must be evaluated in the pump test. Practical experience and actual pump testing are usually substituted for detailed measurements of the rheological properties (viscosity, yield point, gel strength) of the fill material.

In addition, the pump test should include an evaluation of the fresh and cured properties of the material discharged at the end of the pipeline. Pumping not only transfers material, it also adds additional mixing action, time, and pressure all of which can alter the final product. This will affect the unit weight, segregation, consistency and flow properties of the discharged material relative to the material entering the pump hopper. See ACI 304.2R for additional considerations related to pumping concrete/grout/fill material.

Various types of additives (set regulating, water reducing, pumping aids, and suspending agents) can be included in the flowable fill formulation to modify the mixing and pumping properties. Even though the objective is to design a simple formulation and placement system, one or more of these additives is usually necessary. 


\subsubsection{Flowable/Self-Leveling}

There are many parameters that can be used to characterize the placement properties of slurries. The workability, i.e., the ability to mix and place concrete is characterized by the slump, which is measured according to ASTM C-143. Fill materials are placed in a similar but not identical manner as concrete so a different test is used to evaluate the placement properties. The ability of a fill material to flow, self-level, and self-compact is typically evaluated by the ASTM Flow Consistency Test D-6103 per the ACI Standard Practice, ACI 229R-94. A flow of 10 inches (minimum) per this test was set as the acceptable value for materials placed in SRS HLW Tanks 17-F and 20-F. The actual HLW tank fill materials placed in these tanks had flows of greater than 12 inches. These materials were self-leveling and flowed at least 45 feet without segregation (about $1 / 2$ the diameter of the tanks).

Again, additives are available to enhance the flow and self-leveling properties of concrete, grout, and fill materials. Set retarders, foaming agents, pre-formed foam, and water sorptivesuspension agents are commonly used to improve flow at normal or even high water to cement ratios. Water reducing agents and high-range water reducers are two types of admixtures that are commonly used in construction applications to increase mixibility/pumpability/flow while at the same time increasing strength by reducing the water content. Since strength is not an issue, there is usually limited need to reduce the water. Consequently, if these types of admixtures are used in a flowable fill it is usually to achieve some other property.

\subsubsection{Bleed Water}

Bleed water refers to the liquid that accumulates on top of cement slurry as the solids settle out of suspension. In most construction applications where flowable fill is used, bleed water is not a problem because the excess water drains off in to the soil or it evaporates. However, in a closed (impermeable) radioactively contaminated tank or structure, the bleed water can become a significant problem. Eliminating or managing the bleed water is an important design requirement. Eliminating the generation of bleed water is preferable to removal because of the potential for radioactive spills during management operations and the need to store and process the bleed water.

Zero-bleed flowable fills can be achieved in several ways.

- One method involves adding a very fine, high surface area material that reacts in alkaline solution and thereby thickens the mixture. Silica fume is an example of such a material. Mixes containing silica fume require the addition of a set retarder and/or water reducers/high range water reducer to achieve a mixable, pumpable grout that flows and self-levels. This approach was used for eliminating bleed water in the reducing grout placed in tanks 17-F and 20-F at the SRS [Caldwell, 1997].

- Another method involves adding thickening agents that support the solids in the liquid suspension until sufficient hydration occurs to achieve a self-supporting mass. Hydrating gums, high molecular weight complex carbohydrates, are examples of this type of 
thickening agent. Methycellulose concrete admixtures are also used for this purpose. This approach was used for the bulk fill and the 2000 psi grout used in tank closures at the SRS. About 5000 cubic yards of flowable fill/grout containing Welan gum was placed in each of the SRS HLW tanks [Langton and Rajendran, 1998 and 2000].

- A third method involves adding air as the bulking agent to support the solids in the liquid suspension until the mass becomes self-supporting. Foaming agents and pre-formed foam are used to add air. At SRS, light-weight, cellular zero-bleed fill materials have been designed and tested. These mixes have lower materials cost because less sand and cement is used per cubic yard of product compared to other conventional or zero-bleed fills [Langton and Rajendran, 1998].

- Water sorptive-suspension agents, such as bentonite or attapulgite clay are another type of bulking agent that can also be used to enhance flow and reduce bleed water [Ramachandran, 1984; Langton and Rajendran, 1999].

All of these products are off the shelf concrete admixtures/additives. In addition, the concrete admixture manufactures are now marketing new proprietary systems for achieving zero-bleed concrete/grouts/fills since the need has arisen.

\subsubsection{Set Time}

Set time refers to the time required after placement to obtain the properties of a rigid solid. Set time is used in the construction industry to determine at what time after placement can the surface of a slab be finished or a form stripped. Consequently it does not apply directly to fill materials. For fill materials designed to achieve less than $250 \mathrm{psi}$, (solid but not a rigid solid) a resistance to penetration test (ASTM C-360, C-803) is applicable. This test can be used to determine the time required for the material to converte from a slurry/liquid to a solid. For higher strength fill materials, the applicable test is ASTM C-403. Set time or time to respond as a consolidated solid is also important in determining the height of a pour or lift since unset material will transmit more or less of its weight as hydraulic load to the tank walls. The time required to resist penetration and to perform as a consolidated solid is typically less than 48 hours for flowable fills. Longer times do not present any problem provided that other properties are not impacted.

\subsubsection{Fresh Unit Weight}

Fresh unit weight describes the density of the fill slurry. Values in the range of 120 to 145 pounds per cubic foot are typical for flowable fills. Lighter weight fills can be produced by incorporating porous light-weight aggregates and/or sands or by incorporating air into the mix (cellular fills) [Langton and Rajendran. 1999]. Heavier fills can be produced by using heavy-weight sands and/or aggregates such as illmenite, magnetite, hematite, or metallic aggregates in conjunction with proper bulking agents to prevent segregation.

Flowable fills containing porous sand and/or aggregate will have a higher water demand (content) than conventional fills. Depending on the application, the porous aggregate may 
require presoaking. High-water fills are specified for situations where the objectives include maximizing the amount of contaminated water stabilized in a given volume of fill. The fresh unit weight of a flowable fill must be greater than the unit weight of water (62 pounds per cubic foot) in order to prevent buoyancy of the tank/structure. This limits the amount of air that can be incorporated in a cellular mix design. The unit weight of heavy-weight fills is limited by the density of the aggregate and is typically less than 250 pounds per cubic foot.

\subsubsection{Cohesivness/Segregation}

Cohesion and segregation of flowable fills are evaluated by visual observation. Segregation and generation of bleed water are the consequence of gravity settling of the solids from the aqueous suspension. Separation of the sand/aggregate from the paste and crumbling (pulling apart) of the fresh mixture are both indications of lack of adequate cohesion. Both cohesion and segregation can be improved by proper proportioning of paste/(matrix phase) to sand and aggregates and paste to the water content of the mix. The reduction of water and/or the addition of high-surface ingredients (cement, or silica fume) or the addition of gums are three approaches for improving these properties.

\subsubsection{Heat of Hydration}

Heat is generated as the result of the cement and pozzolanic hydration reactions. To date, fill materials have been placed in HLW tanks as mass pours that do not allow for rapid heat dissipation. The simplest approach to controlling the heat of hydration is to develop mix designs that required relatively small amounts of cement and other reactive materials. Consequences of excessive heat generation include: thermal cracking casused by the temperature gradients/differentials between the center of the pour and cooler surface, excessive shrinkage caused by drying/dehydration at the elevated temperatures, and excessive water vapor generation in the tank and the need for increased ventilation. The chemistry, mineralogy, and stabilizing capacity of the matrix phases and additional stabilizing agents may also be affected by excessively high curing temperatures approaching or exceeding $100^{\circ} \mathrm{C}$.

\subsubsection{Resistance to Freeze-Thaw and Wetting-Drying Conditions}

Resistance to freeze-thaw and wetting and drying cycles is important in the design of construction materials that will be exposed to surface or near surface conditions. These properties are not design considerations for tank fills since they are placed below ground where temperature and moisture cycling is minimal. 


\subsection{FLOWABLE FILL CURED PROPERTIES}

\subsubsection{Compressive Strength}

Flowable fills used for tank closures can have a wide range of compressive strength specifications. For example, moderate to high strengths (typically greater than $2000 \mathrm{psi}$ ) may be required for intruder barriers, erosion mitigation, and waste isolation/encapsulation. On the other hand, low strengths (typically 50 to $250 \mathrm{psi}$ ) may be required to assure that the fill can be retrieved and relocated at a later date if necessary. Controlled Low Strength Materials (CLSM) are defined by the American Concrete Institute as flowable fills that have compressive strengths of less than $1200 \mathrm{psi},(8.2 \mathrm{Mpa})$. By increasing the amount of cement/pozzolan, these materials grade into low strength construction grouts used for foundation stabilization and base mat. Further increases in the relative proportions of cements/pozzolans result in construction grouts (4000 psi) and high strength grouts (greater than $5000 \mathrm{psi})$.

The compressive strength of flowable fills containing fine aggregate is typically determined according to the ASTM C-39 test method after curing for 28 days. Longer and shorter curing times $(7,14,54$ and 90,120$)$ days may be relevant depending on the basis for this requirement.

\subsubsection{Excavatable}

Flowable fills with compressive strengths of 50 to 250 psi are typical of consolidated soils and are considered excavatable. Curing times of at least 90 days are required to assure that the material is still excavatable after aging since portland cement based flowable materials continue to hydrate and gain strength with time. In addition, the test specimens should be cured under controlled conditions simulating the placement. Excessive drying or soaking of low strength materials may affect the results.

\subsubsection{Hydraulic Conductivity (Permeability)}

Flowable fill is self-compacting and in construction applications it is a substitute for compacted soil. The staurated hydraulic conductivity (water permeability) of flowable fill is similar to that of a clayey sand soil unless it is designed to be otherwise. The hydraulic conductivity will be in large part controlled by the particle packing of the solid materials in the fill. Graded sand, fly ash and/or other fines can be specified to optimize particle packing and thereby reduce the permeability. The permeabilities of flowable fills range from those of clayey sand soil $(1 \mathrm{E}-6 \mathrm{~cm} / \mathrm{sec})$ to those of common concrete $(1 \mathrm{E}-8 \mathrm{~cm} / \mathrm{sec})$ [Ramachandran and Beaudoin, 2001] depending on the particle packing and the structure of the binder/matrix. 


\subsection{RADIONUCLIDE STABILIZATION - LEACHING PROPERTIES}

Many studies have been conducted on the leaching properties of cement waste forms. The results of these studies are applicable to stabilization of incidental waste by micro- or macroencapsulation with portland cement-based flowable fills since the general chemistry of the composites should be the same. Consequently, the leaching properties of incidental HLW waste in contact with or mixed with flowable fills placed in the HLW tanks are assumed to be similar to those of portland cement waste forms. Waste specific and fill specific testing is required to confirm this assumption.

Stabilization of hazardous and radioactive contaminants using portland cement-based materials has been extensively reviewed elsewhere [USEPA, 1989; Conner, 1990; Conner and Wilk, 1997; Adaska,et al.; 1998; Conner and Hoeffner, 1998; Wiles, 1998; USDOE/NRC, 1999; Oh, 2001].

Environmental transport modeling commonly uses the $\mathrm{K}_{\mathrm{d}}$ values to characterize the partitioning of a contaminant between the liquid (leachate) and solid phases. The higher the $\mathrm{K}_{\mathrm{d}}$ value, the less partitioning of the contaminant into the liquid phase, i.e., the less leachable, more stabilized.

General guidelines for estimating the extent to which mixing with portland cement material can reduce leaching for specific soluble species are provided by and are summarized in Table 3-1 [Bradbury and Sarott, 1995]. These values should be used as a starting point for determining the need for further waste removal or the need for additional waste treatment. Waste form and tank fill grout specific studies should be conducted to verify these guideline values. Non radioactive isotopes and surrogates are often used in grout specific testing. A list of nonradioactive chemicals that may be appropriate surrogates for radioactive constituents is provided elsewhere [Krumhansl, et al., 2001].

Numerous studies have also been conducted on materials that can be added to portland cement waste forms and by analogy, to tank fill formulations, to improve their stabilization capacity for selected contaminants. Some of these reactive ingredients/reagents are listed in Table 3-2.

Many of these materials are also used for direct waste treatment without incorporation in cement waste forms. Some of the reactive reagents can be used to pre-treat the incidental waste or in the adjacent environmental media by reacting with the selected contaminant(s) of concern. Low solubility metal sulfides, phosphates or hydroxides are precipitated in this way and monovalent and divalent cations can be sorbed or irreversibly exchanged before the tanks are filled. 
Table 3-1 Summary of hydrated portland cement and water in oxidizing and reducing environments for various elements [Bradbury and Sarott, 1995].

\begin{tabular}{|l|c|c|c|c|c|c|c|}
\hline \multirow{2}{*}{} & \multicolumn{5}{|c|}{ State of Cement Product Degredation Due to Aging/Leaching* } \\
\cline { 2 - 8 } & \multicolumn{2}{|c|}{ Not Degraded } & \multicolumn{2}{c|}{ Moderately Degraded } & \multicolumn{2}{c|}{ Highly Degraded } \\
\cline { 2 - 8 } & $\begin{array}{c}\text { Oxidizing } \\
\text { Environment }\end{array}$ & $\begin{array}{c}\text { Reducing } \\
\text { Environment }\end{array}$ & $\begin{array}{c}\text { Oxidizing } \\
\text { Environment }\end{array}$ & $\begin{array}{c}\text { Reducing } \\
\text { Environment }\end{array}$ & $\begin{array}{c}\text { Oxidizing } \\
\text { Environment }\end{array}$ & $\begin{array}{c}\text { Reducing } \\
\text { Environment }\end{array}$ \\
\hline \multicolumn{2}{|c|}{ Element } & \multicolumn{5}{|c|}{ Partitioning Coefficient between solid and liquid, $\mathrm{K}_{\mathrm{d}}$ (cm/kg) } \\
\hline $\begin{array}{l}\text { Tritium } \\
\mathrm{HTO}\end{array}$ & 0 & 0 & 0 & 0 & 0 & 0 \\
\hline $\mathrm{Cl}$ & 20 & 20 & 20 & 20 & 2 & 2 \\
\hline $\mathrm{Mn}$ & 100 & 100 & 100 & 100 & 10 & 10 \\
\hline $\mathrm{Ni}$ & 100 & 100 & 100 & 100 & 10 & 10 \\
\hline $\mathrm{Se}$ & 0.1 & 0.1 & 0.1 & 0.1 & 0 & 0 \\
\hline $\mathrm{Sr}$ & 1 & 1 & 1 & 1 & 1 & 1 \\
\hline $\mathrm{Zr}$ & 5000 & 5000 & 5000 & 5000 & 1000 & 1000 \\
\hline $\mathrm{Nb}$ & 500 & 500 & 500 & 500 & 50 & 50 \\
\hline $\mathrm{Mo}$ & 0.1 & 0.1 & 0.1 & 0.1 & 0 & 0 \\
\hline $\mathrm{Tc}$ & 1 & 1000 & 1 & 1000 & 1 & 1000 \\
\hline $\mathrm{Pd}$ & 100 & 100 & 100 & 100 & 10 & 10 \\
\hline $\mathrm{Ag}$ & 1 & 1 & 1 & 1 & 1 & 1 \\
\hline $\mathrm{Sn}$ & 1000 & 1000 & 1000 & 1000 & 100 & 100 \\
\hline $\mathrm{I}$ & 2 & 2 & 2 & 2 & 0 & 0 \\
\hline $\mathrm{Cs}$ & 2 & 2 & 20 & 20 & 20 & 20 \\
\hline $\mathrm{Pb}$ & 500 & 500 & 500 & 500 & 50 & 50 \\
\hline $\mathrm{Ra}$ & 50 & 50 & 50 & 50 & 50 & 50 \\
\hline $\mathrm{Th}$ & 5000 & 5000 & 5000 & 5000 & 1000 & 1000 \\
\hline $\mathrm{Pa}$ & 2000 & 5000 & 2000 & 5000 & 100 & 1000 \\
\hline $\mathrm{U}$ & 2000 & 5000 & 2000 & 5000 & 100 & 1000 \\
\hline $\mathrm{Np}$ & 5000 & 5000 & 5000 & 5000 & 100 & 1000 \\
\hline $\mathrm{Pu}$ & 5000 & 5000 & 5000 & 5000 & 1000 & 1000 \\
\hline $\mathrm{Am}$ & 5000 & 5000 & 5000 & 5000 & 1000 & 1000 \\
\hline $\mathrm{Cm}$ & 5000 & 5000 & 5000 & 5000 & 1000 & 1000 \\
\hline & & & & & & 0 \\
\hline
\end{tabular}

* The extent of degradation follows the trend towards chemical neutralization, i.e., less basic environment. This analysis does not include the loss of chemical reduction. 
Table 3-2 List of reactive reagents effectively used in combination with portland cement to stabilize selected contaminants.

\begin{tabular}{|c|c|c|}
\hline \multirow{2}{*}{ Treatment agent } & \multicolumn{2}{|c|}{ Contaminants of concern to one or more sites } \\
\hline & Radionuclides & RCRA metals \\
\hline \multicolumn{3}{|l|}{ Cements and pozzolans } \\
\hline $\begin{array}{l}\text { Cement and fly ash or } \\
\text { natural pozzolans } \\
\text { (alkaline conditions) }\end{array}$ & $\begin{array}{l}\mathrm{Am}, \mathrm{Cm}, \mathrm{Nb}, \mathrm{Ni}, \mathrm{Np}, \mathrm{Pa}, \mathrm{Pu}, \\
\mathrm{Sr}, \mathrm{Th}, \mathrm{U}, \mathrm{TRU}\end{array}$ & $\mathrm{Cd}, \mathrm{Ba}, \mathrm{Pb}, \mathrm{Ag}, \mathrm{Zr}, \mathrm{Sn}$ \\
\hline $\begin{array}{l}\text { Slag- portland cement } \\
\text { (activated slag) } \\
\text { (alkaline \& chemically } \\
\text { reducing conditions) }\end{array}$ & \begin{tabular}{l}
\multicolumn{1}{c}{ Tc } \\
Am, Cm, Nb, Ni, Np, Pa, Pu, \\
Sr, Th, U, TRU
\end{tabular} & $\begin{array}{c}\mathbf{C r}, \mathbf{H g} \\
\mathrm{Cd}, \mathrm{Ba}, \mathrm{Pb}, \mathrm{Ag}, \mathrm{Zr}, \mathrm{Sn}\end{array}$ \\
\hline \multicolumn{3}{|c|}{ Special agents (used alone, as pretreatment, or in combination with a cement grout) } \\
\hline \multicolumn{3}{|c|}{ Clays (sorption, reversible and irreversible ion exchange) } \\
\hline Illite & Cs & \\
\hline Vermiculite & Cs, I & \\
\hline Bentonite & Cs & \\
\hline \multicolumn{3}{|c|}{ Zeolites (reversible and irreversible ion exchange) } \\
\hline Clinoptilolite & Cs, & $\mathrm{Pb}, \mathrm{Cr}$ \\
\hline Modenite & Cs & $\mathrm{Pb}$ \\
\hline Chabazite & Cs & $\mathrm{Pb}$ \\
\hline Phillipsite & Cs & $\mathrm{Pb}$ \\
\hline Synthetic & $\mathrm{Cs}, \mathrm{Sr}, \mathrm{U}$ & \\
\hline \multicolumn{3}{|c|}{ Synthetic Ion Exchange Resins (reversible and irreversible ion exchange) } \\
\hline Ion exchange resins & $\mathrm{Cs}, \mathrm{Sr}, \mathrm{Tc}$ & $\begin{array}{l}\mathrm{Hg}, \mathrm{Cr}, \text { most other di- and } \\
\text { tri- valent metals }\end{array}$ \\
\hline \multicolumn{3}{|l|}{ Phosphates } \\
\hline Soluble Phosphate** & $\mathrm{Sr}$ & $\mathrm{Pb}$ \\
\hline Apatite $* * *$ & $\mathrm{Sr}, \mathrm{U}, \mathrm{Tc}, \mathrm{Np}$ & $\mathrm{Pb}, \mathrm{Cd}$ \\
\hline
\end{tabular}

* This table lists contaminants that have been reported to have been stabilized by the indicated ingredient in grout waste forms. Absence of treatment may indicate that the reagent was not tested. See Section 4.4 for references.

** precipitation from solution

$* * *$ sorption onto engineered porous solid. 


\subsection{DURABILITY - LONG-TERM PROPERTIES}

The physical properties of fill materials age in the same manner as those of similar materials such as nonstructural concrete and consolidated soil or sediment in the near surface environment. Nonstructural concrete can be considered an artificial (man made) sedimentary rock. Structural failures or cracking due to overloading do not apply to tank fills assuming that self-compaction was initially achieved. Weathering processes will be site specific and the effects will be fill material and condition specific.

In general, the calcium hydroxide, calcium carbonate, and calcium silicate gel in the portland cement matrix in the fill material will be dissolved by weak acids in the soil and infiltrating water, and if exposed, will be simultaneously eroded by surface conditions (water, wind, freeze-thaw cycling and wet-dry cycling). Conditions produced by the addition of chemical reductants to the tank fill grout for the purpose of precipitating selected contaminants may or may not be retained in a near surface environment [Bradbury and Sarott, 1995 and Shuh et al., 2000], depending on the specific site engineering and conditions. More than one "layer" of chemical modification may be required to achieve long-term performance in near surface disposal scenarios.

Long term leaching properties are applicable to the long-lived radionuclides. The general trends related to leaching of specific radionuclides as the result of aging (neutralization) of cement waste forms are also indicated in Table 3.1. The trends are also applicable to cementbased tank fills. Hydrogen and carbon dioxide are produced as the result of radiolysis of organic admixtures used in waste forms and fill materials [Palmer and Fairhall, 1993].

\subsection{SUMMARY OF CLOSURE REQUIREMENTS}

The design, production, and placement requirements for flowable fills used to close DOE HLW tanks will be unique to each site. Treatment strategies for incidental waste will also be site specific. In most cases, once the requirements are established, flowable fills can be designed with available materials and can be manufactured and placed using standard construction techniques. 


\subsection{FLOWABLE FILL MIX DESIGNS FOR HLW TANK CLOSURE}

Flowable fill mix designs for closure of HLW tank can be developed once the waste treatment strategy and materials and processing requirements/limitations are specified. It is assumed that the flowable fill will be placed as a slurry and that it will contain portland cement as at least a portion of the binder phase. A large volume of the fill is assumed to be fine and possibly coarse aggregate. The aggregate may be chemically inert or may provide some form of waste treatment (sorption, ion exchange, etc). Binders other than portland cement, pozzolans (fly ash, slag, silica fume. Etc.), reactive reagents (zeolites, ion exchange resins, natural and modified clays, etc.) to reduce the leachability of the contaminants, and chemical admixtures to modify the fluid properties of the slurries may also be included in the mix design. Specification of these materials for HLW tank flowable fills is based on their function in the mix design. The American Concrete Institute Manual of Concrete Practice, ACI 229R-94 can be used as a guide for initial testing to establish the proportions of these materials to achieve a flowable fill.

\subsection{PORTLAND CEMENT}

Portland cement is typically selected as the primary ingredient for the binder because it reacts in the presence of water to form insoluble matrix phases that "glue" less expensive aggregates together to form a solid material. In addition the microenvironment in the hydrated portland cement matrix is alkaline. Under alkaline conditions, certain contaminants/radionuclides are precipitated and consequently are less leachable. (See Tables 3.1 and 3.2.) Waste particles can also be "glued together" i.e., physically encapsulated in the hydrated portland cement matrix.

The amount of portland cement in a HLW tank fill formulation depends on the cured property requirements. HLW tank fills at the SRS contained between 150 and 1350 pounds of cement per cubic yard, for bulk fill and reducing grout, respectively [Langton and Rajendran, 1998]. This can be compared to the amount of portland cement in generic 4000 psi construction concrete (about 600 to 700 pounds per cubic yard) and the amount of cement in generic flowable fill (50 to 100 pounds per cubic yard).

\subsubsection{Background}

The chemistry and composition of Portland cement are discussed in great detail elsewhere [Conner, 1990; IAEA, 1993; Lea, 1970; Soroka, 1979; Bye, 1983; Ghosh, 1983; Taylor, 1990]. The main points of interest for cement stabilization/solidification are: 1) the alkaline (high $\mathrm{pH}$ ) environment of the cement matrix, 2) the formation of calcium hydroxide as a normal cement hydration product, and 3 ) the relatively low hydraulic conductivity (permeability) of a cemented material relative to soil. Although there is evidence that some contaminants can be incorporated into the structure of the hydrated calcium silicate phases, precipitation of low solubility metal hydroxides in alkaline media is the primary waste 
stabilization mechanism. The leachabilities of metals and radionuclides are commonly expressed as partitioning coefficients $\left(\mathrm{K}_{\mathrm{d}}\right)$ in environmental transport models. See Table 3-1. Solubilities are commonly used for comparing leachabilities of RCRA contaminants. Low solubilities of copper, nickel, iron, cadmium, zinc, silver, and lead compounds under alkaline conditions are well documented [Conner 1990; U. S. Environmental Protection Agency, 1987]. In general, solubility curves for these metals pass through a minimum as a function of $\mathrm{pH}$. The minimum solubility for these metals occurs in a $\mathrm{pH}$ range from about 9 to slightly more than 11 .

During cement hydration the pore solution $\mathrm{pH}$ is in the range of 12-13, well above the minimum solubility for most of these metals due to the calcium and alkali hydroxides [Conner 1990]. Consequently pozzolans, which react with the calcium hydroxide to form insoluble matrix phases, are usually added to the waste form mixes. The result is that the alkalinity of the internal environment is lowered to the optimum range ( $\mathrm{pH}$ of 9-11) for precipitation of many metals and radionuclides [Armstrong and Klingler, 1986].

Several types of portland cement are manufactured. Properties of these different materials are specified in ASTM C 150-89 and are summarized in Table 4-1. ASTM Type I portland cement is most available and most commonly used for waste stabilization because it is the most commonly used and lowest cost option. ASTM Type II Portland cement can be considered a subset of ASTM Type I portland cement and quite often cement is marketed as Type I-II portland cement.

Table 4-1 Description of the various types of portland cement [ASTM, 1989].

\begin{tabular}{|c|l|}
\hline Type & \multicolumn{1}{c|}{ Description } \\
\hline I & Generalpurpose portland cement and usually the least expensive \\
\hline II & $\begin{array}{l}\text { Moderate sulfate resistance and moderate heat of hydration, Type } \\
\text { II-fly ash is typical substitute when job size can't justify Type IV } \\
\text { production }\end{array}$ \\
\hline III & High early strength and cold weather use \\
\hline IV & $\begin{array}{l}\text { Low heat of hydration, used in massive structures (e.g., dams) } \\
\text { where temperature rise can approach adiabatic, generally not } \\
\text { available, mass produced for specific jobs }\end{array}$ \\
\hline V & Sulfate resistant \\
\hline
\end{tabular}

\subsection{BLAST FURNACE SLAG}

Ground granulated blast furnace slag (GGBFS) is often selected as the primary ingredient for the binder because it reacts in the presence of hydroxides (high $\mathrm{pH}$ waste or portland cement pore solution) and water to form insoluble matrix phases. Once activated by alkalies, these specially manufactured slags are cementitious in much the same way as hydrated portland cement, i.e., they "glue" less expensive aggregates together to form a solid material. In the process of hydration, GGBFS produces a chemically reducing environment. Under alkaline and reducing conditions, certain contaminants/radionuclides are precipitated as low solubility 
phases. Consequently they are less leachable than they were in the original waste or in a cement only environment. (See Table 3.7 and 3.2.)

The amount of slag in a HLW tank fill depends on several factors including the:

- compressive strength requirement,

- heat of hydration limitations, (Will the material be placed as mass pours?)

- minimum amount of cement needed for an alkaline leaching environment,

- total amount and ratio of cement and slag, i.e., total amount of binder required to "glue" together the other ingredients,

- reduction capacity required to treat the contaminants.

Chemically reducing HLW tank fill materials designed at the SRS typically contain 200 to 300 pounds of blast furnace slag and 75 to 150 pounds of cement per cubic yard depending on the strength requirement [Langton and Rajendran, 1998].

\subsubsection{Background}

Blast furnace slag is a normal byproduct of the iron and steel industry. In general, the molten slag is quenched to form a glass in two ways (1) air cooling and (2) water quenching (granulation). Slow cooling produces inert crystalline slag useful as an inert fill material, but useless as a cement substitute.

Granulated slag hydrates slowly on contact with water, but is activated to form insoluble hydrates in the presence of alkaline solutions (e.g., calcium hydroxide or sodium hydroxide), calcium sulfate, sodium carbonate, and sodium sulfate [IAEA, 1993]. The granulated slag is finely ground and marketed as a partial substitute for cement. The particle size distribution and the surface area of blast furnace slag is in general finer than or similar to that of portland cements [IAEA, 1993; Nurse, 1984].

The slag grades are important for construction purposes, but not for waste treatment, where strength requirements are usually minimal. The chemical properties of the slag are important for waste treatment. Since these are not addressed in the ASTM specification, the chemical properties required for stabilization of contaminants must be specified by the user and verified by testing.

Table 4-2 Classification of hydraulic slag used in concrete [ASTM C-989].

\begin{tabular}{|c|c|c|}
\hline ASTM Slag Grade & \multicolumn{2}{|c|}{ Minimum Average Slag Activity Index, \% } \\
\hline & 7 day & 28 day \\
\hline 80 & NA & 75 \\
\hline 100 & 75 & 95 \\
\hline 120 & 95 & 115 \\
\hline
\end{tabular}


Slags have been used in grouts developed for radioactive and mixed waste stabilization [Langton et al. 1983; Wolf, 1984; Angus and Glasser, 1986; Pepper, 1986; Spence et. al., 1989; Langton, 1989; Gilliam et. al., 1990; Spence et al., 1995; Clark and Wilhite, 1991; Langton and Wong, 1991] Palmer, 1990; Sahu and Diamond, 1996A and B; Shi and Day, 1996; Bostick, et al., 1990; Tallent, et al., 1988; Serne, et al., 1992, Allan and Kukacka, 1997].

\subsection{POZZOLANS}

Pozzolans, such as fly ash, silica fume, or natural materials (volcanic ash, diatomateous earth, calcined clays), can be included in flowable fills for several purposes. Examples include:

- Improve/enhance fresh slurry properties (workability, pumpability, flow, consistency, segregation) as the result of modifying the particle size distribution.

- Improve/decrease the permeability of the flowable fill by reacting to form additional binder phases, i.e., densify the matrix.

- Increase the strength for a given cement content. Since pozzolans cost less than cement, this type of material substitution is often used.

- Decrease the temperature rise (rate and amount of heat generated as the result of hydration reactions) relative to an equivalent amount of portland cement.

- Modify the chemical environment by reacting with a portion of the lime. This will result is a less alkaline environment in the range of $\mathrm{pH} 9$ to 11.

- Selectively react with certain contaminants to form insoluble compounds. Since strontium behaves similarly to calcium, cement-pozzolans will also tend to tie up Sr-90 better than cement alone. Cement-fly ash has traditionally been the stabilizer of choice for Sr-90, although cement alone can stabilize Sr to some extent (Laguna 1970; McDaniel et al. 1982; Moore et al. 1975; Moore 1976; Atkinson et al. 1986).

Up to about 20 weight per cent of the cement can be replaced with fly ash or other pozzolans with no effect on strength. If the pozzolan is added as more than about 20 weight per cent of the cement, the amount in excess of the 20 percent will act as very fine inert filler. The particle size and the size distribution of this filler affect the fresh and cured properties of the mix.

The amount of fly ash or other pozzolan required for a HLW tank fill is determined the difference between "fines" requirement for the mix and the amount of cement plus slag. If the amount of cement plus slag meets the fines requirement, no additional 1 to 100 micrometer material is necessary to achieve a workable, pumpable mix. If the total amount of fines in a mix is insufficient, the mix appears and is referred to as "lean." If excess fines are present, the mix appears and is referred to as "fat." Flow, set time, heat of hydration, and cost are some of the issues associated with excess binder.

At the SRS, HLW tank fills that contain concrete sand as the primary aggregate typically contain 600 to 800 pounds of cement plus slag plus pozzolan (Class F fly ash) per cubic yard of fill. However, flowable fill formulations containing no sand can be developed for certain 
HLW tank applications. For example it is possible to specify fly ash (or any other fine material compatible with portland cement systems) as the primary aggregate in the mix design. In this case it will make up over 50 weight percent of the mix. Such a mix resembles a waste form rather than a fill. Mixes designed as pumpable/flowable concretes may also have applications as tank fills.

Silica fume is a very fine pozzolan that is used to produce high strength, low permeability waste forms. Such waste forms have improved leaching properties for soluble contaminants including: H-3, Cl-36, Cs-137, and Sr-90 [Johnston and Wilmot, 1992].

\subsubsection{Background}

Fly ash is a pozzolan that is produced as a by-product from burning coal in electric power plants. It is formed as a consequence of melting and subsequently quenching clays and minerals that were present in the coal. Fly ashes react with the calcium hydroxide which is produced by the hydration of portland cement to form hydrated alkali silicates matrix/binder phases. Other pozzolanic materials include: volcanic glasses, volcanic tuffs, calcined clays and shales, diatomites, rice husk ash, volatilized silica (silica fume), blast furnace slag, and other slags (IAEA 1993).

ASTM refers to these materials as mineral admixtures and describes two fly ashes and one natural or calcined pozzolan for use in portland cement concrete. A brief description is given in Table 4-3.

Table 4-3 Description of fly ash and natural pozzolans.

\begin{tabular}{|c|l|}
\hline Mineral Admixture (Class) & \multicolumn{1}{c|}{ Description } \\
\hline $\mathrm{N}$ & Raw or calcined natural pozzolans \\
\hline $\mathrm{F}$ & $\begin{array}{l}\text { Fly ash normally produced from anthracite or bituminous } \\
\text { coal, has pozzolanic properties }\end{array}$ \\
\hline $\mathrm{C}$ & $\begin{array}{l}\text { Fly ash normally produced from lignite or sub-bituminous } \\
\text { coal, has pozzolanic and cementitious properties, may } \\
\text { contain lime }>10 \%\end{array}$ \\
\hline
\end{tabular}

Although both Class C and Class F can be and have been used, ASTM Class F fly ash is generally preferred for flowable fill because it is inert during processing. The Class $\mathrm{C}$ fly ash reacts upon contact with water. This difference in reactivity is indirectly related to the higher minimum specified content of silica, alumina, and iron oxide for Class F (70 wt \%) compared to Class C (50 wt \%). Although the lime content is not specified in the standard, a large fraction of the remaining composition is reactive $\mathrm{CaO}$ (quick lime). 


\subsection{REACTIVE INGREDIENTS FOR STABALIZING CONTAMINANTS}

Chemicals (hydroxides, sulfides/thiosulfates, and phosphates) and reactive ingredients (natural and treated clays, zeolites, ion exchange resins, etc.) are routinely used to stabilize radionuclides and hazardous metals. This subject has been extensively reviewed in numerous studies and publications [Conner, 1990; Wilk, 1999; USDOE/National Research Council, 1999; Langton, 2001; Wagh, et. al, 2001; Kaplan, et. al., 1999]. A variety of products containing proprietary ingredients are also commercially available for stabilizing selected contaminants. Many of these materials are portland cement based or can be mixed into cement fills.

Portland cement and blast furnace slag are materials which function as both binders and as chemically reactive reagents. They were discussed in detail earlier. The hydrated cement results in an alkaline environment and the hydrated slag results in chemically reducing conditions. Reagents used to clean HLW tanks and/or pre-treat the incidental waste or environmental media surrounding HLW tanks are beyond the scope of this review. (Cleaning chemicals include acids and chelating chemicals that are not compatible with portland cement fills/grouts.)

Reactive/stabilizing reagents (other than cement and slag) are typically minor components in the fill (less than 10 weight per cent of the mix). However, they can be added as primary components in place of fly ash and/or sand. If less than one per cent is specified, metering the chemical or material into the mixer as a slurry is often the most effective method of addition.

\subsubsection{Background - Illite Clay.}

Over the years, illite, a clay mineral with a layered structure, has become a standard ingredient in grout formulations developed at Oak Ridge National Laboratory for stabilizing Cs-137 [Moore et al., 1975; Moore, 1976; Gilliam and Loflin, 1986; Gilliam, 1986; Serne, et al., 1989A and B; Tallent, et al., 1989; Huang, et al., 1994; Serne, 3t al., 1992; Sams and McDaniel, 1988]. Illite has been known as a selective sorbent for cesium for decades [Tamura, 1961; Tamura, 1963; Tamura and Jacobs, 1960; Cowser, et al., 1966; Kaplan, et al., 1999]. Illite has a relatively low equivalent exchange capacity, but the interlayer spacing between silicate sheets in the crystalline is well matched to the cesium ion diameter. The cesium ions must remain mobile on the external ion exchange sites so they can diffuse into and become irreversibly trapped in the interlayer structure.

There are many sources of illitic clays. ORNL uses Indian Red Pottery Clay (IRPC) since it is the most readily available commercial source. The standard ORNL grout recipe evolved into a portland cement based mix containing $8 \mathrm{wt} \%$ of IRPC. The main reason for $8 \mathrm{wt} \%$ IRPC in the dry blend was to distribute enough IRPC throughout the waste form so that all of the Cs-137 had access to the IRPC and mass transport distances were minimized. This strategy has served well for many years as witnessed by the high ANSI/ANS-16.1 leachability indexes reported for Cs-137 over the years for grouts containing IRPC. 
Other sources were identified for environmental studies [Kaplan, et al., 1999]. Illite is also a constituent in many types of rocks, such as, shales and siltstones that could be used as aggregates in a fill. The cesium leach rate from a cement waste form decreased by 10, 100, and 1000 times with the addition of grundhite, Indian Red Pottery Clay, and Conasauga Shale, respectively [McDaniel, et. al., 1989].

Crystalline silico titanate (CST) has recently been developed as a highly efficient ion exchange media for cesium. Illite improved the cesium leachability index for a slag-cementfly ash grout from about 8 to about 10 and was further increased to about 11 by adding an equal amount of CST or by adding more illite. In addition, CST improved the strontium index from about 10 to about 12. Illite had no effect on the strontium leachability index. Given the high cost of CST resin, it is unlikely it will be a useful ingredient for HLW tank fills.

\subsubsection{Clinoptilolite and Other Zeolites}

Clinoptilolite is a natural zeolite formed from weathering volcanic glass. Zeolites are alumino silicate phases with channel structures that can incorporate specific size cations. The cesium exchange capacities for clinoptilolite from several sources have been reported [Ogard et al., 1984]. For the same reason, it has been proposed as a treatment agent to:

- $\quad$ sorb/extract cations from waste [Ingram et al., 1996; Li and Bowman, 1997; Li, 1998; Colella, 1999; Hernandez-Barrales and Granados-Correa, 1999],

- immobilize cations in the waste itself as a part of a waste treatment [Lewis et al., 1993; Greene and Barich, 1994; Crawford and Gafford, 1996; Zorpas and Loizidou, 1999; Zorpas et al., 2000], and

- immobilize cations in grouted waste forms [Serne et al., 1993].

Colella (1999) reported the following cation selectivities for the four natural zeolites tested:

$\begin{array}{llrl}\text { Chabazite: } & \mathrm{Cs}>\mathrm{NH}_{4}>\mathrm{Pb}>\mathrm{Na}>\mathrm{Cd}>\mathrm{Sr}>\mathrm{Cu}>\mathrm{Zn} \\ \text { Clinoptilolite: } & \mathrm{Cs}>\mathrm{Pb}>\mathrm{NH}_{4}>\mathrm{Na}>\mathrm{Sr}>\mathrm{Cd} \mathrm{Cu} \mathrm{Zn} \\ \text { Mordenite: } & \mathrm{Pb}>\mathrm{Cs}>\mathrm{NH}_{4}>\mathrm{Na}>\mathrm{Cd} \\ \text { Phillipsite: } & \mathrm{Cs}>\mathrm{Pb}>\mathrm{NH}_{4}>\mathrm{Na}>\mathrm{Sr}>\mathrm{Cd}>\mathrm{Zn}\end{array}$

This implies that $\mathrm{Cd}, \mathrm{Sr}, \mathrm{Cu}$, and $\mathrm{Zn}$ may not be effectively immobilized for the Na-form of these zeolites or for high Na-bearing wastes, as found in most of the HLW tanks.

Synthetic mordenite and two other synthetic zeolites, but not natural clinoptilolite, were found to be effective in sorbing $U$ from solution [Ingram et al., 1996]. They concluded that this relative effectiveness was a function of the pore dimensions, chemical composition, and cation concentration of each zeolite. In addition, the $\mathrm{U}$ remained sorbed under redissolving conditions, demonstrating the potential for irreversible immobilization. 
Clinoptilolite or other zeolites has proven effective in sorbing metals, $\mathrm{Cd}, \mathrm{Cr}, \mathrm{Cu}, \mathrm{Fe}, \mathrm{Mn}, \mathrm{Ni}$, $\mathrm{Pb}, \mathrm{Zn}$, when mixed with contaminated compost, soil, or waste [Crawford and Gafford, 1994; Greene and Barich, 1994; Zorpas and Loizidou, 1999; Zorpas et al., 2000]. Even though such sorption makes the metals less leachable by acids, it has been demonstrated that some metals such as, $\mathrm{Pb}$ and $\mathrm{Zn}$ become more bioavailable and biotoxic when absorbed on zeolites compared to the same metals in untreated soil [Greene and Barich, 1994]. In addition, clinoptilolite was found to be effective in sorbing Co-60 from solution [Hernandez-Barrales and Granados-Correa, 1999]. Adding zeolites to a cement waste form decreased the apparent cesium diffusion coefficient from about $10^{-10}$ to $10^{-12} \mathrm{~m}^{2} / \mathrm{s}$ [Tostenfelt and Hedin, 1989].

In summary, clinoptilolite is expected to improve the leach resistance of cesium, lead, and cobalt; but not strontium, cadmium, copper, and zinc cations, or any anions (chromate, pertechnetate, selenate, and nitrate) without surfactant-modification of the surface. Zeolites can also improve the leach resistance of uranium.

\subsubsection{Vermiculite.}

Vermiculite, a silicate mineral, has excellent sorption capacity for cesium and is an effective stabilization agent for cesium when it is incorporated into cement waste forms. Singh et al. (1995) measured the gross beta leach curves of the supernate of intermediate-level waste solidified by a simple blend of Portland cement and vermiculite. Vermiculite was added to enhance the leach resistance of radioisotopes still soluble at the high $\mathrm{pH}$ of the supernate, but this enhancement was not measured as no samples without vermiculite were leached. Incomplete conversion of vermiculite into organophilic clay allows the simultaneous sorption of both anionic radio-iodine and cationic radio-cesium and strontium, but the vermiculite distribution ratio significantly decreased for both cations (Bors et al., 1996). Vermiculite was also reported to result in a lower cesium leach rates than montmorillonite, attapulgite, and illite [Lee and Brown, 1981].

The details of other sorption studies are presented elsewhere [Jha, et al., 1966; Levi and Miekeley, 1967; Sebastian, et al., 1973; Lee, 1974; Komarneni and Roy, 1978, 1979,1981, 1982, and1986; Plecas, et al., 1990; Tymochowicz, 1981; Vejmelka et al., 1990; Gelis and Kozlitin, 1993; Singh et al., 1995; Bors et al., 1996; Gougar et al., 1996; Doilnitsyn et al., 1997; Huang and Wu, 1999; Doh and Lee, 2001].

\subsubsection{Phosphate Precipitation and Sorption}

Many divalent and trivalent cations will precipitate as insoluble phosphate compounds at room temperature provided that soluble phosphate is available. In addition, apatite and hydroxyapatite, calcium phosphate compounds can sorb di- and trivalent cations and thereby reduce the leachability of these contaminants. Engineered micro porous material that is surface treated has also been reported to effectively sorb certain anionic species such as $\mathrm{TcO}_{4}$ so that the Tc sorption is irreversible [R. Moore, 2001]. Effectiveness of the engineered 
porous apatite sorbents at high $\mathrm{pH}$ (10 to 12) and in the presence of portland cement waste forms has yet to be demonstrated.

Soluble phosphate can be added as a reagent for pre-treating tank waste or it can be mixed with or injected into contaminated soil. A phosphate-based cement slurry or a portland cement slurry containing solid phosphate compounds (apatite) can also be introduced into a waste tank or into contaminated soil. Phosphate-based cement is a slow reacting, mixture of solids that react to produce phosphoric acid and soluble divalent metals. These materials have recently been developed for waste treatment.

Ceramicrete ${ }^{\mathrm{TM}}$ is a phosphate cement/chemically bonded ceramic containing reagents that treat hazardous and radioactive wastes. It is a mixture of powders that react with water to form a weak phosphoric acid and a soluble base that react to form cementitious precipitates. Details of the Ceramicrete ${ }^{\mathrm{TM}}$ process are presented elsewhere [Singh et al. 1996A; Singh et al., 1996B; Singh et al., 1997; Singh et al., 1998A; Singh et al, 1998B; Singh et al., 1998C; Singh et al., 1998D; Wagh et al. 1999].

Ceramic or mineral waste forms, including phosphates and apatites, have been proposed for some time, dating before the 1970s [McCarthy, 1973; Roy, 1977; Komarneni and Roy, 1986; Boatner, et al., 1980]. Over the past decade, several patents have been issued for phosphate treatment of waste [Pal and Yost, 1993; Chesner, 1996; Webster, 1999; Amer, 2001; Bhat, 2001; Forrester, 2001].

Phosphate-induced metal stabilization (PIMS) has been developed by Washington State University and Los Alamos National Laboratory [Conca et al., 2000]. Xtaltite technology is based on synthetic mineral immobilization technology (SMITE) from Australia [White et al., 1994].

Phosphates are especially effective in stabilizing $\mathrm{Pb}$ [Conner and Hoeffner, 1998]. In general precipitated phosphate phases are not cementitious (except for the phosphate cements formed by acid-base reactions). However, they can be mixed with portland cement or other cements to obtain a hard solid block [Conner and Hoeffner, 1998].

Commercial phosphate treatment of soil contaminated with $\mathrm{Pb}$ has become a common practice and at least two patents specifically target $\mathrm{Pb}$ stabilization [Pal and Yost, 1993; Chesner, 1996]. Other patents claim the more general treatment of RCRA metals using triple super phosphate (TSP), magnesium sulfite, calcium carbonate, and hydroboracite [Bhat, 2001] or mixtures of apatite, zeolite, clay, lime, fly ash, cement, coagulants, and flocculants [Amer, 2001] or mixtures of phosphates, portland cement, silicates, and sulfates [Forrester, 2001]. Another cited patent actually uses a phosphate to prevent oxidation of sulfide, the main stabilizing agent [Webster, 1999]. The presence of soluble phosphate increased the resistance of certain grouts to sulfate attack [Guerrero, et al., 1997].

Additional information related to waste treatment utilizing soluble phosphate and apatite is presented elsewhere [McCarthy, 1973; Broman, 1975; Roy, 1977; Komareni and Roy, 1986; Wiles, 1991; Hines, 1993; Pal and Yost, 1993; White et al., 1994; Contos and Regan, 1995; 
Chesner, 1996; Nilsson, 1996; Singh et al. 1996A; Singh et al., 1996B; Tickanen and Turpin, 1996; Anguiano and Floyd, 1997; Eighmy et al., 1997; Shaw, 1997; Singh et al., 1997; Conner and Hoeffner, 1998; Eighmy et al., 1998; Singh et al., 1998A; Singh et al, 1998B; Singh et al., 1998C; Singh et al., 1998D; Knontopoulos and Theodoratos, 1998; Gering, 1999; Iretskaya et al., 1999; Wagh et al. 1999; Webster, 1999; Conca et al., 2000; Crannell et al., 2000; Hettiarachchi et al., 2000; Amer, 2001; Bhat, 2001; Forrester, 2001].

\subsection{SLURRY PROPERTY MODIFIERS AND ADMIXTURES}

Set retarding, set accelerating, and water reducing admixtures are routinely used in the construction industry to achieve acceptable working times and strengths of concrete and grout mixes. The general classification and use of these materials is defined in ASTM C494. Use of these chemicals to produce flowing concrete is specified in ASTM C-1017. A comprehensive description of the chemistry and use of concrete admixtures is provided elsewhere [Ramachandran, 1984]. Admixture manufacturers are constantly improving existing products and bringing new products to market. Therefore, testing is required to identify and evaluate the admixture system selected for the flowable fill. These materials are added in very small quantities and are usually metered into the mix as liquids. Admixture suppliers also sell metering and transfer equipment for their specific products.

Bulking agents are routinely use in flowable fills/grouts placed in tanks or other structures where bleed water is unacceptable. Foaming agents, pre-formed foam, and gums are commonly used to control segregation [Langton and Rajendran, 1998]. Water sorptivesuspension agents such as gelling clays are also used to minimize settling in high water mixes. Silica fume, an ultra fine by-product of the silicon metal refining industry, can also be considered to be a combination pozzolan and slurry modifier when it is used in alkaline systems such as portland cement fills. These admixtures can also be described as pumping aids and improve the plastic properties of the mix where strength is not the primary concern [Ramachandran, 1984]. Some of these materials are discussed in more detail below.

\subsubsection{Background - Foaming Agents and Pre-Formed Foam}

Foaming agents are special surfactants (detergents) sold by concrete admixture suppliers. They are added to a concrete mixing truck or stationary mixer and are used to produce lightweight cellular, light-weight concrete and grout. These surfactants generate macroscopic bubbles as a result of agitation at the air-water/slurry interface. Cellular mix designs generally do not produce bleed water and are used in many applications where some degree of flow is required (flat roofs). Flow can be enhanced for tank fill applications by adding set retarders and/or high range water reducers [Langton and Rajendran, 1998].

Another method of producing cellular fills, grouts or concrete is to add the entrained air as a pre-formed foam. The foam is created in a generator next to the grout mixer and pumped into the mix as a thick froth/aerosol. This method is well suited for a continuous production facility such as an auger plant and was successfully demonstrated at the SRS in several field 
test [Langton and Rajendran, 1998]. Several suppliers provide the surfactants and foam generating equipment required for this type of material. Specifications for foaming agents used in making pre-formed foam for cellular concrete are presented in ASTM C-869, and standard practices for proportioning cellular concrete are provided in ACI 523.

\subsubsection{Background - Gums}

High molecular weight polysaccharides (complex carbohydrates) such as xanthum and welan gum are used in flowable concrete and grout as bulking agents. These admixtures reduce segregation and bleed water and in general improve the workability of the slurries. Gums are typically added as powders ( a few pounds per cubic yard) and are pre-mixed in the cement to achieve uniform dispersion in the concrete/grout. Otherwise, the gums hydrate on contact with water to form sticky pastes that become very difficult to incorporate into the final product. A special admixture system was developed at the SRS that enabled small amounts of welan gum to be added to a continuous auger mixer. The dehydrated powdered gum was mixed with a non-hydrating, liquid high-range water reducer (superplasticizer) to form a suspension, and was metered into the mixer as a liquid. This allowed for good dispersion before the gum became hydrated with the mixing water and "bulked" the mix.

\subsubsection{Background - Water Sorptive-Suspension Agents}

Traditionally, two methods are used to control the bleed water in cement slurries/grouts/concrete: 1) decreasing the water-to-total cementitious solids ratio, w/s, and 2) adding gel clays to the mixture. Other organic thickening or bulking agents, such as air, are also used and described elsewhere in this report.

Gel clays hydrate in water to form a thick, stable dispersion. This prevents suspended particles, such as, fly ash, cement, or slag, from settling while minimizing the dry blend added for treatment and the subsequent volume increase. The gel clay technology originated in the oil field drilling fluids industry and has been adapted for waste form production [E. W. McDaniel 1984; Grim 1962].

Attapulgite (Attagel 150) is also used as gel clay for applications where the mixing solution has a high ionic strength (high salt content) [E. W. McDaniel 1984; de Laguna et al. 1968]. The American Petroleum Institute (API) has specifications for both bentonite and attapulgite [American Petroleum Institute, 1983 and 1984].

Sodium silicate is another type of suspension agent. It forms a hydrogel in water, a threedimensional polymeric structure incorporating up to $90 \%$ water. It has the added feature of reacting with multivalent metal cations in solution to form low-solubility precipitates. Adding sodium silicate solution to a portland cement-based grout can be quite effective at controlling bleed water because it accelerates setting. For this reason, it may be added as the last step in mixing to prevent any mixing problems. 


\subsection{FINE AND COARSE AGGREGATE}

Fine and/or coarse aggregates make up the bulk of the material in a flowable fill mix. This material is an inert filler that does not react with the water or the cement matrix. Consequently it is not sensitive to dry shrinkage or expansion/swelling and provides dimensional stability to the mix design.

Flowable fills containing only fine aggregates are common. The fine aggregate is typically ASTM C33 concrete sand (quartz sand). However, masonry sand (finer than concrete sand) or even Class F fly ash (comparable to portland cement in fineness) can be used as the fine aggregate. If a flowable fill contains coarse aggregate, greater than about $3 / 8$ inch in diameter, the mix should also contain fine aggregate to achieve adequate particle packing.

In general, locally available materials that are suitable for concrete will also meet the aggregate requirements for cement-based fills. Light-weight aggregates include certain volcanic ashes, and manufactured products, such as expanded clays, shales, and volcanic materials. These porous materials are useful for achieving high-water fills for cases where the mixing water is contaminated and requires treatment/disposal. Zero-bleed mixes containing over 110 gallons of water per cubic yard have been successfully formulated using $-1 / 8$ inch expanded clay sand. (Light- weight aggregates may require pre-soaking to minimize floatation and to achieve a workable mix. Otherwise they tend to absorb the mixing water and dry out the mix.) Heavy weight aggregates are typically metal oxides (heavy sands) or metallic aggregate.

\subsection{MIXING WATER}

Potable water is specified as the mixing water for cement-based products. Testing is required if fill materials are prepared with contaminated water or come in contact with contaminated solutions (especially salt solutions, alkaline solutions, or acid solutions) prior to setting. If fill materials are placed in contact with sulfates or other chemicals that are known to attack concrete, additional testing is required. In most cases, HLW tanks are not located in such environments. 


\subsection{COMPARISON OF TANK FILL TECHNOLOGY AND SITE NEEDS}

Flowable fill was identified by all of the DOE sites as the material of choice for closing (physically stabilizing) the HLW tanks. (Difficulties associated with consolidating and compacting non-flowable soil, sand or gravel backfills were acknowledged by all of the sites.) American Concrete Institute Standard Practices [ACI 229-R] for designing, preparing and placing flowable fills are applicable for tank closure materials. However, several requirements related to tank fill materials are not addressed in the standard practices because they are not relevant to construction fills. The most obvious exceptions to construction practices for flowable fills are:

1. Minimizing or eliminating bleed water for placements in structures where the excess mixing water can not drain away or evaporate.

2. Including ingredients in the mix that can chemically treat incidental waste to reduce contaminant leachability.

3. Controlling set time to provide flexibility with respect to lift heights requirements.

4. Controlling heat of hydration for mass pour applications.

The DOE Site requirements for placing and curing HLW tank fill materials are tabulated in Table 5-1 along with a list of available technology and a list of technology needs. The requirements for treating contaminants in the waste heel are tabulated in Table 5-2 along with treatment reagents and technology needs.

Additional research is not required to develop new methods for controlling set time and heat of hydration. Set time is not applicable to low-strength flowable fills. If it is an issue for modified higher strength fills, the set time can be adjusted with set accelerating or retarding commercially available admixtures. Heat of hydration is dependent on the amount of cement and hydraulic material used in the mix. Guidelines for mass pour mix designs can be interpreted with respect to flowable fills and are provided in ACI 211.1-91.

Additional effort to identify cost effective zero bleed admixtures is warranted. For example, the admixture system used in the SRS zero bleed CLSM bulk fill and the zero bleed $2000 \mathrm{psi}$ intruder barrier grout added about $\$ 15$ to the materials cost for a cubic yard of fill. The admixture cost for the fill used in two SRS tanks $(12,000$ cubic yards) was about $\$ 180,000$. Consequently identifying less expensive zero-bleed admixtures can lower the materials cost significantly. Both laboratory and field-testing are required.

Research is required to more fully develop waste treatment strategies and to improve stabilization of certain contaminants. This includes:

1. determining the leachability of the waste itself and of the waste in contact with the fill material,

2. determining the effectiveness of repeated washing and removal of the wash water as an effective approach for treating the soluble contaminants of concern (i.e., removal of nitrate, nitrite, soluble C-14, I-129, Tc-99, Np-237 from the tanks), 
3. evaluating reagent mixtures and proportions for effectiveness in fill materials (mixtures of portland cement, fly ash and hydraulic slag),

4. specifying reagents, reagent mixtures and proportions for use in fill materials for simultaneously treating a large number of radionuclides such as those identified by Hanford,

5. identifying and testing alternative stabilization reagents, such as phosphate precipitation or absorption for selected contaminants and non-sulfide technetium stabilizaiton.

Field measurements should be conducted on all tank fill materials to confirm the design properties prior to full-scale placements. In addition, compatibility of the admixtures and the reactive stabilizing ingredients should be confirmed. 
Table 5-1. Tank fill physical properties versus available technology and technology needs.

\begin{tabular}{|c|c|c|c|}
\hline Grout Property & Site Response & $\begin{array}{l}\text { Available } \\
\text { Technology }\end{array}$ & Technology Needs \\
\hline \multicolumn{4}{|l|}{ Fresh Properties } \\
\hline Pumpable & Yes & \multirow{4}{*}{$\begin{array}{c}\text { Yes } \\
\text { (demonstrated at } \\
\text { SRS) }\end{array}$} & \multirow{4}{*}{$\begin{array}{l}\text { Alternative less } \\
\text { expensive admixtures }\end{array}$} \\
\hline Flowable & Yes & & \\
\hline Self-leveling & Yes & & \\
\hline Bleed water & Minimum to None & & \\
\hline Set time & $\begin{array}{l}<72 \mathrm{hr} \\
\text { months } \\
?\end{array}$ & Yes & $\begin{array}{l}\text { Justify and confirm } \\
\text { requirements }\end{array}$ \\
\hline Resist solids settling & $\begin{array}{l}\text { N/A } \\
\text { Yes } \\
\text { No }\end{array}$ & Yes & $\begin{array}{l}\text { Justify and confirm } \\
\text { requirements }\end{array}$ \\
\hline Heat of hydration & $\begin{array}{l}\text { Yes } \\
\text { Maybe }\end{array}$ & Yes & $\begin{array}{l}\text { Identify method and } \\
\text { test protocol for } \\
\text { evaluating heat of } \\
\text { hydration }\end{array}$ \\
\hline \multicolumn{4}{|l|}{ Cured Properties } \\
\hline Strength & $\begin{array}{l}\text { Low } \\
>50 \text { psi, } \\
>500 \text { psi }\end{array}$ & $\begin{array}{l}\text { Yes } \\
\text { Yes } \\
\text { Yes } \\
\end{array}$ & None \\
\hline Excavatable & $\begin{array}{l}\text { Yes } \\
\text { No } \\
\text { Maybe }\end{array}$ & Yes & None \\
\hline $\begin{array}{l}\text { Hydraulic } \\
\text { conductivity }\end{array}$ & $\begin{array}{l}\text { Maybe } \\
?\end{array}$ & Yes & Identify requirements \\
\hline Durability & $\begin{array}{l}\text { None (ORR) } \\
50-100 \text { years }(\mathrm{WV}) \\
500 \text { years }(\text { INEEL) } \\
500-1000 \text { years }(\text { Hanford) } \\
10,000 \text { years }(\text { SRS })\end{array}$ & No & $\begin{array}{l}\text { 1. Confirm and justify } \\
\text { requirements. } \\
\text { 2. Identify testing } \\
\text { and/or protocol for } \\
\text { assessing durability }\end{array}$ \\
\hline Implementation & $\begin{array}{l}\text { 1. Use grout to displace heel } \\
\text { so it can be removed by } \\
\text { pumping (INEEL) } \\
\text { 2. Mix heel w/grout } \\
\text { (Hanford and SRS) } \\
\text { 3. Displace heel so it can be } \\
\text { encapsulated with a single } \\
\text { "lift" of grout (SRS) }\end{array}$ & $\begin{array}{l}\text { Possibly } \\
\text { (depends on } \\
\text { specific waste } \\
\text { and grout and } \\
\text { tank features) }\end{array}$ & $\begin{array}{l}\text { 1-3. Conduct pilot- } \\
\text { scale testing of the } \\
\text { waste retrieval and } \\
\text { waste mixing concepts } \\
\text { for proof of principle. }\end{array}$ \\
\hline $\begin{array}{l}\text { Fill Materials } \\
\text { Identified }\end{array}$ & $\begin{array}{l}\text { Yes (most sites) } \\
\text { No (Hanford) }\end{array}$ & $\begin{array}{c}\text { Yes } \\
\text { (SRS closed two } \\
\text { tanks) }\end{array}$ & $\begin{array}{l}\text { Specify and validate fill } \\
\text { material properties, } \\
\text { tank closure plans, and } \\
\text { waste treatment } \\
\text { strategies for DOE }\end{array}$ \\
\hline
\end{tabular}


Table 5-2. Tank fill leaching properties versus available technologies and technology needs.

\begin{tabular}{|c|c|c|c|}
\hline Grout Property & Site Response & Available Technology & Technology Needs \\
\hline \multicolumn{4}{|c|}{ Stabilization/Solidification Properties } \\
\hline \multirow{16}{*}{ Radionuclides } & $\mathrm{Am}$ & Hydroxide/Portland cement & Confirm effectiveness \\
\hline & $\mathrm{C}$ & Portland cement, $\mathrm{CaCO}_{3}$ & $\begin{array}{l}\text { Confirm effectiveness } \\
\text { Identify improved treatment }\end{array}$ \\
\hline & $\mathrm{Cm}$ & Hydroxide/Portland cement & Confirm effectiveness \\
\hline & Cs & $\begin{array}{c}\text { Clay (Illite) } \\
\text { Zeolite (clinoptilolite) }\end{array}$ & Confirm effectiveness \\
\hline & $\mathrm{I}$ & Silica fume for low porosity & $\begin{array}{c}\text { Confirm effectiveness } \\
\text { Identify improved treatment }\end{array}$ \\
\hline & $\mathrm{Nb}$ & Hydroxide/Portland cement & Confirm effectiveness \\
\hline & $\mathrm{Ni}$ & Hydroxide/Portland cement & Confirm effectiveness \\
\hline & $\mathrm{Np}$ & $\begin{array}{c}\text { Sulfide/Slag } \\
\text { Engineered porous apatite }\end{array}$ & $\begin{array}{c}\text { Confirm effectiveness } \\
\text { Same as for Tc }\end{array}$ \\
\hline & $\mathrm{Pu}$ & Hydroxide/Portland cement & Confirm effectiveness \\
\hline & $\mathrm{Se}$ & Sulfide/Slag & Confirm effectiveness \\
\hline & $\mathrm{Sn}$ & $\begin{array}{c}\text { Hydroxide/Portland cement } \\
\text { Sulfide/Slag }\end{array}$ & Confirm effectiveness \\
\hline & $\mathrm{Sr}$ & $\begin{array}{c}\text { Cement, Cement-Pozzolan } \\
\text { Zeolite } \\
\text { Synthetic ion exchange resins } \\
\text { CST (Crystalline silico titanate) } \\
\text { Phosphate (acidic system) } \\
\text { Engineered porous apatite }\end{array}$ & $\begin{array}{l}\text { Test in fills/grouts } \\
\text { Identify preferred stabilization } \\
\text { agent. Evaluate engineered } \\
\text { apatite in cement waste forms } \\
\text { and tank fills }\end{array}$ \\
\hline & Tc & $\begin{array}{c}\text { Sulfide/Slag } \\
\text { Engineered porous apatite } \\
\text { (irreversible sorption) }\end{array}$ & $\begin{array}{l}\text { Identify and test sulfide/slag } \\
\text { alternatives for stabilizing Tc } \\
\text { in the grout such as, ion } \\
\text { exchange resins. Evaluate } \\
\text { engineered apatite in cement } \\
\text { waste forms \& tank fills }\end{array}$ \\
\hline & $\mathrm{U}$ & Hydroxide/Portland cement & Confirm effectiveness \\
\hline & TRU & Hydroxide/Portland cement & Confirm effectiveness \\
\hline & None & NA & \\
\hline \multirow{9}{*}{ RCRA metals } & As & Sulfide/Slag & \multirow{9}{*}{$\begin{array}{l}\text { Test in fills/grouts. } \\
\text { Determine maximum total } \\
\text { concentrations and maximum } \\
\text { TCLP leachate concentrations. } \\
\text { Determine acceptable upper } \\
\text { limits for each contaminant and } \\
\text { for mixtures of all contaminants. }\end{array}$} \\
\hline & $\mathrm{Ag}$ & Soluble $\mathrm{Cl}$ & \\
\hline & $\mathrm{Ba}$ & Hydroxide/Portland cement & \\
\hline & $\mathrm{Cd}$ & Hydroxide/Portland cement & \\
\hline & $\mathrm{Cr}$ & Sulfide/Slag & \\
\hline & $\mathrm{Hg}$ & Sulfide/Slag & \\
\hline & $\mathrm{Pb}$ & $\begin{array}{l}\text { Hydroxide/Portland cement } \\
\text { Phosphate }\end{array}$ & \\
\hline & $\mathrm{Se}$ & $\begin{array}{c}\text { Sulfide/Slag } \\
\text { Portland cement } \\
\end{array}$ & \\
\hline & None & NA & \\
\hline \multirow[t]{3}{*}{ Others } & $\mathrm{NaOH}$ & Blast Furnace Slag, Pozzolans & $\begin{array}{l}\text { Review and confirm } \\
\text { requirements and effectiveness }\end{array}$ \\
\hline & Nitrate & None identified & \\
\hline & Nitrite & None identified & \\
\hline
\end{tabular}




\subsection{SUMMARY}

In-situ closure of large empty tanks contaminated with radioactive and hazardous waste is unique to the United States and possibly to Russia. Other countries with nuclear waste plan to clean the contaminated storage tanks and to dispose of them in designated repositories or landfills.

Several DOE sites are currently developing plans for in-situ tank closures. The site specific plans are driven by the:

- applicable regulatory requirements,

- extent of environmental contamination associated with the tanks,

- construction restrictions and integrity of the tanks,

- success of the waste retrieval activities,

- treatment strategy selected for the tank heel and/or incidental waste,

- tank void stabilization strategy,

- intruder barrier methodology, and

- surface cover system (landfill capping technology).

All of the sites identified low-strength flowable fill materials, i.e. controlled low strength material (CLSM), for physically stabilizing the void spaces inside of the large HLW tanks. Enhancements to a generic flowable fill formulation [ACI 229-R94] depended on sitespecific needs for contaminant stabilization and on the emphasis placed on certain physical properties.

Flowable fill suitable for routine construction applications was used at ORNL for the OHF tank closure. Fill materials designed for closing tanks at the INEEL are also similar in concept to the ORNL fill except that higher strengths are desired, consequently the formulations contain more cement. Also fly ash was substituted for sand in the INEEL pipe grout to enhance the flow through small openings. Waste treatment was unnecessary and generation and management of bleed water was not an issue at these sites.

Management of bleed water was undesirable at the SRS. Consequently zero-bleed formulations were developed. In addition, a waste treatment strategy was developed and tested that required a chemically reducing environment. This was accomplished by including blast furnace slag and sodium thiosufate in the fill that was placed in contact with the waste.

Stabilization of potential contaminants is a need at WV. Proprietary formulations containing ion exchange resins and/or other reactive ingredients were developed. The tank fill materials for closure of the WV tanks must also be excavatable so the material can be retrieved if necessary at a later time.

In summary, work is in progress in the DOE complex to permanently remove HLW tanks from service and to close/dispose of the tanks in-place. Cement-based grouts are currently being used to fill the tanks and to stabilize the incidental waste remaining in the empty tanks. 


\subsection{REFERENCES}

Adaska, W. S., ed., 1994. "Controlled Low-Strength Materials, American Concrete Institute," Special Publication, SP-150, American Concrete Institute, Detroit MI,

Adaska, W. S., Tresouthick, S. W., and West, P. B., 1998. "Solidification and Solidification of Wastes Using Portland Cement, 2nd, EB071, Portland Cement Association, Skokie, IL.

Allan, M. L. and Kukacka, 1. E., 1997. "Permeability and Leach Resistance of Grout-Based Materials Exposed to Sulphates," Mat. Res. Soc. Symp. Proc., Mechanisms of Chemical Degradation of Cement Based Systems, K. L. Scrivener and J. F. Young, eds., Chapter 50, p 436-443.

Amer, S. I..,2001. Composition and Process for Remediation of Waste Streams. US Patent 6,180,023 B1.

ACI 229R-94. "Controlled Low Strength Materials (CLSM)," American Concrete Institute Manual of Concrete Practice, Part I Materials and General Properties of Concrete, American Concrete Institute, Farmington Hills, MI, 1999.

ACI 304R-89. "Guide for Measuring, Making, Transporting, and Placing Concrete," American Concrete Institute Manual of Concrete Practice, Part II: Construction Practices and Inspection Pavements, American Concrete Institute, Farmington Hills, MI, 1999.

ACI 311.1R-98. “ACI Manual of Concrete Inspection ninth edition,” American Concrete Institute Manual of Concrete Practice, Part II: Construction Practices and Inspection, Pavements, American Concrete Institute, Farmington Hills, MI, 1999.

ACI 523.3R-93. "Guide for Cellular Concretes Above 50 pcf, and for Aggregate Concretes Above 50 pcf with Compressive Strengths Less Than 2500 psi," American Concrete Institute Manual of Concrete Practice, Part V: Masonry, Precast Concrete, Special Processes, American Concrete Institute, Farmington Hills, MI, 1999

American Petroleum Institute, 1984. "Specifications for Materials and Testing Oil-Well Cements," API Specification 10, 2nd ed., American Petroleum Institute, Dallas.

American Petroleum Institute, 1983. "API Specification for Oil-Well Drilling-Fluid Materials," API Specification. 12A, 9th ed., American Petroleum Institute, Dallas.

ASTM C 150-89. "Standard specification for Portland cement," Annual Book of ASTM Standards Section 4 Construction, Vol. 04.02, Concrete and Aggregates, American Society for Testing and Materials, Philadelphia PA.

ASTM C 360-91. "Test Method for Ball Penetration in Fresh Portland Cement Concrete," 
Annual Book of ASTM Standards Section 4 Construction, Vol. 04.05, American Society for Testing and Materials, Philadelphia PA.

ASTM C 403-90. "Test Method for Time of Setting of Concrete Mixtures by Penetration Resistance," Annual Book of ASTM Standards Section 4 Construction, Vol. 04.02, Concrete and Aggregates, American Society for Testing and Materials, Philadelphia PA.

ASTM C 618-92a. "Standard Specification for Fly Ash and Raw or Calcined Natural Pozzolans for Use as a Mineral Admixture in Portland Cement Concrete," Annual Book of ASTM Standards Section 4 Construction, Vol. 04.02, Concrete and Aggregates, American Society for Testing and Materials, Philadelphia, PA.

ASTM C 796-87a. "Method of Testing Foaming Agents for Use in Producing Cellular Concrete Using Preformed Foam," Annual Book of ASTM Standards Section 4 Construction, Vol. 04.02, Concrete and Aggregates, American Society for Testing and Materials, Philadelphia, PA.

ASTM C 869-91. "Specification for Foaming Agents Used in Making Preformed Foam for Cellular Concrete," Annual Book of ASTM Standards Section 4 Construction, Vol. 04.02, Concrete and Aggregates, American Society for Testing and Materials, Philadelphia, PA.

ASTM C 989-89, "Specification for Ground Granulated Blast-Furnace Slag for Use in Concrete and Mortars," Annual Book of ASTM Standards Section 4 Construction, Vol. 04.02, Concrete and Aggregates, American Society for Testing and Materials, Philadelphia PA.

ASTM D 6103-97. "Standard Test Method for Flow Consistency of Controlled Low Strength Material (CLSM)," American Society for Testing and Materials, Philadelphia PA.

Anguiano, T. and Floyd, D., 1997. "Stabilization/solidification of Battery Debris and Lead Impacted Material at Schuykill Metals, Plant City, Florida," Int. Containment Technology Conference Proceedings, p. 561-567, 1997.

Angus, M. J. and Glasser, F. P., 1986. "The chemical environment in cement matrixes," Mater. Research Society Symposium Proceedings, v. 50, p. 547- 556.

Armstrong, K. M. and Klingler, L. M., 1986. "Evaluation of a Unique System for the Thermal Processing of Radioactive and Mixed Wastes," Proceedings of Conference on All Aspects of Low Level Waste, Chicago, Feb. 28, 1986, also in "Evaluation of a Unique System for the Thermal Processing of Radioactive and Mixed Wastes," MLM-3340(OP), Mound Laboratory, Monsanto Research Corp., Miamisburg, OH.

Atkinson, A., Nelson K., and Valentine T. M., 1986. "Leach test characterization of cementbased nuclear waste forms," Nuclear and Chemical Waste Management, v. 6, p. 242-253. 
Bayliss, S., Ewart, R. t., Howse, R. M., Smith-Briggs, J. L., Thomason, H. F., 1988. "The Solubility and Sorption of Lead-210 and Carbon-14 in a Near-Field Environment," Mat. Res. Soc., Symp. Proc., No. 112, p.33-42.

Bhat, V. K., 2001. Method and Compositions of Heavy Metals, Acid Gas Removal and pH Control in Contaminated Matrices, US Patent 6,191,068 B1.

Bignell, D. and Ling, L., 1998. "Innovative Approach to Liquid HLRW Tank Closure at DOE’s Savannan River Site,” Proc. High-Level Waste Management, No. 8, p. 708-709.

Boatner, L. A., Beall, M. W., Abraham, M. M., Finch, C. B., Huray, P. G., and Rappaz, M., 1980. "Monazite and Other Lanthanide Orthophosphates as Alternate Actinide Waste Forms," Sci Basis Nucl. Waste Management, v. 2, p. 289-290.

Bors, J. Gorny, A., and St. Dultz, 1996. "Studies on the Interaction of Radionuclides with Organophilic Clays," Radiochim. Acta, 74:231-234.

Bostick, J. D, Shoemaker, J. L., Osborne, P. E., and Evans-Brown, b., 1990. "Treatment and Disposal Options for Heavy Metal Sludge Containing Soluble Technetium-99," Chapter 20, Emerging Technologies in Hazardous Waste Management, ACS Symp., Ser., p. 345-367.

Bradbury, M. H. and Sarott, F.-A., 1995. "Sorption Databases for the Cementitious NearField of a L/ULW Repository for Performance Assessment," PSI Bericht Nr. 95-06, Marz, 1995, ISSN 1019-0643, Paul Scherrer Institute, Wurenlingen and Villigen, CH-5232 Villigen/PSI.

Broman, P.G., 1975. "Purification of Industrial and Municipal Waste Water by Means of Mineral Slime," Int. Miner. Process Congr. $11^{\text {th }}$ Proceedings, p; 1371-1396.

Bye, G. C., 1983. Portland Cement Composition, Production, and Properties, Pergamon Press, NY NY.

Caldwell, T. B., d'Entremont, P. D., Langton, C. A., Newman, J. L., Saldivar, E., and Rajendran, N., 1998. "Closing High-Level-Waste Tanks at the Savannah River Site," RADWASTE Magazine, p. 19-26, March 1998.

Caldwell, T. B., 1997. "Tank Closure reducing Grout (U),” WSRC-TR-97-0102 Rev.0, Westinghouse Savannah River Compnay, Aiken, SC.

Clark, I. D., Dayal, R., and Khoury, H. N., 1994. “The Maqarin (Jordan) Natural Analogue for C-14 Attenuation in Cementitious Barriers," Waste Management, v. 14, p. 467-477.

Chesner, W. H., 1996. Enhanced Stabilization of Lead in Solid Residues Using Acid Oxyanion and Alkali-Metal Carbonate Treatment, U. S. Patent 5,545,805. 
Clark, S. B., and Wilhite E. L., 1991. "Low-Level Liquid Waste Disposal at the Savannah River Site: A Large Scale Demonstration of Saltstone," Waste Management '91, Proceedings, Symposium on Waste Management, p. 603-09, Tucson, Arizona, February 2428, 1991.

Colella, C., 1999. "Environmental Applications of Natural Zeolite Materials Based on Their Natural Microporous Materials in Environmental Technology, P.

Misaelides, et al. eds., NATO Sci. Ser., E. Kluwer Academic Publishers. Netherlands, p. 207224.

Conca, J., Wright, J., and Triay, I., 2000. "PIMS: A Simple Technology for Clean-UP of Heavy Meatls and Radionuclides Throughout the World," The Environmental Challenges of Nuclear Disarmament, T. E. Baca and T. Florkowski, eds., NATO Sci. Ser. 1 p. 223-236.

Conner, J. R., 1990. Chemical Fixation and Solidification of Hazardous Wastes, Van Nostrand Reinhold, NY, NY.

Conner, J. R. and Hoeffner, S. L., 1998. "A Critical Review of Stabilization/Solidification Technology." Critical Reviews in Environmental Science and Technology, v. 28, no. 4, p. 397-462.

Conner, J. R., and Wilk, C. M., 1997. "Guide to Improving Cement Based

Stabilization/Solidification,” EB211, Portland Cement Association, Skokie, IL.

Contos, L. G., and Regan, R. W., 1995. "Stabilization of Metal-Containing Cupola Sludges with Triple Super Phosphate,” Am Foundrymen's Soc. Trans. v. 103, p. 641-646.

Crannell, B. S., et al., 2000. "Heavy Metal Stabilization in Municipal Solid Waste Combustion Bottom Ash Using Soluble Phosphate," Waste Management, v. 20, no. 2-3, p. 135-148.

Crawford, P. and Gafford, J., 1996. Method for the Stabilization and Detoxification of Waste Material, US Patent 5,484,533.

Dayal, R. and Klein, R., 1988. " $\mathrm{CO}_{2} /$ Grout Interactions and Their Relevance to C-14 Attenuation in Cementitious Backfill," Radiochemica Acta, v. 44/45, p. 263-270.

Dayal, R. and Reardon, E. J., 1992. "Cement-Based Engineered Barriers for Carbon-14 Ioslation," Waste Management, v. 12, p. 189-200.

Dayal, R. and Reardon, E. J., "Carbon -14 Behavior in a Cement-Dominated Environment: Implication for Spent Candu Resin Waste," Waste Management, v. 14, p. 457-466.

Doh, J. Y. and Lee, K. J., 1986. "Experimental Study of Leaching Phenomena of Cs-137 from a Cement Matrix Generated at PWR Plant," J. of Korean Association for Radiation Protection, v. 11, no. 2, p. 91-103. 
Doilnitsyn, V. A., et al., 1997. "Purification of Slightly Contaminated Low-Salt Water form the Long-Lived Radionuclides," Radioactive Waste Management Environmental Remediation, Proceedings, International conference, ASME, p. 527-528.

Eighmy, T. T., et al., 1997. "Heavy Metal Stabilization in Municipal Solild Waste Combustion Dry Scrubber Residue Using Soluble Phosphate," Environ. Sci. Technol., v. 31, no. 11 , p. 3330-3338.

Eighmy, T. T., Crannel, B. S., Krzanowski, J. E., Butler, L. G., Cartledge, F. K., Emery, E. F., Dykstra, J. D., Shaw, E. L., and Francis, C. A., 1998. "Characterization and Phosphate Stabilization of Dusts from the Vitrification of MSW Combustion residues," Waste Management, V. 18, no. 6-8, p.513-524.

Forrester, K. E., 2001. Method of Stabilizing Heavy Metal In a Material or Waste, US Patent, 6,186,939 B1.

Gelis V. M. and Kozlitin,E. A., 1993. "Application of Inorganic Adsorbents and Ion Exchange Resins for Decontaminating Solution form Cesium and Strontium Radionuclide," Technol. Programs Radioact. Waste Manage. Environ. v. 2, p.1839-1841.

Gering, K. L., 1999. "Problematic Incinerator Ash: A Case Study in Finding a Successful Treatment Approach,” WM'99, Proceedings, p.2188-2209.

Ghosh, S. N. (ed.), 1983. Advances in Cement Technology Critical reviews and Case Studies on Manufacturing, Quality Control, Optimization and Use, Pergamon Press, NY, NY.

Gilliam, T. M., Spence, R. D., Bostick, W. D., and Shoemaker, J. L., 1990.

"Solidification/stabilization of technetium in cement-based grouts," J. of Hazardous

Gilliam, T. M., 1986. "Leach Testing of Hydrofracture Grouts Containing Hazardous Waste," Journal of the Underground Injection Practices Council, v. 1 p. 192-212.

Gilliam, T. M., and Loflin, J. A., 1986. "Leachability Studies of Hydrofracture Grouts," ORNL/TM-9879, Oak Ridge National Laboratory, Oak Ridge TN.

Gougar, M. L. D., Siemer, D. D., and Scheetz, B. E., 1996. "Disposal of INEL Spent Nuclear Fuel Reprocessing Waste Using a Glass-Forming Cement," Embedded Top. Meet. DOE Spent Nuclear Fuel, p. 359-366.

Grim, R. E., 1962. Applied Clay Mineralogy, McGraw-Hill, New York.

Guerrero, A. M., Hernandez, M. S., and Goni, S., 1997. "Reaction Between Simulated Sulphate Radioactive Liquid Waste and Cement Based Materials," $10^{\text {th }}$ Proc. Int. Congr., Chem. Cem., v. 4. 
Hernandez-Barrales, E. and Granados-Correa, F., 1999. "Sorption of Radioactive Cobalt in Natural Mexican Clinoptilolite,” J. Radioanal. Nucl. Chem. v. 242, no.1, p. 111-114.

Hettiarachchi, G. M., Pierzynski, G. M., and Ransom, M. D., 2000. "In-Situ Stabilization of Soil Lead Using Phosphorous and Manganese Oxide,” Environ. Sci. Technol., v. 34, no. 21, p. 4614-4619.

Hinton, T. G., Kaplan, D. I., Knox, A. C., and Serkiz, S. M., 1999. "In-Situ Remediation of 137Cs Contaminated Wetlands Using Naturally Occurring Minerals," WSRC-TR-99-00229 Revision 0, Westinghouse Savannah River Company, Aiken, SC 29808.

Huang, C.-T., and Wu, G. 1999. "Improvement of Cs Leaching Resistance of Solidified Radwastes with Copper Ferrocyanide (CFC) -Vermiculite," Waste Mange. v. 19, no, 4, p. 263-268.

Ingram, C. W., et al., 1996. "Zeolite Shape Selectivity in the Uptake of Uranium from Solutions," Nucl.Hazard. Waste Manage., Proceedings Inter. Meeting, No. 2, p. 1098-1105.

International Atomic Energy Agency (IAEA), 1993. "Improved Cement Solidification of Low and Intermediate Level Radioactive Wastes," Technical Reports Series No. 350, International Atomic Energy Agency, Vienna.

Iretskaya, S., Nzihou, A, Zahraoui, C., and Sharrock, P., 1999. "Metal Leaching form MSW Fly Ash Before and After Chemical and thermal Treatments," Environ. Progress., V. 18, No. 2, p.144-148.

Jha, J. C., Chinoy, A. R., and Thomas, K. T., 1966. "Studies on Cesium Sorption Properties of Some Indian Vermiculites,” Nucl. Rad. Chem. Symp., Proceedings, p. 40-45.

Johnston, H. M. and Wilmot, D. J., 1992. "Sorption and Diffusion Studies in Cementitious Grouts,” Waste Management, v. 12, p. 289-297.

Kaplan, D., Serkiz, S., Hinton, T., and Knox, A., 1999. "In-Situ remediation of Cs-137 Contaminated Wetlands Using Naturally Occurring Minerals (U),”WSRC-TR-99-00229, Westinghouse Savannah River Company, Inc., Savannah River Site, Aiken, SC 29801.

Kauschinger, J. L., Spence, R. D., and Lewis, B., E., 1998. "In Situ Grouting Technology Demonstration and Field Specification Overview for Hot Deployment of the Multi-Point Injection System in Gunite and Associated Tank TH-4," ORNL/TM-13710, Oak Ridge National Laboratory, Oak Ridge, TN, October, 1998.

Komarneni, S. and Roy, R., 1986. "Low -Temperature Materials for Waste disposal: I, Hydroxylated Phases," Advances in Ceramics: Nuclear Waste Management II, American Ceramic Society, 20, p, 199-206. 
Komarneni, S. and Roy, R., 1982. "Interactions of Backfill Materials with Cesium in a Bittern Brine Under Repository Conditions,” Nucl. Technol. v. 56, no. 3, p.575-579.

Komarneni, S. and Roy, R., 1981. "Hydrothermal Transformations in Candidate Overpack Materials and their Effects on Cesium and Strontium Sorption," Nucl. Technol., v. 54 no. 1, p. 118-122.

Komarneni, S., and Roy, D. M., 1979. "Shale as a Radioactive Waste Repository: The Importance of Vermiculite,” J. Inorg. Nucl. Chem., v. 41, no. 2, p.1793-1796.

Komarneni, S., and Roy, D. M., 1978. "Effect of Layer Charge and Heat Treatment on Cs Fixation by Layer Silicate Minerals," J. Inorg. Nucl. Chem., v. 40, no. 5, p.893-896.

Kontopoulos, A. and Theodoratos, P.1998. "Stabilization of Highly Polluted Soils," Contam. th Intern. FZK/TNO Conf. Proceedings, p. 1115-1116.

Krumhansl, J. L., Brady, P. V., Zhang, P. C., Arthur, S., Hutcherson, S. K., Liu, J., Qian, M., and Anderson, H. 1., 2001. "Phase Chemistry and Radionuclide Retention of High-Level Nuclear Site Remediation: First Accomplishments of the Environmental Science Program, P. G. Eller and Heineman, W. H., eds., ACS Symp. Ser. 778, ACS, Washington, DC, p. 98-112.

Langton, C. A., 2001. "Chemical Fixation and Stabilization," in Hazardous and Radioactive Waste Treatment Technologies Handbook, ed., Oh, C. O., CRC Press, NY NY.

Langton, C. A. and Rajendran, N., 2000. "High Performance Zero-Bleed CLSM/Grout Mixes for High-Level Waste tank Closures - Strategic research and Development - FY99 Report" (U), WSRC-RP-99-01014, Revision 0, January 15, 2000, Westinghouse Savannah River Company, Aiken, SC.

Langton, C. A. and Rajendran, N., 1998. "Laboratory and Field testing of High Performance Zero-Bleed CLSM Mixes for Future Tank Closure Application” (U), WSRC-TR-98-271, Westinghouse Savannah River Company, Aiken, SC.

Langton, C. A., 1988. "Metal Toxicity Evaluation of Savannah River Plant Saltstone: Comparison of EP and TCLP Test Results,' Waste Management '88, Tuscon AZ, 1988.

Langton, C. A. and Wong, P. B., 1991. "Properties of slag concrete for low-level waste containment," Ceramic Transactions, Nuclear Waste Management IV, p. 191-199, The American Ceramic Society, also presented at American Concrete Institute Spring Meeting, March 17-21, 1991.

Langton, C. A., Dukes M. D., and Simmons R. V., 1983. "Cement-Based Waste Forms for Disposal of Savannah River Plant Low-Level Radioactive Salt Waste," Scientific Basis for Nuclear Waste Management VII, p. 575-582, Proceedings of the Materials Research Society Annual Meeting, Boston, MA, November 14-17, 1983. 
Lea, F. M., 1970. The Chemistry of Cement and Concrete, 3rd ed. Chemical Publishing Co., Inc., NY NY.

Lee, D. J. and Brown, D. J., 1981. "Factors Affecting the Leachability of Caesium and Strontium from Cemented Simulated-Evaporator Wastes," AEEW-R 1461, UK Atomic Energy Authority.

Lee, S. H., 1974. "Studies on the Sorption and Fixation of Cesium by Vermicultie," J. Korean Nucl. Soc. V. 6, no. 2, p. 97-111.

Levi, H. W. and Miekeley, N., 1967, “Studies on Ion Diffusion in Vermiculite,” Disposal Radioact. Wastes Ground, Proc. 161-168.

Levi, H. W., and Miekeley, N., 1967. "Studies on Ion Diffusion in Vermiculite," Disposal of Radioactive Wastes, Proceedings, p. 161-168.

Lewis, M. A., Fischer, D. F., and Smith L. J., 1993. Salt-Occluded Zeolites as an Immobilization Matrix for Chloride Waste Salt," J. AM. Ceram. Soc., v. 76, no. 11, p. 28262832.

Li, Z., 1998. “Chromate Extraction form Surfactant-Modified Zeolite Surfaces,' J. Environ. Qual., v. 27, no. 1, p. 240-242.

Li, Z. and Bowman, R. S., 1997. "Counterion Effects on the Sorption of Cationic Surfactant and Chromate on Natural Clinoptilolite," Environ. Sci. Technol., v. 37, no. 8, p. 2407-2412.

Ling, L. T., Gnann, H. B., and Bignell, D, 1998. "Closure of the Nation's First High-Level Radioactive Waste Storage Tank," Proc. Int. Conf. On Decommissioning and Decontamination and on Nuclear and Hazardous Waste Management, Sept., 13-18, 1998, Denver, CO, ANS, LaGrange Park IL, v. 2 p. 1113-1118.

Loomis, G. G., 1997. "In-Situ Stabilization Wall for Containment and Hot Spot Retrieval," Proc. Int. Top. Meet. Nuclear and Hazardous Waste Management, SPECTRUM '96, $6^{\text {th }}$ p. 367-374.

McCarthy, G. J., 1973. "Quartz Matrix Isolation of Radioactive Wastes," J. Mater. Sci. Lett., v. 8, p. 1358.

McDaniel, E. W., et al., 1984. "Basis for Selecting Cement-Based Waste Forms for Immobilizing Radioactive Waste,” Mat. Res. Soc. Symp. Proc., v. 127, p. 421-430.

McDaniel, E. W., Morgan, M. T., Moore, J. G., Devaney, H. E. and Dole, L. R., 1982. "Strontium Leachability of Hydrofracture Grouts for Sludge-Slurries," ORNL/TM-8198, Oak Ridge National Laboratory. Oak Ridge, TN, March. 1982. 
Moore, J. G., 1976. "Development of Cementitious Grouts for the Incorporation of Radioactive Wastes. Part 2: Continuation of Cesium and Strontium Leach Studies," ORNL5142, Oak Ridge National Laboratory, Oak Ridge, TN, September 1976.

Moore, J. G., Godbee, H. W., Kibbey, A. H. and Joy D. S., 1975. "Development of Cementitious Grouts for the Incorporation of Radioactive Wastes. Part 1: Leach Studies," ORNL-4962, Oak Ridge National Laboratory, Oak Ridge TN, August 1975.

Moore, R., Sandia National Laboratory, personal communication, 2001.

Morgan, M. T., Moore, J. G., Devaney, H. E., Rogers, G. C., Williams, C., and Newman, E., 1978. "The Disposal of Iodine-129," Proc. of the Symp. On Science Underlying Radioactive Waste Management, Boston MA, Nov. 29-Dec. 1, 1978.

Nilsson, K., 1996. "Treatment of Waste Incineration Solid Residues," $7^{\text {th }}$ ISWA Int. Congr. Exhib. II p. 82-89.

Nurse, R. W., 1984. "Slag Cements," in The Chemistry of Cements, ed. H. F. W. Taylor, v. 2, p. 37-68, Academic Press, New York.

Oh, C. H, ed., 2001. Hazardous and Radioactive Waste Treatment Technologies Handbook, CRC Press, NY NY.

Pal, D., and Yost, K., 1993. Fixation and Stabilization of Lead in Contaminated Soil and Solid Waste, US Patent 5,193,936.

Palmer, J. D., 1990. "Formulation of Durable Waste Forms for UK Reprocessing Wastes," Nucl Waste Manage. III, Ceramic Trans. v. 9 p. 137-151.

Pepper D. W., 1986. "Transport of Nitrate from a Large Cement-Based Wasteform," DPST85-963, Savannah River Laboratory, Aiken SC.

Plecas, I. J., et al., 1990. "Radionuclide Migration Through Porous Waste Forms," Radioactive Waste Manage. Nucl. Fuel Cycle, v. 14, no. 3, p. 195-205.

Ramachandran, V. S., ed., 1984. Concrete Admixtures Handbook - Properties, Science, and Technology, Noyes Publications, Park Ridge, NJ.

Ramachandran, V. S. and Beaudoin, J. J., ed., 2001. Handbook of Analytical Techniques in Concrete Science and Technology, Noyes Publications, Park Ridge, NJ, William Andrew Publishing, Norwich, NY.

Sams, T. L. and McDaniel, E. W., 1988. "Development of a Cement-Based Grout for Immobilization of a Low-Level Waste Stream Containing Sodium Sulfate," Proc. Symp. Waste Manage., v. 1, p. 47-53. 
Sahu, S. and Diamond, S., 1996A. "Pore Solution Chemistry of Simulated Low-Level Liquid Waste Incorporated in Cement Grouts," Mat. Res. Soc. Symp. Proc. p. 411-418.

Sebastian, T. A., Bhat, I. S., and Kamath, P. R., 1973. "Vermiculite Decontamination of Atomic Power Station Effluents,” Environ. Pollut., Proceedings, p. 95-97.

Serne, R. J., W. J. Martin, R. O. Lokken, V. L. LeGore, C. W. Lindenmeier, and P. F. C. Martin., 1989A. "Leach and EP Toxicity Tests on Grouted Waste from Tank 106-AN," PNL6960. Pacific Northwest National Laboratory.

Serne, R. J., W. J. Martin, V. L. LeGore, C. W. Lindenmeier, S. B. McLaurine, P. F. C. Martin, and R. O. Lokken. 1989B. "Leach Tests on Grouted Made with Actual and Trace Metal-Spiked Synthetic Phosphate/Sulfate Waste," PNL-7121. Pacific Northwest National Laboratory.

Serne, R. J., R. O. Lokken, and L. J. Criscenti. 1992. "Characterization of Grouted LowLevel Waste to Support Performance Assessment," Waste Management. v. 12, p. 271-287.

Serne, R. J., C. W. Lindenmeier, V. L. LeGore, P. F. C. Martin, L. L. Ames, and S. J. Phillips. 1993. "Leach Testing of In Situ Stabilization Grouts Containing Additives to Sequester Contaminants," PNL-8492. Pacific Northwest National Laboratory.

Shi, C., and R. L. Day. 1996. "Alkali-Slag Cements for the Immobilization of Radioactive Wastes," Stabilization and Solidification of Hazardous, Radioactive, and Mixed Wastes, $3^{\text {rd }}$ Volume. STP 1240, ASTM, West Conshohocken, Pennsylvania, p. 163-173.

Shaw, P, 1997. "Lab Scale Testing of Novel Natural Analogs as In-Situ Stabilization Agents," Int. Containment Technol. Conf. Proceedings, p. 593-599.

Shuh, D. K., Edelstein, N. M., Burns, C. J., Lukens, W. W., Bucher, J. J., Fickes, M. G., and Scott, B. L., 2000. "Research Program to Investigate the Fundamental Chemistry of Technetium - Final Report," Project Number EMSP-60296, USDOE.

Singh, D., V. Mandalika, A. S. Wagh, R. Strain, and M. Tlustochowicz, 1998A. "Immobilization of ${ }^{99} \mathrm{Tc}$ in Low-Temperature Phosphate Ceramic Waste Forms," Ceram. Trans.: Environmental Issues and Waste Management Technologies III, v. 87, p. 653-664.

Singh, D., K. Patel, A. S. Wagh, and S. Y. Jeong, 1998B. "Modified Phosphate Ceramics for Stabilization of Salt Mixed Wastes," Decomm. Decontam. Nucl.Hazard. Waste Manage, International Proceedings, v. 1 p. 553-560.

Singh, D., A. S. Wagh, R. V. Strain, and S. Y. Jeong, 1998C. "An Overview of Ceramicrete ${ }^{\mathrm{TM}}$ Technology for Stabilization of Low-Level Mixed Wastes. Book of Abstracts, $215^{\text {th }}$ ACS National Meeting, American Chemical Society, I\&EC-137. 
Singh, D., A. S. Wagh, M. Tlustochowicz, and S. Y. Jeong, 1998D. "Phosphate Ceramic Process for Macroencapsulation and Stabilization of Low-Level Debris Wastes," Waste Manage. 18(2), p. 135-143.

Singh, D., A. S. Wagh, J. C. Cunnane, and J. L. Mayberry, 1997. "Chemically Bonded Phosphate Ceramics for Low-Level Mixed-Saste Stabilization,” J. Environ. Sci. Health. 32(2), p. 527-541.

Singh, D., A. S. Wagh, S. Y. Jeong, and M. Dorf, 1996A. "Leaching Behavior of PhosphateBonded Ceramic Waste," Ceram. Trans.: Environmental Issues and Waste Management Technologies II. v. 72, p. 279-289.

Singh, D., A. S. Wagh, and M. Tlustochowicz, 1996B. "Zirconium Phosphate Waste Forms for Low-Temperature Stabilization of Cesium-137-Containing Waste Streams," Ceram. Trans.: Environmental Issues and Waste Management Technologies II. 72 p. 167-178.

Singh, U. S., A. Mishra, R. G. Yeotikar, and K. Raj, 1995. "Immobilisation of Intermediate Level Alkaline Radioactive Liquid Waste in Cement Matrix," Nucl. Radiochem. Symp. Proceedings, p. 426-428.

Soroka, I., 1979. Portland Cement Paste and Concrete, Chemical Publishing Co., Inc., NY NY.

Spence, R. D., Kauschinger, J. L., and Hunt, R. D., 1999. "Grout Perfromance in Support of In-Situ Grouting of the TH4 Tank Sludge," ORNL/TM-13739, Oak Ridge National Laboratory, Oak Ridge, TN, April 1999.

Spence, R. D., Gilliam, T. M., and Bleier, A., 1995. "Cementitious stabilization of chromium, arsenic, and selenium in a cooling tower sludge," Paper \#AM95-15, in Hazardous, Radioactive, and Mixed Waste, v. 15, Proceedings of the 88th Annual Meeting of the Air and Waste Management Association, San Antonio, TX, June 18-23, 1995.

Spence, R. D., and Kauschinger, J. L., 1997. "Grout Performance in Support of In Situ Stabilization/Solidification of the GAAT Tank Sludges," ORNL/TM-13389, Oak Ridge National Laboratory, Oak Ridge TN, May 1997.

Spence, R. D., Bostick, W. D., McDaniel, E. W., Gilliam, T. M., Shoemaker, J. 1., Tallent, O. K., Morgan, I. L., Evans-Brown, B. S., and Dodson, K. E., 1989. "Immobilization of Technetium in Blast Furnace Slag Grouts," Proceedings of the 3rd International Conference on the Use of Fly Ash, Silica Fume, Slag, and Natural Pozzolans in Concrete, v. 2, p. 15791596, Trondheim, Norway, June 19-24, 1989.

Tallent, O. K., McDaniel, E. W., G. D. Del Cul, Dobson, K. E., and Trotter, D. R., 1988. "Immobilization of Technetium and Nitrate in Cement-Based Materials," Mat. Res. Soc. Symp. Proc., no. 112, p. 23-32. 
Tallent, O. K., McDaniel, E. W., G. D. Del Cul, Dobson, K. E., and Trotter, D. R., 1989. "Development of Immobilization Technology for Hanford Double-Shell Slurry Feed Waste," ORNL/TM-10906, Oak Ridge National Laboratory.

Tamura, T., 1961. "Cesium sorption reactions as indicator of clay mineral structures," Clays and Clay Minerals, Proceedings of the National Conference on Clays and Clay Minerals, v. 10, p. 389-398.

Tamura, T., 1963. "Cesium sorption reactions as indicator of clay mineral structures," Proceedings of the International Clay Conference, Stockholm, Sweden, v. 1 p. 229-237.

Tamura, T., and Jacobs, D. G., 1960. "Structural implications in cesium sorption,” Health

Taylor, H. F. W., 1990. Cement Chemistry, Academic Press, NY NY.

Tickanen, L. D. and Turpin, P. D., 1996. "Treatment of Heavy Metal-Bearing Wastes Using a Buffered Phosphate Stabilization System," $51^{\text {st }}$ Purdue Industrial Waste Conference Proceedings. Ann Arbor Press, Inc. p. 627-635.

Torstenfelt, B. and Hedin,G., 1989. "Leaching of Cesium from a Cement Matrix," Mat. Res. Soc., Symp. no. 127, p. 495-500.

Tymochowicz, S., 1981. "Sorptive Properties of Mineral Deposits Occurring in Poland," Nukleonika, v. 26, no. 4-6, p. 595-599.

US Department of the Army and the Air Force, 1983. "Backfill for Subsurface Satructures," US Army Technical Manual 5-818-4, US Air Force AFM 88-5, Chap.5, June 1983.

US Department of the Army and the Air Force, 1970. "Grouting Methods and Equipment," US Army Technical Manual 5-818-6, US Air Force AFM 88-32 February 1970.

USDOE/NRC, 1999. "The State of Development of Waste Forms for Mixed Waste," US Department of Energy/National Research Council, National Academy Press, Washington, D.C.

USEPA, 1996. "Solidification/Stabilization Processes for Mixed Waste, EPA 402-r-96-014, Washington, D.C., June 1996.

USEPA, 1989. "Stabilization/Solidification of CERCLA and RCRA Wastes, Physical Testing Procedures, Technical Screening, and Field Activities," EPA/625/6-89/022, US Environmental Protection Agency, Washington, D. C., June 1989.

USEPA, 1987. Federal Register No. 52(155), p. 29999, Aug. 12, 1987. 
Vejmelka, P. Rudolph, G., Kluger, W., and Koster, R., 1990. "Conditioning of Radioactive Waste Solutions by Cementation," KfF4800, Kernforschungszent Karlsruhe.

Wagh, A. S., Singh, D., Jeong, S. Y., Graczyk, D., and TenKate, L. B., 1999. "Demonstration of Packaging of Fernald Silo I Waste In Chemically Bonded Phosphate Ceramic, Waste Management '99 Conference Proceecings, p. 2790-2796.

Webster, W. C., 1999. Treatment Process for Contaminated Waste, US Patent 5,877,393.

White, T. J. Eaton, G. F., Kyle, J., and Lincoln, F., 1994. "Xtalite - A Mineral Approach to the Disposal of Mercury and Arsenic Wastes," Extr. Process. Treat. Minimization Wastes, Proceedings, p. 217-227.

Wiles, C. C., 1998. "Solidification and Stabilization Technology," in Standard Handbook of Hazardous Waste Treatment and Disposal, Freeman, H. M., ed., 2nd ed. p. 7.31-7.46, McGraw -Hill, NY NY.

Wilk, C. M., 1999. "Solidification/Stabilization Treatment: Principles and Practice," Environmental Management, July, p. 31-37.

Zorpas, A. A. and Loizidou, M., 1999. "The Use of Inorganic Material Such as Zeolite for the Uptake of Heavy Metals from the Composting Process," Hazard. Ind. Waste 31 ${ }^{\text {st }}$, p. 611620. 
WSRC-TR-2001-00359, REVISION 0

JULY 31, 2001

8.0 APPENDIX A. TANK CLOSURE NEEDS SURVEY FORM

Page 68 of 105 
To: $\quad$ Those responsible for Tank Closure

From: $\quad$ Roger Spence (ORNL) and Christine Langton (SRTC)

Subject: $\quad$ Survey of enhanced grout needs for tank closure

Based on the needs statements from the DOE sites, Larry Bustard of TFA Tank Closure has funded us to study the current state of the art of grouts and to develop enhanced grout(s) for tank closure. The emphasis is filling "empty" tanks (i.e., waste removed leaving only tank heels) where they sit for closure in place. For this purpose, we have devised the survey in an attempt to discern the needs and concerns of those responsible for implementing tank closures at the DOE sites. If you know of others in your organization that can contribute, please pass this survey to them or work together as a team to complete the survey. You can either complete the survey in the attached Word file or access it on the Web at

http://www.ct.ornl.gov/tfa_questionnaire/survey.htm

whichever is more convenient for you. We intend to follow up on this survey with a phone call to better understand your needs and what grout properties that you are seeking. For this reason, please include your name and a means of contacting you. The intent was for you to answer the lead-in questions. The follow-up details were in case this question was too general and to give some idea of what we were thinking. Feel free to just fully answer the lead-in question, the detailed follow-ups, or both, as long as what you see as the tank closure grout needs are addressed.

Larry has informed us of the following, based on past communications with the sites.

1. Hanford will be closing tank forms under RCRA.

2. Idaho will be closing tanks using RCRA and soils beneath using CERCLA. The baseline grout is considered to be the SRS reducing grout.

3. Savannah River is closing tanks per South Carolina waste water regulations and closing the tank farm (soils, etc.) using CERCLA.

4. West Valley is the only site regulated by NRC. The stakeholders really want their two tanks dug up and removed from the site. West Valley has suggested the alternative of using a retrievable grout so if it is decided to remove the tanks in 50-100 years, the grout can be removed first.

If this accurately describes answers questions along these lines on the survey and you do wish to repeat this information, please just confirm the short summary above for those questions that it addresses.

Thank you for taking the time to complete this survey and helping us understand what you want from the grout that you use for tank closure. 


\section{Survey of Enhanced Grout Needs for Tank Closure}

\section{Name(s):}

\section{Telephone \#(s):}

Email address(es):

\section{Site:}

1) What tank closure needs do you have?

a) What are your drivers for closure?

i) Regulatory drivers?

(1) RCRA?

(2) CERCLA?

(a) Do you have a ROD?

(b) Has a RI/FS been done?

(c) What definition is being used for empty tanks?

(3) Radioactivity (DOE/NRC/EPA)?

ii) Must you grout piping while closing tanks. What about slurry pumps or other equipment left in the tank?

b) What is your definition of success?

2) What properties are you seeking in the "grout" used in tank closure? (Different terms are used for the material used to fill tanks during closure, including flowable fill, and some may not set in the way most expect traditional grouts to set. Nevertheless, the term "grout" will be used for all of these materials in this survey for the sake of expediency.)

a) What grout physical/handling properties are you seeking and why are you seeking these particular properties?

i) Strength?

ii) Flowability?

iii) Self-leveling

iv) Pumpability?

v) Viscosity?

vi) Workability time?

vii) Set time?

viii) Bleed water?

ix) Hydraulic conductivity?

x) Excavatable

xi) Resistant to solids segregation?

xii) Heat of hydration?

b) What grout chemical properties are you seeking?

i) What are the contaminants of concern?

(1) RCRA metals?

(2) Radionuclides?

(3) Others?

ii) What mechanism, if any, of enhancing leach resistance do you prefer?

iii) Do you want stabilization of the contaminants of concern?

iv) $\mathrm{pH}$ ?

v) $\mathrm{E}_{\mathrm{h}}$ ? 
vi) Is reversible sorption acceptable?

c) What long term, or durability, properties are you seeking?

i) Which durability test?

ii) Short term accelerated testing?

iii) Long term testing? How long?

3) Are there any ingredients/additives that you would like to specify and see tested?

4) What implementation technique do you plan or want to use?

a) Dump the grout into the tank?

b) Pump the grout?

i) How far?

ii) Pump type?

c) Attempt to mix grout and tank heels?

i) Mechanical mixer?

ii) Low pressure jetting or agitation (pulse jets etc)?

iii) High shear turbulent mixing (MPI®, etc)?

5) What other tank closure issues or grout properties would you like to see addressed in this project? 
WSRC-TR-2001-00359, REVISION 0

JULY 31, 2001

9.0 APPENDIX B. INEEL TANK CLOSURE NEEDS SURVey 


\section{INEEL}

To: $\quad$ Roger Spence (ORNL) and Christine Langton (SRTC)

From: $\quad$ Keith Quigley

Subject: $\quad$ Survey of enhanced grout needs for tank closure

\section{Survey of Enhanced Grout Needs for Tank Closure}

Name(s): Keith Quigley

Telephone \#(s): (208) 526-3779

Email address(es): Kquigle@inel.gov

Site: INEEL

1) What tank closure needs do you have? We have 11 300,000 gallon HLW tanks and 4 30,000 gallon tanks that need to be closed.

a) What are your drivers for closure? We will close the tanks under RCRA and DOE 435.1.

i) Regulatory drivers?

(1) RCRA? Our tanks are RCRA tanks and therefore will be closed under RCRA. This includes the piping related to the tanks.

(2) CERCLA? The soils around and under the tanks will be closed under CERCLA

(a) Do you have a ROD? The final EIS is scheduled to be completed in June 2001 and the ROD scheduled for July 2001.

(b) Has a RI/FS been done? RCRA uses the EIS process and the CERCLA activities have completed a RI/FS.

(c) What definition is being used for empty tanks? We have agreed with the State of Idaho that empty is defined as removing materials to the tank heel. This is between 3 and 10" in the different tanks. When we have a cease use of the tank the tank needs to be emptied to the heel and turned over to tank closure. We will decon and remove the residuals to meet the Performance assessment and a RCRA risk assessment.

(3) Radioactivity (DOE/NRC/EPA)? DOE regulates this under DOE 435.1.

ii) Must you grout piping while closing tanks. What about slurry pumps or other equipment left in the tank? We are planning on grouting the pipes that penetrate our tanks. The tanks will be filled with grout, which will entomb the equipment left in the tank.

b) What is your definition of success? We must meet the requirements is DOE 435.1, our RCRA closure plan and our Performance assessment.

2) What properties are you seeking in the "grout" used in tank closure? (Different terms are used for the material used to fill tanks during closure, including flowable fill, and some may not set in the way most expect traditional grouts to set. Nevertheless, the term "grout" will be used for all of these materials in this survey for the sake of expediency.)

a) What grout physical/handling properties are you seeking and why are you seeking these particular properties? We are using the normal properties of grout for our 
closure. No special grout except for additive to help flowability will be added to our grout.

i) Strength? Strength is not a great factor. We need $>500$ psi grout.

ii) Flowability? We need our grout to flow into our tank and pipes. We have used additives to help our flowability.

iii) Self-leveling. We are going to use a five pour sequence to displace the heel with grout. This displacement will help move the heel toward the steam jet and help remove the residuals. The final layers of grout need to be more self leveling if possible.

iv) Pumpability?

v) Viscosity?

vi) Workability time?

vii) Set time?

viii) Bleed water? Minimum bleed water is required.

ix) Hydraulic conductivity?

x) Excavatable

xi) Resistant to solids segregation?

xii) Heat of hydration?

b) What grout chemical properties are you seeking? Our grout is being used to displace the grout and help remove as much as possible and to place and residuals in a solid form.

i) What are the contaminants of concern?

(1) RCRA metals?

(2) Radionuclides?

(3) Others?

ii) What mechanism, if any, of enhancing leach resistance do you prefer?

iii) Do you want stabilization of the contaminants of concern?

iv) $\mathrm{pH}$ ? Our heel is a negative $\mathrm{pH}$ level.

v) $\mathrm{E}_{\mathrm{h}}$ ?

vi) Is reversible sorption acceptable?

c) What long term, or durability, properties are you seeking? We are using a 500 year life for the Performance Assessment.

i) Which durability test?

ii) Short term accelerated testing?

iii) Long term testing? How long?

3) Are there any ingredients/additives that you would like to specify and see tested?

4) What implementation technique do you plan or want to use?

a) Dump the grout into the tank?

b) Pump the grout? We plan on pumping our grout to the tanks. We tested the pour sequence last year and will test the grout arm this year.

i) How far?

ii) Pump type?

c) Attempt to mix grout and tank heels? None. We want to remove the risk and not just mix it.

i) Mechanical mixer?

ii) Low pressure jetting or agitation (pulse jets etc)? 


\section{WSRC-TR-2001-00359, REVISION 0}

JULY 31, 2001

iii) High shear turbulent mixing (MPI $®$, etc)?

5) What other tank closure issues or grout properties would you like to see addressed in this project? 
WSRC-TR-2001-00359, REVISION 0

JULY 31, 2001

10.0 APPENDIX C. Hanford TANK CLOSURE NEEDS SURVey

Page 76 of 105 


\title{
HANFORD
}

\section{Survey of Enhanced Grout Needs for Tank Closure}

\author{
Name(s): Jerry W. Cammann \\ Telephone \#(s): (509) 372-2757 \\ Email address(es): Jerry_W_Cammann@rl.gov \\ Site: Hanford Site, CH2M Hill Hanford Group, Inc.
}

1) What tank closure needs do you have?

(1) Characterization of residual wastes; requires off-riser sampling; in situ characterization of chemicals and radionuclides preferable to avoid sampling and laboratory analysis costs. Primary need is to demonstrate that tank waste residuals are exempt from NRC licensing due to the fact they are "wastes incidental to reprocessing" (NRC Class $\mathrm{C}$ requirements).

(2) Stabilization of tank void spaces to prevent differential settlement and subsidence, and potential impacts on surface cover systems ability to control water infiltration and plant, animal, and human intrusion; stabilization method must not preclude cost effective retrieval of tank waste residuals in the future and may include void filling with nonstructural grouts, sand, gravel, etc.

(3) Immobilization of tank waste residuals to "tie-up" long-lived, mobile radionuclides that drive long-term groundwater pathway risk analyses (i.e., Tc-99, I-129, C-14, Se-79, chromium, nitrate, nitrite, complexed uranium); need to irreversibly sorb mobile contaminants using materials such as apatitic compounds, zeolites, etc. Residual waste immobilization must also address contaminants of concern from an intruder pathway perspective (i.e., Pu series, Am-241, U series, C-14, Ni-59/63, Nb-94, Tc-99, I-129, Cm242, transuranics with half-lives greater than 5 years, Sr-90, Cs-137, and Sn-126.

(4) Immobilization of contaminants in the vadose zone surrounding tanks as a result of past tank leaks or retrieval leakage losses. Will require solution grouts, dissolved reagents in solution, or some other form of sequestering agents capable of flowing through Hanford soils and immobilizing contaminants of concern. Hanford sediments are characterized generally as sands, gravels, and cobbles. There are silt stringers, caliche layers, clastic dikes, and other geologic features that can affect the fate and transport of contaminants in the vadose zone. The groundwater system is roughly at a depth of 200250 feet below the surface in Hanford's primary waste management areas (200 East and West Areas).

(5) Surface cover systems or barriers that control water infiltration, and plant, animal, and human intrusion for 500 to 1,000 years. Under the RCRA post-closure care period, a 30year time frame is established. Every 5-years an assessment will be conducted to ensure continued effectiveness of provisions to protect human health and the environment. Due 


\section{WSRC-TR-2001-00359, REVISION 0}

JULY 31, 2001

to the persistence of some of the contaminants in tank waste residuals, the wastes left in place under a "Landfill" closure option will require long-term monitoring and stewardship throughout that period of time they pose a hazard to human health and the environment. Hanford had a long-running protective barrier development program in the mid- to late-1980's. The results of roughly 8 -years of research and development led to the construction of a full-scale protective barrier prototype (surface cap) on the 216-B-57 crib in 200 East Area. Performance data is being collected on the prototype barrier.

(6) Post-closure monitoring in the groundwater and vadose zone systems. Post-closure monitoring under semi-arid conditions is needed for the 30-year post closure care period to demonstrate the effectiveness of closure methods in terms of minimizing impacts to human health and the environment. This requires technologies capable of measuring small volumes of moisture under variably saturated conditions. Soil moisture conditions are typically very low.

a) What are your drivers for closure? Tank closure at Hanford will be complicated by the need to coordinate and integrate the regulatory requirements as prescribed under RCRA, CERCLA, DOE Orders, and other appropriate or relevant and applicable requirements. In general, the following list represents the primary regulatory drivers: RCRA, Hanford Federal Facility Agreement and Consent Order (Tri-Party Agreement), NEPA, CERCLA, Atomic Energy Act, Clean Air Act, Safe Drinking Water Act, Hazardous Waste Management Act, State laws (Washington Administrative Codes), DOE Orders and Management Directives, Code of Federal Regulations, Energy Reauthorization Act, and Nuclear Waste Policy Act. Under the Tri-Party Agreement, initiation of a tank closure demonstration is planned in the 2012 time frame with completion of the closure demonstration in the 2014 time frame. The initial closure demonstration will be on an operable unit or tank farm basis. Closure of all SSTs is to be accomplished by the year 2024 .

i) Regulatory drivers?

(1) RCRA? Hanford tanks are regulated as treatment, storage, and disposal (TSD) facilities under RCRA. Since contaminants have been detected in the groundwater under some of Hanford's tanks, Hanford is in the process of performing site characterization activities in support of remedial facility investigation (RFI) and corrective measure studies (CMS) under RCRA. In a few cases, interim corrective measures are being implemented to minimize the impacts of tank farm operations of human health and the environment. Activities underway include the cutting and capping of excess water lines, pressure testing of water lines in use, and construction of surface barriers to control run-on of rain water and snow melt.

\section{(2) CERCLA?}

(a) Do you have a ROD? The Hanford Defense Waste Environmental Impact Statement (HDW-EIS) deferred decisions regarding the final disposition of tanks and tank wastes pending further evaluation of the wastes and alternatives for waste retrieval and tank closure. A supplemental EIS is 


\section{WSRC-TR-2001-00359, REVISION 0}

JULY 31, 2001

planned in the next few years as Hanford acquires more information on retrieval system performance and closure technology capabilities. A single-shell tank closure plan has been drafted and is undergoing review and comment. The closure plan will be updated every two years to incorporate lessons learned in terms of retrieval and closure system performance.

(b) Has a RI/FS been done? RI/FS's have been completed for contaminated soil sites (cribs, ponds, ditches, etc.) and cleanup efforts are proceeding under CERCLA. For the tanks however, actual closure decisions have not been made. The current assumption is that tank closure at Hanford will occur under the RCRA requirements for "landfill" closure. This is due in part to the presence of contaminated soils under some of the tanks and the fact that it would be cost prohibitive to remove all of the contaminated soils, tanks, pipelines, and ancillary structures under a "clean" closure scenario.

(c) What definition is being used for empty tanks? The goal under the TriParty Agreement is to remove $99 \%$ of the wastes from the tanks or to the limits of the retrieval technologies. Since 67 of Hanford's 149 single-shell tanks (SSTs) are assumed or confirmed to have leaked and all SSTs have exceeded their intended design lives, retrieval systems are being design to use little if any liquids. Those liquids that will be used will be implemented in low volumes and in a controlled manner (i.e., confined sluicing). A Retrieval Performance Evaluation (RPE) methodology has been adopted to support decisions regarding retrieval and LDMM system designs. The RPE methodology is a risk-based, tank-specific approach that considers past tank leaks, potential leakage losses during retrieval, and residual waste inventories to establish retrieval release criteria and target leak detection rates as a function of tank waste inventories and tank integrity considerations. The RPE methodology provides and indication of how well retrieval systems need to perform to provide adequate protection of human health and the environment.

(3) Radioactivity (DOE/NRC/EPA)?

ii) Must you grout piping while closing tanks. What about slurry pumps or other equipment left in the tank? Some method of waste residuals stabilization and immobilization will have to be demonstrated. This may be grout, grout impregnated with specially formulated sequestering agents, or some other form of material capable of irreversibly sorbing contaminants of concern. The grout or other formulation will have to possess good flow properties (low viscosity) to allow ease of flow around and through in-tank instrumentation and structures that will be abandoned and stabilized in the tanks. This will include, but not be limited to, failed equipment, thermocouple trees, liquid observation wells, mixer pumps, transfer pumps, etc. Hanford's tanks also contain things such as diatomaceous earth, concrete, fuel rods, and other miscellaneous debris.

b) What is your definition of success? Tank closure success is defined by achieving risk-based retrieval performance objectives calculated by the RPE methodology; immobilizing residual contamination in tanks, pipelines, ancillary structures, and 


\section{WSRC-TR-2001-00359, REVISION 0}

JULY 31, 2001

surrounding soils to a level protective of human health and the environment; stabilizing tank void spaces to prevent differential settlement and subsidence; providing a surface barrier capable of controlling water infiltration and plant, animal, and human intrusion; and implementation of post-closure monitoring to ensure the overall performance of the closure system.

2) What properties are you seeking in the "grout" used in tank closure? (Different terms are used for the material used to fill tanks during closure, including flowable fill, and some may not set in the way most expect traditional grouts to set. Nevertheless, the term "grout" will be used for all of these materials in this survey for the sake of expediency.)

a) What grout physical/handling properties are you seeking and why are you seeking these particular properties?

i) Strength? Must be cost-effectively retrievable in case decisions are made to remove residual wastes.

ii) Flowability? Must be able to flow in, around, and through in-tank instrumentation and structures. Under worst case conditions, the formulation must be able to flow through roughly 2 miles of cross-site, underground, transfer lines.

iii) Self-leveling Yes

iv) Pumpability? Yes. See "ii".

v) Viscosity? Low

vi) Workability time? Pours will range in volume from 500,000 to 1,000,000 gallons per tank.

vii) Set time? On the order of weeks to months.

viii) Bleed water? Minimal, potential source for contaminant migration.

ix) Hydraulic conductivity? In ex-tank applications, must be capable of flowing freely through soils characterized as sands, gravels, and cobbles.

x) Excavatable Yes, in case retrieval of residuals becomes required at some future time.

xi) Resistant to solids segregation? Yes

xii) Heat of hydration? Possible issue if driving off volatile contaminants of concern or driving contaminants deeper into the vadose zone.

b) What grout chemical properties are you seeking? Must be capable of irreversibly sorbing contaminants of concern.

i) What are the contaminants of concern? See response to the first question.

(1) RCRA metals?

(2) Radionuclides?

(3) Others?

ii) What mechanism, if any, of enhancing leach resistance do you prefer? No preference. Leach resistance must be demonstrated for 500 to 1,000 years.

iii) Do you want stabilization of the contaminants of concern? Yes

iv) $\mathrm{pH}$ ?

v) $\mathrm{E}_{\mathrm{h}}$ ?

vi) Is reversible sorption acceptable? Not desirable.

c) What long term, or durability, properties are you seeking? The selected waste form needs to perform over a period of 500 to 1,000 years. Primary tests would include leach resistance. Actual testing on Hanford tank wastes will require hot cells due to 
the level of radioactivity. Surrogate wastes could be used under cold test conditions. There is much available information regarding the chemicals and radionuclides in Hanford tank wastes.

i) Which durability test?

ii) Short term accelerated testing?

iii) Long term testing? How long?

3) Are there any ingredients/additives that you would like to specify and see tested? Based on conversations with researchers at Sandia National Laboratories, apatitic compounds have been demonstrated to irreversibly sorb actinides, strontium, lead, and technetium. In addition to its potential use as a subsurface reactive zone in support of tank waste retrieval operations, it is speculated that apatitic compounds could be mixed with tank waste residuals to immobilize many of the contaminants of concern.

4) What implementation technique do you plan or want to use?

a) Dump the grout into the tank? Will be difficult due to tank dome load limits and the potential structural instability of the domes.

b) Pump the grout? Likely method.

i) How far? Normally within a tank farm (on the order of a few hundred feet). The cross-site transfer line runs roughly 2 miles.

ii) Pump type? High reliability.

c) Attempt to mix grout and tank heels? This will be desirable to achieve macro- and micro-encapsulation of contaminants of concern. However, due to the lack of leak integrity of the single-shell tanks, very little if any liquids can be used to facilitate mixing of grout with residual waste heels. Alternative retrieval methods planned for demonstration and use in support of SST waste retrieval include saltcake dissolution, crawler-based confined sluicing, power fluidics, and pulse mixing. One or more of these techniques may be applicable to mixing needs associated with the grout and tank heels. However, evaluations are required to ensure that the grout formulation will not plug-up, restrict, or otherwise render the retrieval methods inoperative as the grout begins to set up. Mechanical mixers may be the best bet.

i) Mechanical mixer?

ii) Low pressure jetting or agitation (pulse jets etc)?

iii) High shear turbulent mixing (MPI®, etc)?

5) What other tank closure issues or grout properties would you like to see addressed in this project? None at this time beyond those items mentioned above. 
WSRC-TR-2001-00359, REVISION 0

JULY 31, 2001

11.0 APPENDIX D. WVDP TANK CLOSURE NEEDS SURVey 


\section{WVDP}

\section{West Valley Responses to Survey of Enhanced Grout Needs for Tank Closure}

Please note suggested language change to the upfront West Valley summary.

West Valley is the only HLW management site regulated by NRC. West Valley=s stakeholders are generally not fully supportive of long-term irreversible in-place facility closure. A lthough DOE has not yet made a decision on the final site configuration, including tank disposition, W est Valley has suggested one alternative for evaluation of using a retrievable grout so if it is decided to remove the tanks in 50-100 years, the grout can be more easily removed.

Select responses to the questions contained in the survey of enhanced grout needs for tank closure provided by Roger Spence (ORNL) and Christine Langton (SRTC).

Question \#1a(i) What are your regulatory drivers for closure?

RCRA is a driver. CERCLA is not applicable at this time at West Valley. The New York State Department of Environmental Conservation is the cognizant regulatory agency for RCRA closure. The NRC would eventually resume regulatory responsibility for the West Valley site after DOE completes its requirements under the West Valley Demonstration Project Act and returns control of the site to New York.

Question \#1b Must you grout piping while closing tanks. What about slurry pumps or other equipment left in the tank?

The detailed final configuration is not known at this time, since DOE has not reached a Record of Decision on final tank disposition. However, the preference at this time would be to remove as much equipment and piping as is feasible. Any piping and/or equipment that might be left in the tanks would need to be grouted to eliminate void space and preferential transport pathways over time.

Question \#2a What grout physical/handling properties are you seeking and why are you seeking these particular properties?

We have already evaluated the grout for the physical handling properties we require. The only additional property yet needed to be evaluated or calculated is the heat of hydration.

The heat of hydration is of concern in our application considering the elevated temperatures that will be encountered within the High Level Waste Tanks. Additional temperatures, if extreme, could create a highly deleterious rupture condition within 
the storage tanks. With this in mind, it is definitely necessary to understand what temperatures, thus the heat of hydration, of the CLSM as placed.

Question \#2b What grout chemical properties are you seeking?

i) (1) There are eight RCRA metals of concern segregated into a two-tiered level of importance. The first tier metals, of highest concern, are Mercury $(\mathrm{Hg})$ and Chromium (Cr). The remaining second tier metals are Arsenic (As), Barium (Ba), Cadmium (Cd), Selenium (Se), Silver (Ag), and Lead (Pb).

i) (2) The Radionuclides of concern are Americium (Am), Cesium (Cs), Neptunium $(\mathrm{Np})$, Plutonium (Pu), Strontium (Sr), Technicium (Tc), and Uranium (U).

i) (3) Other contaminants of concern are Sodium Hydroxide $(\mathrm{NaOH})$, Nitrate $\left(\mathrm{NH}^{+3}\right)$, and Nitrite $\left(\mathrm{NH}^{+2}\right)$. The concern here is whether we need a pretreatment system to wash these out prior to grout application.

iv) $\mathrm{pH}$ - The $\mathrm{pH}$ of the grout needs to be within a certain range to be able to provide for a highly alkaline environment which is optimal for immobilizing the radionuclides and RCRA metals present.

v) Eh - Redox potential is another key property of the grout. By defining our oxidation potential we will be able to determine the sulfides available for reduction with metal cations (i.e. Plutonium).

Question \#2c What long term, or durability, properties are you seeking?

ii) Short term accelerated testing should be performed upon the WVDP grout using ASTM D 4319-93, Standard Test Method for Distribution Ratios by the Short-Term Batch Method with an emphasis being placed on Np-237, Tc-99, and Pu-239/240.

Question \#3

Are there any ingredients/additives that you would like to specify and see tested?

Aside from the use of the prescribed ingredients, the use of either a Titanium Powder or Oxide would be viable candidates for evaluation to possibly replace the UOP IONSIV TIE-96 as one of the principal sorptive ingredients.

Question \#4

What implementation technique do you plan or want to use?

The method that we would like to see implemented for grout mixing, and application are as follows.

The grout should be batched and mechanically mixed prior to placing in the closure facilities. 
The placement method for the tanks should employ the use of tremie pipes to lower the grout to the bottom of the tank without segregation. Then, the grout should be blended with the heel to ensure uniform mixing. Once the mixing of the grout and heel has been completed and given time to set, any additional lifts of the reducing grout should then be tremied into place. Once these grouts have set, a generic grout will be placed, by tremie, to fill the tank

The placement method for the remaining facilities should be performed by use of alternate height tremies and pre-set select grout pumps to ensure complete filling of the process areas.

Question \#5 What other tank closure issues or grout properties would you like to see addressed in this project?

Any tank pre-treatment processes that might benefit grout emplacement and/or long-term performance. 
WSRC-TR-2001-00359, REVISION 0

JULY 31, 2001

12.0 APPENDIX E. SRS-HLW TANK CLOSURE NEEDS SURVey

Page 86 of 105 


\section{SRS HLW \\ (Chuck Hayes)}

\section{Survey of SRS HLW Enhanced Grout Needs for Tank Closure}

\section{Name(s):}

\section{Telephone \#(s):}

\section{Email address(es):}

\section{Site:}

1) What tank closure needs do you have?

a) What are your drivers for closure?

i) Regulatory drivers?
(1) RCRA? No
(2) CERCLA? Yes

(a) Do you have a ROD? No

(b) Has a RI/FS been done? No Actually, we have a RI/FS for the groundwater in HTF, but I see your point

(c) What definition is being used for empty tanks? Meeting 435.1 and Performance Standards

(3) Radioactivity (DOE/NRC/EPA)? Yes

ii) Must you grout piping while closing tanks. What about slurry pumps or other equipment left in the tank? To the extent possible I would state it that we are planning to grout piping over 1" dia.

b) What is your definition of success? Meeting 435.1 and Performance Standards

2) What properties are you seeking in the "grout" used in tank closure? (Different terms are used for the material used to fill tanks during closure, including flowable fill, and some may not set in the way most expect traditional grouts to set. Nevertheless, the term "grout" will be used for all of these materials in this survey for the sake of expediency.)

a) What grout physical/handling properties are you seeking and why are you seeking these particular properties?

i) Strength?

ii) Flowability?

iii) Self-leveling

iv) Pumpability?

v) Viscosity?

vi) Workability time?

vii) Set time?

viii) Bleed water?

ix) Hydraulic conductivity?

x) Excavatable

xi) Resistant to solids segregation?

xii) Heat of hydration?

b) What grout chemical properties are you seeking?

i) What are the contaminants of concern?
(1) RCRA metals?
Yes, mercury and characteristically haz 
(2) Radionuclides?

Yes especially tech 99

(3) Others?

ii) What mechanism, if any, of enhancing leach resistance do you prefer? Physical \& chemical

iii) Do you want stabilization of the contaminants of concern? Yes

iv) $\mathrm{pH}$ ?

v) $\mathrm{E}_{\mathrm{h}}$ ?

vi) Is reversible sorption acceptable?

c) What long term, or durability, properties are you seeking? 10,000 years for chemical, as long as possible for physical

i) Which durability test?

ii) Short term accelerated testing?

iii) Long term testing? How long?

3) Are there any ingredients/additives that you would like to specify and see tested?

Need to conduct follow-up studies on the use of SRS flyash in grout mixtures. Also need to test with commonably obtainable sand, cement and superplasticziors (sp?)

4) What implementation technique do you plan or want to use?

a) Dump the grout into the tank?

b) Pump the grout?

i) How far? Up to 2000 feet

ii) Pump type? Positive displacement pump

c) Attempt to mix grout and tank heels? Yes

i) Mechanical mixer?

ii) Low pressure jetting or agitation (pulse jets etc)?

iii) High shear turbulent mixing (MPI®, etc)?

5) What other tank closure issues or grout properties would you like to see addressed in this project?

Cost of grout is a concern. An eye should be kept on the cost of grout materials and manufacturing expenses throughout the grout enhancement process. 
WSRC-TR-2001-00359, REVISION 0

JULY 31, 2001

13.0 APPENDIX F. SRS-FDD TANK CLOSURE NEEDS SURVey 


\title{
SRS Reactor Disassembly Basins \\ (J. Pickett and H. Dukes)
}

\section{Survey of Enhanced Grout Needs for Tank Closure}

\author{
Name(s): John Pickett, Heatherly Dukes \\ Telephone \#(s):803-725-38338, 725-3771 \\ Email address(es): john.pickett@ @srs.gov, heatherly.dukes@ srs.gov \\ Site:
}

- What tank closure needs do you have?

We have 3 disassembly basins currently full of water, ranging from 4 to 5 million gallons, that we would like to close in the next 3-10 years. We will have the Receiving Basin for Off-Site Fuel (RBOF) basin to close in 6-10 years. We will have 2 other disassembly basins in 10-15 years.

- What are your drivers for closure?

- Regulatory drivers?

- RCRA? No

- CERCLA? Yes, probably under non-time critical removal action

- Do you have a ROD? No, we plan to close under an EE/EC

- Has a RI/FS been done?, No, and none planned

- What definition is being used for empty tanks? NA

- Radioactivity (DOE/NRC/EPA)? DOE

- Must you grout piping while closing tanks. What about slurry pumps or other equipment left in the tank? The water in our basins will be grouted in-situ. The grouting equipment can be rinsed and re-used on the successive closures. The final closure may be able to accept the grouting equipment, or we can send it to our burial ground.

- What is your definition of success? Basins partially drained (to have enough space to accept the grout plus all above ground walls and roofs, the remaining water grouted, and a cap installed.

- What properties are you seeking in the "grout" used in tank closure? (Different terms are used for the material used to fill tanks during closure, including flowable fill, and some may not set in the way most expect traditional grouts to set. Nevertheless, the term "grout" will be used for all of these materials in this survey for the sake of expediency.)

- What grout physical/handling properties are you seeking and why are you seeking these particular properties?

- Strength? Low, minimum 50 psi, 100-200 psi better, but not required.

- Flowability? Under water flowability

- Self-leveling Not critical

- Pumpability? Yes, up to 300 feet

- Viscosity? Low enough to pump, high enough to set before dispersing underwater

- Workability time? NA

- Set time? Not critical

- Bleed water? Low is better, but not critical, any bleed water can be controlled with a final clay soil backfill

- Hydraulic conductivity? NA 
- Excavatable No

- Resistant to solids segregation? No

- Heat of hydration? NA

- What grout chemical properties are you seeking?

- What are the contaminants of concern?

- RCRA metals? No

- Radionuclides? Tritium, cesium, strontium, I-129, C-14, and Tc-99

- Others?

- What mechanism, if any, of enhancing leach resistance do you prefer? The lower the permeability the better. Reducing grout not needed for our situation

- Do you want stabilization of the contaminants of concern? No, just immobilization

- $\mathrm{pH}$ ? NA

- $\mathrm{E}_{\mathrm{h}}$ ? NA

- Is reversible sorption acceptable? Probably

- What long term, or durability, properties are you seeking?

- Which durability test? ANSI 16.1 would be nice, but not critical

- Short term accelerated testing? No

- Long term testing? How long? No

- Are there any ingredients/additives that you would like to specify and see tested? Whatever it takes to meet the above criteria and provide the least volume increase from water to grout.

- What implementation technique do you plan or want to use?

- Dump the grout into the tank? Mix water in basin with dry mixture, and return to basin(s)

- Pump the grout? Yes

- How far? Up to 300 feet

- Pump type? (Whatever)

- Attempt to mix grout and tank heels? Yes, but the "heels" in the basin are only 7\% solids, so pumping them shouldn't be a problem.

- Mechanical mixer? probably

- Low pressure jetting or agitation (pulse jets etc)? probably not

- High shear turbulent mixing (MPI®, etc)? probably not

- What other tank closure issues or grout properties would you like to see addressed in this project? As stated previously, the lower the final volume the better. 
WSRC-TR-2001-00359, REVISION 0

JULY 31, 2001

14.0 APPENDIX G. SRS-ER TANK CLOSURE NEEDS SURVey

Page 92 of 105 


\section{SRS Small Tanks}

(M. Welty)

\section{Survey of Enhanced Grout Needs for Tank Closure}

\section{Name(s):}

\section{Telephone \#(s):}

\section{Email address(es):}

\section{Site:}

1) What tank closure needs do you have?

a) What are your drivers for closure?

Are only Remedial Action Objective, as identified in the Proposed Plan and Interim Record of Decision, is to structurally stabilize the ORWBG OSTs.

i) Regulatory drivers?
(1) RCRA?
(2) CERCLA?

The ORWBG OSTs are a solid waste management unit regulated under RCRA 3004(u) Solid Waste Management Unit. The FFA (1993) lists the OSTs as a component of the ORWBG operable unit, which is a RCRA/CERCLA unit in Appendix C of the FFA for SRS.

(a) Do you have a ROD?

WSRC ERD has submitted an Interim Record of Decision, WSRC-RP-2000-4193, Rev. 0 dated February 2001.

(b) Has a RI/FS been done?

Yes, WSRC-RP-98-4012, Rev. 1.1, dated September 2000

(c) What definition is being used for empty tanks?

Empty tanks are tanks that contain no visible residuals.

(3) Radioactivity (DOE/NRC/EPA)?

Yes, hundreds of thousands of gallons of solvent were used in the chemical separation facilities at SRS in a process that removes plutonium and uranium form spent fuel rods. The spent solvent generated from this plutonium-uranium extraction (PUREX) process consisted of a mixture of tri-n-butyl phosphate and dodecane. It was managed as low level radioactive waste and stored for aging in the OSTs. 
ii) Must you grout piping while closing tanks. What about slurry pumps or other equipment left in the tank?

Some of the tanks do contain internal piping that will be entombed within the grout matrix and will not be filled by design. If there is an open pathway in these internal pipes then will get at least partially filled with grout. No external piping exists for the ORWBG OSTs.

b) What is your definition of success?

Completely filling the tanks with grout having an unconfined compressive strength of $50 \mathrm{psi}$ or greater. Safely completing the project with no negative impacts to human health or the environment. Completing the project on time and within budget.

2) What properties are you seeking in the "grout" used in tank closure? (Different terms are used for the material used to fill tanks during closure, including flowable fill, and some may not set in the way most expect traditional grouts to set. Nevertheless, the term "grout" will be used for all of these materials in this survey for the sake of expediency.)

a) What grout physical/handling properties are you seeking and why are you seeking these particular properties?

i) Strength? UCS greater than $50 \mathrm{psi}$

ii) Flowability? Yes

iii) Self-leveling Yes

iv) Pumpability? Yes

v) Viscosity?

vi) Workability time?

vii) Set time? 28 day cure

viii) Bleed water? zero bleed

ix) Hydraulic conductivity?

x) Excavatable

xi) Resistant to solids segregation?

xii) Heat of hydration? Less than 125 degrees $\mathrm{F}$

b) What grout chemical properties are you seeking?

Non-reactive with tank residuals.

i) What are the contaminants of concern?

(1) RCRA metals? No

(2) Radionuclides? Yes

(3) Others? Solvents

ii) What mechanism, if any, of enhancing leach resistance do you prefer? N/A

iii) Do you want stabilization of the contaminants of concern?

No, stabilization is not required from a regulatory standpoint. 
iv) $\mathrm{pH}$ ?

v) $\mathrm{E}_{\mathrm{h}}$ ?

vi) Is reversible sorption acceptable?

c) What long term, or durability, properties are you seeking? >50 Psi UCS

i) Which durability test?

ii) Short term accelerated testing?

iii) Long term testing? How long?

3) Are there any ingredients/additives that you would like to specify and see tested? No

4) What implementation technique do you plan or want to use? Pump

a) Dump the grout into the tank? No

b) Pump the grout? Yes

i) How far? Approximately $50 \mathrm{ft}$.

ii) Pump type? Have not specified yet but some form of positive displacement pump

c) Attempt to mix grout and tank heels?

Yes, solidification of the tank heels will be accomplished prior to production grouting of the tank void space. Plan is to deliver the grout in $1-2 \mathrm{ft}$. stages and partially solidifying the residuals in increments until a solid matrix exist at the tank bottom. Only mixing will occur by agitation/turbulence due to grout delivery.

i) Mechanical mixer? No

ii) Low pressure jetting or agitation (pulse jets etc)? No

iii) High shear turbulent mixing (MPI®, etc)? No

5) What other tank closure issues or grout properties would you like to see addressed in this project?

Unconfined compressive strength of 50 psi or greater. 
WSRC-TR-2001-00359, REVISION 0

JULY 31, 2001

15.0 APPENDIX H. UK TANK CLOSURE NEEDS SURVey

Page 96 of 105 


\section{UK}

From: httpd@infosrv1.ctd.ornl.gov

Subject: WWW Email Form Response

To: spencerd@ ornl.gov

The following was submitted using Mosaic Forms.

Name_of_Responder $=$ Richard Simmons

Responder_Telephone = 011441305202191

Responder_email = richard.simmons@aeat.co.uk

Responder_site $=$ Winfrith Technology Centre

Tank_Closure_Needs = In general, all major radioactive waste producers in UK store liquid waste in above-ground tanks. The UK strategy for such waste is to retrieve the waste from the tanks and condition it (solidify) for disposal as appropriate - ILW to deep geological disposal (to be developed), LLW to shallow land burial (existing route). The UK strategy for 'decommissioning' nuclear power plant, generally applied to all nuclear liabilities, is to underake decommissioning as soon as is reasonably pratical to do so and return the nuclear sites to 'greenfield' status. Consequently the strategy for 'tank closure' is to remove all the waste and eventually dismantle the tanks for disposal. I am not aware of any waste producer who has a declared intention to perform any grouting of contents within the tanks.

Radioactivity $=$ ON

What_about_slurry_pumps_or_other_equipment = Drivers are UK Government strategy managemnt and disposal of waste to protect the public, workforce and the environment.

Definition_of_Success $=$ Dismantlement and disposal of contents of tanks and return of site to 'greenfield' status - to allow reuse.

Additional_Comments = Since no grouitng of tank contents is intended in-situ, remainder of questionaire is not applicable.

Properties_Sought_and_Why_Generic =

Strength_Value_01 =

Stength_Value_02 =

Stength_Value_03 =

Strength_Comments =

Flowability_Value_01 =

Flowability_Value_02 =

Flowability_Value_03 =

Flowability_Comments =

Self_Leveling_Value_01 =

Self_Leveling_Value_02 =

Self_Leveling_Value_03 =

Self_Leveling_Properties =

Pumpability_Value_01 =

Pumpability_Value_02 =

Pumpability_Value_03 =

Pumpability_Comments = 
Viscosity_Value_01 = Viscosity_Value_02 = Viscosity_Value_03 = Viscosity_Comments = Workability_Time_Value_01 = Workability_Time_Value_02 = Workability_Time_Value_03 = Workability_Time_Comments = Set_Time_Value_01 = Set_Time_Value_02 = Set_Time_Value_03 = Set_Time_Comments = Bleed_Water_Value_01 = Bleed_Water_Value_02 = Bleed_Water_Value_03 = Bleed_Water_Comments = Hydraulic_Conductivity_Value_01 = Hydraulic_Conductivity_Value_02 = Hydraulic_Conductivity_Value_03 = Hydraulic_Conductivity_Comments = Escavatable_Value_01 = Escavatable_Value_02 = Escavatable_Value_03 = Excavatable_Comments $=$ Resistance_Value_01 = Resistance_Value_02 = Resistance_Value_03= Resistant_to_Solids_Segregation = Heat_of_Hydration_Value_01 = Heat_of_Hydration_Value_02 = Heat_of_Hydration_Value_03 = Heat_of_Hydration_Comments = Contaminants_of_Concern_Comments =

What_mechanism_of_leaching_do_you_prefer = Do_you_want_stabilization_of_concern_contaminants = $\mathrm{pH}=$

$\mathrm{Eh}=$

Is_reversible_sorption_acceptable = Durability_Properties_Sought = Durability_test_comments =

Short_term_accelerated_testing = Long_term_testing_how_long = Specified_Ingredients_and_Additives = Dump_the_grout_into_the_tank_comments = How_far $=$

Pump_type $=$ 
$\mathrm{S} 1=$

Mechanical_mixers_comments =

Low_pressure_jetting_or_agitation_Comments =

High_shear_turbulent_mixing_comments =

Other_implementation_technique $=$ Yes

Other $=$

What_other_closure_issues_Additional_Comments = B1 = Submit 
WSRC-TR-2001-00359, REVISION 0

JULY 31, 2001

16.0 APPENDIX I. France TANK CLOSURE NEEDS SURVey

Page 100 of 105 


\section{FRANCE}

From: C H Mattus <h6z@ornl.gov>

Subject: Survey

To: "Roger D. Spence" <spencerd@ornl.gov>

Roger,

I got an answer from Michel Jorda, my section head many years ago, who is now working for ANDRA (Agency for the disposal of waste). He said that to his knowledge, France does not have large tanks of radioactive wastes, since the waste itself is considered as a part of the process and is treated without delay by grouting, vitrification or even with bitumen.

Therefore, there are some small units inside of the plants generating waste that are collecting the waste until enough is obtained for treatment. He never heard of in line grouting. He mentioned that except Russia, he did not know of any country with large tanks like the US have. I hope this will help in your survey.

Catherine

\section{Catherine H. Mattus}

Oak Ridge National Laboratory

PO Box 2008

Bldg 4505, MS 6202

Oak Ridge,TN 37831-6202,

E-mail:h6z @ ornl.gov

Phone: (865)-574-6793

Fax : (865)-574-7241

Pager: (865)-417-5729 
WSRC-TR-2001-00359, REVISION 0

JULY 31, 2001

17.0 APPENDIX J. ORR GAAT Tank Flowable Fill Technical Specifications 


\section{EXHIBIT "E"}

\section{TECHNICAL SPECIFICATIONS}

1. SPECIFICATIONS:

$\underline{\text { SPECIFICATION NO. }}$ REV. $\quad \underline{\text { DATE }}$ $\underline{\text { TITLE }}$

SPG-OR051-A001 0

TECHNICAL SPECIFICATION FOR FLOWABLE FILL GROUT MATERIAL 


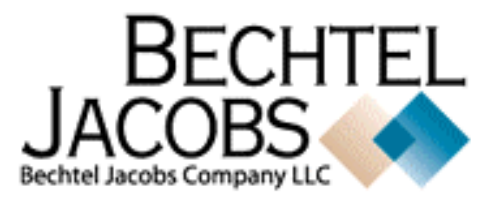

ACTING UNDER US DEPARTMENT OF ENERGY PRIME CONTRACT

NO. DE-ACO5-98OR22700

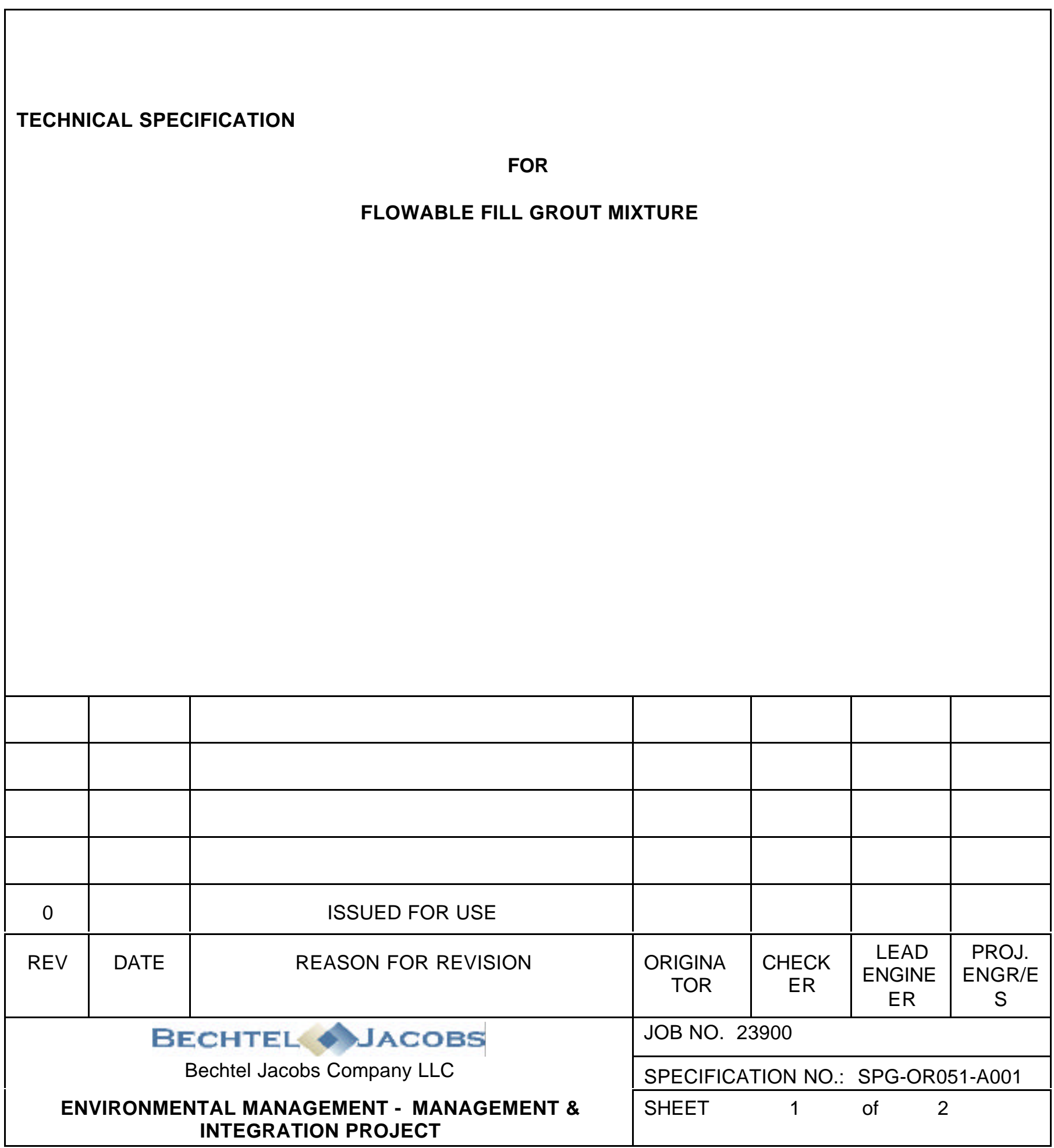


BJC-DE-01, EDPI 4.56-01, DE01-456.03

\section{GENERAL}

1.1 SUMMARY

The following specification for grout mixture is to be used when filling the Gunite and Associated Tanks (GAAT) tanks and pits with a stabilizing agent for the purpose of in-place remediation.

\subsection{ABBREVIATIONS AND ACRONYMS}

GAAT - Gunite and Associated Tanks

\subsection{WORK SMART STANDARDS}

All Work Smart Standards included in Exhibit G as applicable to the work will apply.

\subsection{SITE DESCRIPTION}

See Exhibit $\mathrm{F}$ for drawings depicting each of the covered tanks.

\section{PRODUCTS}

The grout mixture shall have the following properties:

- Compressive strength of at least 50 psig after 28 days;

- Flowable such that it is self leveling;

- Set time of less than 72 hours;

- No bleed water setting;

- Minimum heat generation during curing.

The Subcontractor shall provide certification of the grout mixture proving that it meets the above properties criteria.

Dry media may be added to aid in stabilizing the residual material in the bottom of the tank and/or between layers of the grout to aid in liquid absorption if desired by the Subcontractor. 